I.

Aus der psychiatrischen und Nervenklinik in Halle (Prof. Hitzig).

\title{
Alte und neue Untersuchungen über das Gehirn IV.
}

Von

\author{
Prof. Dr. Eduard Hitzig \\ in Halle. \\ (Mit Abbildungen.)
}

\section{Ceber die Beziehungen der Rinde und der subcorticalen Ganglien znm Sehact des Hundes.}

(Fortsetzung.)

\section{Welcher Art sind die durch corticale Läsionen hervorge- brachten Sehstörungen, sind sie hemianopischer Natur oder nicht, insbesondere entsprechen sie den Lehren Munk's?}

Inhalt: Einleitung S. 2. a) Versuche an der frontalen Partie der Hemisphäre S. 2. a) Gyrus sigmoides S. 3. B. Anätzungen S. 3. C. Unterschneidungen, $\alpha$. Einseitige Operationen S. 5 . $\beta$. Operationen der 2. Seite S. 9. D. Scarificationen S. 12. E. Exstirpationen, $\alpha$. Einseitige Operationen S. 15. $\beta$. Operationen der 2. Seite S. 25. F. Doppelseitige frontale Durchtrennung des vorderen Schenkels des Gyrus sigm. S. 30. 1. Sehstörungen, aa. Reaction gegen Fleisch S. 32. bb. Reaction gegen Licht S. 33. 2. Optische Reflexe S. 38. 3. Das Verhältniss der Sehstörungen zu den optischen Reflexen S. 39. 4. Störungen des Nasenlidreflexes S. 40. 5. Der ursächliche Zusammenhang zwischen den Störungen des Sehactes und der durch den Opticus und den Trigeminus angeregten Reflexthätigkeit S.42. 6. Motilitätsstörungen S. 43. 7. Sectionsbefunde S. 43. b) Laterale Nachbarwindungen des Gyrus sigmoides S. 44. A. Versuche ohne motorische Folgen S. 49. 1. Sehstörungen S. 60 . 2. Optische Reflexe S. 61 . 3. Nasenlidreflex S. 61. 4. Motilitätsstörungen S. 61. 5. Operationen und Sectionen S. 62. 6. Das Verhältniss der Symptome zu dem Ort der Verletzung S. 63 . B. Versuche mit motorischen Folgen S. 69. 1. Sehstörungen S. 85. 2. Optische Reflexe S. 87. 3. Nasenlidreflex S. 88. 4. Das gegenseitige Verhältniss der Sehstörung, der optischen Reflexe und des Nasenlidreflexes S. 88. 5. Schlussfolgerungen S. 94. 
In der Il. dieser Abhandlungen I) habe ich bereits eine kurze Ueber. sicht über die hauptsächlichsten Angaben der Autoren von der Art der nach Eingriffen in die Convexitat des Hundehirns entstehenden Sehstörungen gegeben. Es genügt deshalb, wenn ich hier kurz recapitulire, dass $\mathrm{Munk}$ behauptet, Rindenblindheit, d. h. absolute und dauernde Blindheit verschiedener Partieen der Netzhaut werde durch Ausschaltung verschiedener Partieen seiner Sehsphäre hervorgebracht, während alle anderen Autoren mit wenigen Ausnabmen angeben, dass auf alle, gleichviel wie localisirte oder doch die meisten Eingriffe in die Convexität eine Sebstörung hemianopischer Natur folge und dass Loeb insofern eine Sonderstellung unter ihnen einnimmt, als nach seiner Ansicht bei jeder so entstandenen Sehstörung, auch wenn die Stelle $A_{1}$ angegriffen worden ist, die Stelle des deutlichsten Sehens immer am wenigsten geschädigt erscheint. Durch diese seine Versuche wollte Loeb die Irrthümlichkeit der Ansicht IIunk's über die Abhängigkeit der "Seelenblindheit" von der Zerstörung der Stelle $A_{1}$ nachweisen.

Hiermit sind die höchst mannigfaltigen Aufgahen, welche die nächste Reihe unserer Versuche zu lösen hat, in grossen Umrissen vorgezeichnet. Wir werden uns zunächst noch eingehender mit der Art, dem Grade und dem Ursprungedernach Eingriffen in die vordere Partie der Hemisphäre entstehenden Sehstörungen zu beschäftigen haben. Erst dann werden wir unsere Untersuchung auf die nach Eingriffen in den Hinterlappen in die Erscheinung tretenden Sehstörungen ausdehnen können. Ich werde mich dabei, wo es angelit, auf die früher gegebene Uebersicht über die Litteratur beziehen und mich, wo es erforderlich erscheint, noch etwas eingehender mit den thatsächlichen Angaben einiger Autoren beschäftigen.

a) Versuche an der frontalen Partie der Hemisphäre.

In dem I. Kapitel dieser Abhandlung hatte ich gezeigt, dass die blosse Freilegung der Pia auch zu Störungen des Sehvermögens und der optischen Reflexe führen kann. In dem folgenden Kapitel werde ich zunächst untersuchen, welchen Einfluss verschiedene andere Eingriffe in den Gyrus sigmoides auf den Sehact ausüben und mich alsdann mit der Lösung der Frage beschäftigen, ob dieser Einfluss einen Eingriff in die Rinde des Gyrus sigmoides mit Nothwendigkeit voraussetzt, oder

1) E. Hitzig, Historisches, Kritisches u. Experimentelles über Methoden und Theorien der Grosshirnforschung. Dieses Archiv Bd. 35. Heft 2. 
ob die Beschädigung eines Theiles der Markstrahlung, event. welchen Theiles dazu genügt. Bei diesem Anlasse werden einige andere Fragen zur Erörterung gelangen, die sich mit Rücksicht auf die angegriffene Localität in den Vordergrund der Discussion drängen.

Der erste Theil dieses II. Kapitels hätte inbaltlich ebenso gut dem I. Kapitel angefügt werden können; indessen erschien es mir zweckmässiger, Parallelversuche an den vorderen und den hinteren Abschnitten der Hemisphäre direct mit einander zu vergleichen, in ähnlicher Weise, wie dies schon im ersten Theil dieser Arbeit geschehen ist und auch in dem III. Kapitel dieser Abhandlung geschehen wird. In erster Linie kam es mir freilich darauf an, zu untersuchen, ob der Grad und damit vielleicht auch der Charakter der gesetzten Sehstörung bei verschiedenen Variabeln, die sämmtlich die Eigenschaft einer schwereren Verletzung als die blosse Aufdeckung besassen, stärker in die Erscheinung treten würden. Ferner aber musste sich auf diese Weise ein breiterer Boden zur Vergleichung dex frontalen und occipitalen Sehstörung gewinnen lassen.

a) Gyrus sigmoides.

Ich werde für diesen Abschnitt nur solche Versuche benutzen, welche ich seit dem Jahre 1899 angestellt habe. Zahlreiche theils früher, theils während dieser Periode angestellte Versuche bleiben unerwähnt, entweder, weil sie mir nicht genügten, oder und vornehmlich, weil das hier zusammengestellte Material zur Lösung der aufgeworfenen Fragen ausreichte.

B. Anätzungen.

\section{Beobachtung : 3 .}

Mittelgrosser Hund: Schädellïcke links $15 \mathrm{~mm}$ sagittal, $20 \mathrm{~mm}$ frontal. Aetzung des hinteren Schenkels und der hinteren Hälfte des vorderen Schenkels mit 5 proc. Karbolsäure.

Während des Heilungsverlaufes vorübergehende Schwellung der Operarationsstelle (Cerebrospinalflüssigkeit).

Motilitätsstörungen: Hochgradig, am 3. Tage stärker als am 2., insofern als Voltelaufen beobachtetwird; sehr allmählich abnehmend, bei geeigneten Untersuchungsmethoder noch nach mehr als 4 Monaten nachweisbar. Jackson'sche Krämpfe. Am 3. Tage in der rechten Vorderextremität während des Fütterns Adductions- und Beugekrämpfe. Am 5. Tage bei energischer Intention der Muskeln, z. B. beim Ausgleiten auf dem glatten Tisch mehrere Secunden dauernde tonische Streck- und Adductionskrämpfe rechts vorn und hinten. Unmittelbar nachher Thier offenbar abgespannt, apathischer und weniger fresslustig. Einige Minuten später wieder munter. Am 6. Tage auf dem Tisch mehrfach tonischer Krampf der Streck- und Adductionsmuskeln rechts vorn 
und hinten. Am 9. Tage einmal ein ca. 1 Minute dauernder tonischer Streckkrampf vorn und hinten; am 14. Tage sehr oft noch beim Ausgleiten auf dem glatten Tisch tonischer Streckkrampf rorn und hinten. Am 16. Tage Anfall von allgemeinen epileptiformen Krämpfen mit nachfolgendem Sopor; 2 Monate später nochmals localisirter Anfall.

In der Schwebe: Hängt noch nach mehr als 4 Monaten gestreckt; beim Begreifen ohne Reaction. Am 14. und 17. Tage stärkerer Widerstand bei passiven Bewegungen.

Sehstörung: Reagirt unverändert bis zum 6. Tage auf dem rochten Auge gegen Licht gar nicht (links scheut er), gegen Fleisch nur über dem Nasenrücken. Stösst im Zimmer nicht an. Während dieser Zeit greift oder schnappt das Thier nach Gegenständen, die in dem sehenden nasalen Streifen erscheinen, sehr unsicher. Am 6. und 7. Tage rechtes Auge bis auf nasalen Streifen wie bisher blind, doch scheinen Gegenstände von rechts aussen kommend, schon etwas eher als bisher eine unbestimmte Empfindung auszulösen; da das Thier mehrfach, bevor der betreffende Gegenstand in das Gebiet jenes nasalen Streifens kommt, seine Augen auf denselben einzustellen sucht. Am 8. Tage appercipirt das rechte Auge schon Gegenstände, wenn dieselben von aussen her gerade die Mittelebene des Gesichtsfeldes überschritten haben. Am 9. Tage werden Gegenstände schon kurz vor Ueberschreiten des verticalen Meridians appercipirt. Am 14. Tage Sehstörung nicht mehr nachweisbar.

Optische Reflexe: In den ersten Tagen unsicher. Am 5. Tage gänzliches Fehlen. Vom 9. Tage an schnelle Wiederkehr der Reflexe, am 12. Tage normal.

Nasenlidreflex: 8 Tage fehlend, dann langsam wiederkehrend; am 12. Tage normal.

Gestorben 5 Monate nach der Operation in einem epileptischen Anfall.

Da der Hund an der gleichen Stelle noch einmal operirt worden ist, wird das Ergebniss der Section hier nicht mitgetheilt.

\section{Beobachtung 21 .}

Kleiner junger Hund. Aufdeckung des Gyrus sigmoides mit Ausnahme der medialsten Partie. Absperrung gegen die Umgebung mit Watte. Aetzung mit 5 proc. Karbolsäurelösung.

Motilitätsstörungen erheblich, jedoch am 7. Tage kanm noch nachweisbar.

In der Schwebe: Hängt gestreckt, ohne Reaction beim Begreifen bis zum 5. Tage. Später fehlen sichere Notizen.

Sehstörung: Nur in der temporalen Partie, nicht hochgradig und bereits am 7. Tage nicht mehr nachweisbar.

Optische Reflexe fehlen yom 2. bis 11. Tag. (Ende der Beobachtung.)

Nasenlidreflex dauernd abgeschwächt.

Gestorben nach vier Monaten, in Folge einer neuen Narkose. Da an der gleichen Stelle noch zwei andere Operationen ausgeführt waren, so wird das Ergebniss der Section hier nicht mitgetheilt. 
C. Unterschneidungen.

Bei den folgenden Operationen wurde die Rinde möglichst flach mit einem vorn abgerundeten, 4,7 mm breiten Präparatenheber unter Schonung des Sulcus cruciatus unterschnitten.

a. Einseitige Operationen.

Beobachtung 25 .

Ziemlich junger Hund. Operation über linkem Gyrus sigmoides. Schädellücke sagittal 17, frontal $13 \mathrm{~mm}$. Unterschneidung der grauen Substanz des hinteren und des lateralen Drittels des vorderen Schenkels mit Präparatenheber, fast ohne Blutung auf höchstens $3 \mathrm{~mm}$ Tiefe. Heilung im Uebrigen per primam, nur der laterale Wundwinkel eitert während einiger Tage etwas.

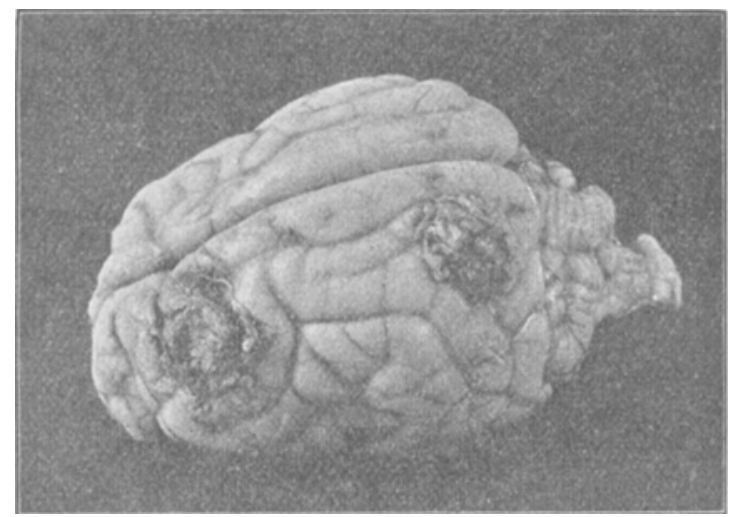

Fig. 27 .

Motilitätsstörungen: Am 2. Tage mässig hochgradig, am 4. Tage hochgradig. Vom 8 . Tage an hinten, rom 9 . Tage an vorn abnehmend. Am 30. Tage immer noch nachweisbar.

In der Schwebe: Hängt vom 2. Tage bis zum Schluss der Beobachtung rechts gestreckt und reagirt auf Begreifen nicht.

Sehstörung: Am 2. Tage fehlt Reaction auf der rechten lateralen Gesichtsfeldhälfte oder die Gegenstände werden nicht erkannt. Gegen Licht scheut er links stark, rechts zweifelhafte Reaction. Diese unsichere Reaction gegen Licht bestand auch noch bis zum 11. Tage. Am 4. Tage gegen Fleisch in derSchwebe anf weniger als der temporalen Gesichtsfeldhälfte, aber auch da nicht ganz reactionslos; wenn.ihm auf dem Tisch beim Fressen von Gemüse Fleisch vorgehalten wurde, nahm er links sofort davon Notiz, rechts nicht. Vom 5. Tage an Sehstörung gegen Fleisch nicht mehr nachweisbar.

Optische Reflexe: Fehlen vom 2. bis 20. Tage, von da an allmählich wiederkehrend, am 23. Tage noch abgeschwächt, am 25. Tage normal. 

normal.

Nasenlidreflex: Abgeschwächt bis zun 4. Tage; rom 5. Tage an

Getödtet mit Curare zwei Monate nach der Operation.

Section: Dura und Pia normal, nirgends verwachsen. Es ist ziemlich genau der hintere Schenkel des Gyrus sigmoides vom Sulcus cruciatus an bis

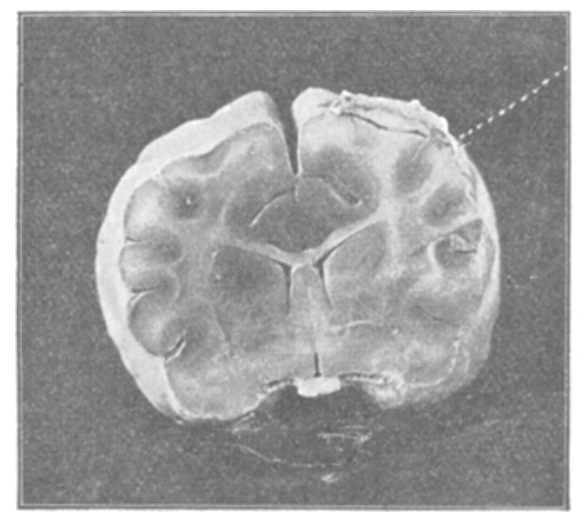

Fig. 28. 0: Operationsstelle.

etwas über die hintere Grenze des Gyrus sigmoides hinaus, dann etwas vom lateralen Theil des vorderen Schenkels, im Ganzen lateral etwas auf die 2. Urwindung übergreifend mit Narbengewebe bedeckt. Der Durchschnitt zeigt eine sehr flache, im Ganzen auf die Rinde beschränkte Zerstörung. Das Rindengrau fehlt unter dem ganzen hinteren Schenkel, etwas hellere Verfärbung auch noch im medialen Theil des Granes des erwähnten Theils der 2. Urwindung. Keine erweichten Stellen. Der Ventrikel leicht nach der Narbe zu verzogen. Die ganze linke Hemisphäre leicht atrophisch.

\section{Beobachtwng: 26.}

Kleiner Spitz. Schädellücke links sagittal 21, frontal $15 \mathrm{~mm}$. Da der Gyrus sigmoides sehr klein ist, ist die Basis des Stirnlappens und der obere hintere Theil der 2. Urwindung, insoweit er dem hinteren Schenkel unmittelbar anliegt, mit aufgedeckt. Unterschneidung des hinteren Schenkels und des lateralen Theils des vorderen Schenleels von lateralwärts her, etwas tiefer als sonst.

Motilitätsstörungen: Sehr hochgradig rom 1. Tage, 3 Stunden nach der Operation an; zwar allmählich abnehmend, aber nach 5 Wochen noch hochgradig.

Rechte Lidspalte bis zum 32. Tage erweitert.

In dor Schwebe: Hängt rechts stark gestreckt ca. vier Wochen lang, dann gelegentlich weniger gestreckt. Beim Begreifen bis zum Schluss der Beobachtung ohne Reaction. 
Sehstörung: Am 2. 'lage reagirt er auf Fleisch rechts nur übor dom Nasenrücken; dort schnuppert er aber sofort in der Luft herum und sucht das Fleisch zu ergreifen. Auf dem Tisch sieht er rechts von ihm liegendes Fleisch. nicht, links liegendes sofort. Links ist kein Gesichtsfelddefect nachweisbar. Gegen Licht rechts keine Reaction, links sofort sehr unruhig.--Abnehmend vom 4. Tage an, sodass am 8. Tage Fleisch auf den lateralen zwei Dritteln des

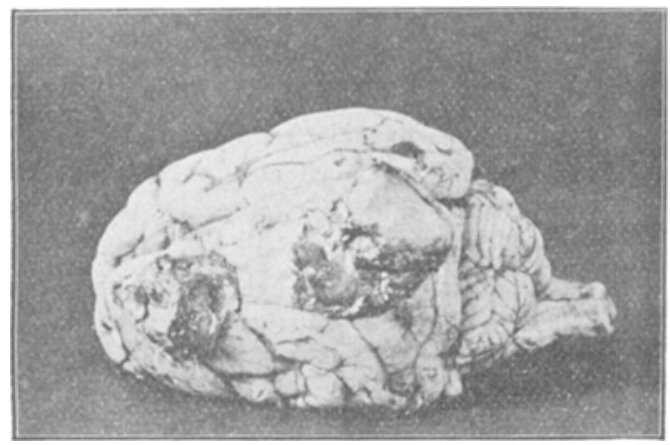

Fig. 29 .

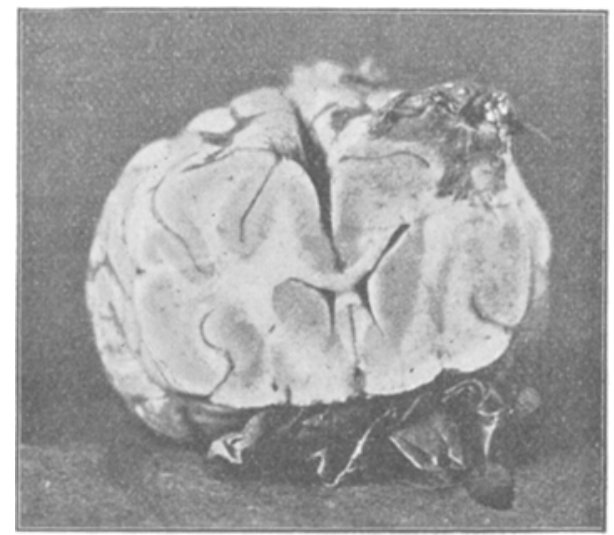

Fig. 30 .

Gesichtsfeldes noch nicht appercipirt wird und am 11. Tage nur noch ganz temporal in Defect nachzuweisen ist. An den nächsten Tagen vielleicht temporal noch etwas unsicher, dann normal. Die Reaction gegen oscillirendes. Licht schwankt etwas, sie fehlt ganz bis zum 5. Tage, während der Hund links sofort schent; dann ist sie an einzelnen Tagen abwechselnd and vom 10. Tage an regelmässig vorhanden. 
Optische Reflexe fehlen gänzlich bis zum Schluss der Beobachtung. Nasenlidreflex bis zuletzt abgeschwächt.

Getödtet zwei Monate nach der Operation, nachdem inzwischen eine zweite Operation im Hinterlappen 5 Wochen nach der ersten ausgeführt war.

Section: Pia und Dura zwischen vorderer und hinterer Operationsstelle verwachsen; vorn leicht, vor der hinteren Stelle etwa $1 \mathrm{~cm}$ breit so fest, dass die Trennung nur mit Verletzung der Hirnoberfläche möglich gewesen wäre. Die Narbe reicht medial bis fast an die Längsspalte, nach vorn bis auf den vorderen Schenkel des Gyrus sigmoides, doch nicht bis an den vorderen Rand des Schenkels, medial etwas weiter nach vorn als lateral, nach lateral den lateralsten Theil des vorderen Sohenkels freilassend, den lateralen Theil des hinteren Schenkels bedeckend und noch auf die 2. Urwindung übergreifend, nach hinten noch etwas über die hintere Grenze des Gyrus sigmoides hinausgehend. Auf dem Durchschnitt zeigt sich ein bräunlich verfärbtes Narbengewebe von der Narbendecke nach innen gehend bis in die weisse Substanz. Die Rinde ist im Gebiet der Narbendecke theils durch Narbengewebe ersetzt, theils heller verfärbt. Der Ventrikel ist nach der Narbe zu ausgezogen.

\section{Beobachtung ?r.}

Freilegung des ganzen linken Gyrus sigmoides, Ưmschneidung desselben mit dem Messer, Unterschneidung mit dem scharfen Löffel. Das unterschnittene Stück wird in loco belassen.

Motilitätsstörungen: Anfänglich und zwar schon gleich nach der

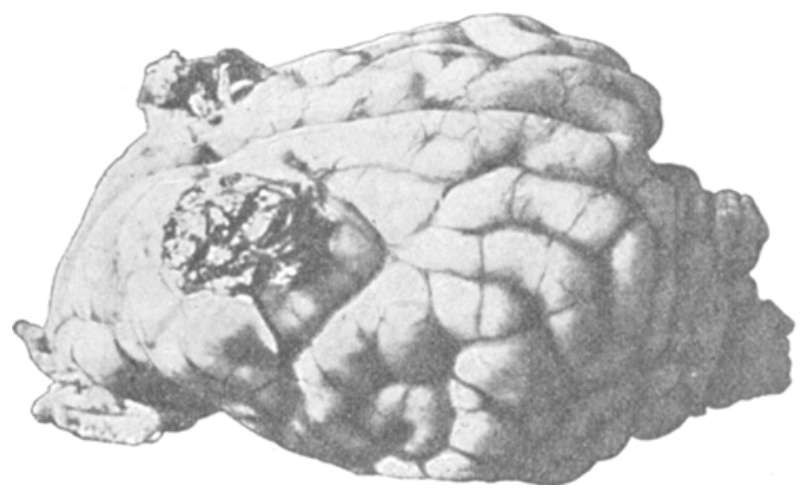

Fig. 31.

Operation sehr hochgradig, sehr allmählich abnehmend; am 22. Tage und später setzt er das Vorderbein bei der leisesten Berührung fort, lässt es aber nooh dislociren und mit dem Dorsum aufsetzen. Ebenso noch am 29. Tage, dann 2. Operation.

In der Schwebe: Vergl. Beobachtung 6. 
Sehstörung: Gegen Fleisch schlecht zu untersuchen, scheint es jedoch bereits am 3. Tage ganz lateral zu bemerken. Gegen Licht: in den ersten Tagen beiderseits gleichgültig, am 4. und 5. Tage fehlt jedoch rechts die nunmehr links vorhandene Reaction.

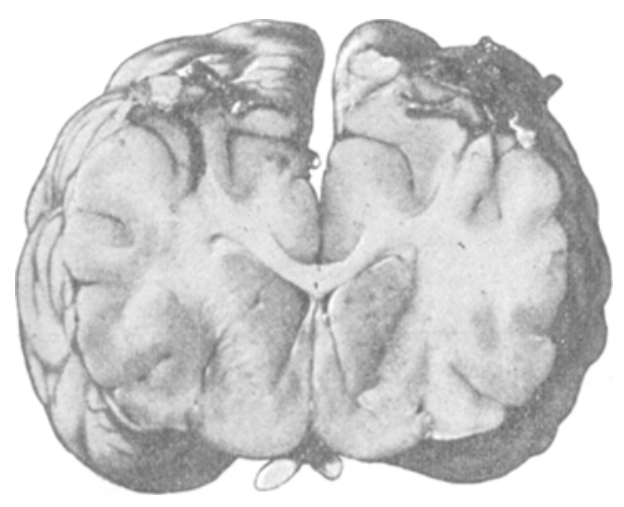

Fig. 32.

Optische Reflexe fehlen oder sind mindestens stark abgeschwächt bis zum 7. Tage, vom 8. Tage an beiderseits gleich.

Nasenlidreflex: Bis zum 5. Tage rechts etwas abgeschwächt, rom 6. Tage an beiderseits gleich.

Getödtet nach 6 Wochen.

Section: Hirnhäute normal. Die etwa $18 \mathrm{~mm}$ sagittal und $22 \mathrm{~mm}$ frontal messende Narbe sitzt dem Gyrus sigmoides in der Weise auf, dass sie nach hinten mit dem hinteren Rard des hinteren Schenkels, nach lateral mit dem lateralen Rand abschliesst, nach vorn reicht sie bis etwas über den Sulcus cruc. in den vorderen Schenkel hinein. Nach medial bis $7 \mathrm{~mm}$ von der Medianspalte. Die Hirnoberflächenpartie von der Narbe bis zur Medianspalte ist leicht höckerig, narbig eingezogen. Durchschnitt (dicht hinter dem Sulc. cruc.): Die Rinde ist flach in der Ausdehnung der Narbe zerstört; von der Narbe ans geht im Markweiss des Gyrus sigmoides ein feiner, blutig verfärbter Erweichungsstreifen $4 \mathrm{~mm}$ weit basalwärts.

\section{ß. Operationen der zweiten Seite.}

\section{Beobachtung 28 .}

Derselbe Hund von Beob. 27. Operation am 30. Tage nach der ersten Operation. Unterminirung des rechten Gyrus sigmoides.

Motilitätsstörungen: Hochgradig, jedoch am 14. Tage (als der Hund getödtet wird) merklich gebessert. Rechts durch die 2. Operation nicht verschlimmert, beim Tode noch nachweisbar. 
In der: Schwebe: Vergl. Beob. 6.

Sehstörung: Gegen Fleisch: Am 2. Tage auf der lateralen Hälfte ohne Reaction, an den nächsten Tagen schlecht zu untersuchen, vom 7. Tage an Sehstörung nur im lateralen Streifen, am 14. Tage daselbst noch geringe Abschwächung. Gegen Licht: Am 2. und 3. Tage fehlende Reaction, rom 4. Tage bis zom Tode Abschwächung.

Optische Reflexe fehlen am 2. Tage, am 3. Tage abgeschwächt, dann normal.

Nasenlidreflex ungestört.

Getödtet 14 Tage nach der Operation.

Section: Hirnhänte normal. Die $15 \mathrm{~mm}$ sagittal, ca. $12 \mathrm{~mm}$ frontal messende Narbe sitzt genau symmetrisch, nur reicht sie nicht ganz bis zum

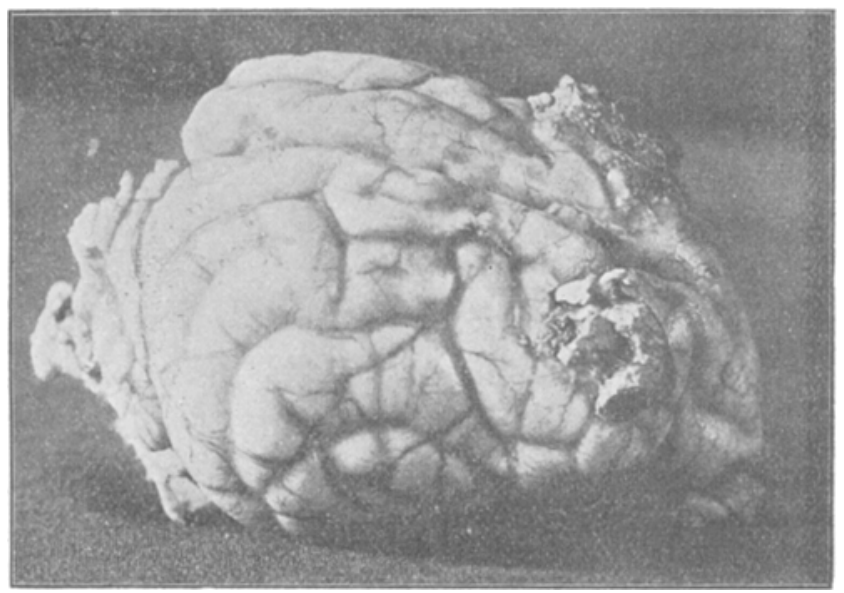

Fig. 33.

hinteren Rand des hinteren Schenkels des Gyrus sigmoides. Durchschnitt: (dicht hinter dem Sulc. cruc.) Rinde der Narbenausdehnang entsprechend flach zerstört, das unter der Narbe liegende, den einschneidenden Sulci folgende Rindengrau erscheint wie auch links, vielleicht etwas abgeblasst. In der Markleiste des Gyrus sigmoides (laterale Verbindung zwischen vorderem und hinterem Schenkel desselben) stejgt ebenfalls ein blutig verfärbter Erweichungsstreifen basalwärts; derselbe ist etwa $9 \mathrm{~mm}$ lang.

\section{Beobachtung 29 .}

Derselbe Hund von Beobachtung 32. Aufdeckung über Gyrus sigmoides rechts auf $18 \mathrm{~mm}$ sagittal, $13,5 \mathrm{~mm}$ frontal. Unterschneidung des hinteren Schenkels und des lateralen Theiles des vorderen Schenkels mit Präparatenheber. Wundheilung: am 4. Tage Wunde stark geschwellt, Entleerung 
einer blutig serösen Flüssigkeit. Am 9. Tage ist der untere Wundwinkel etwas aufgegangen, entleert etwas seros eitriges Secret, wird durch Naht und Jodoformcollodium wieder verschlassen.

Motilitätsstörungen: Maximal, am2. Tage beim Laufen eigenthümliche, wie automatische Bewegungen im linken Vorderbein. Voltelaufen nach rechts. Gegen Mittag Jackson'sche Krämpfe vornehmlich des Hinterbeins und Nackens, später auch der Gesichts- und Kiefermuskilatur mit Betheiligung des linken Orbicularis paip. Dann bei Drehung des Kopfes nach rechts auch krampfartige Schluck- und Leclibewegungen. Am 3. Tage keine Krämpfe, aber Tendenz den Kopf nach rechts zu drehen, am 4. Tage Vormittags heftige rechtsseitige Krämpfe, mit Déviation conjuguée de la tête et des yeux nach rechts. Nachmittags allgemeine Krämple mit automatischen Laufbewegungen und dilatirten Pupillen. Am 5. Tage Zuckungen in der rechten Körperhälfte nur noch selten, Gesichtszuckungen fehlen ganz, später keine Krämpfe mehr. Erholt sich schnell; Notilitätsstörungen bis zum 7 . Tage maximal, dann abnohmend, aber bis zum 30 . Tage hocbgradig, bis zum 36 . Tage (todt) mässig. Hund ist nach der 2. Operation blödsinnig geworden.

In der Schwebe die gewöhnlichen Störungen.

Sehstörung: Gegen Fleisch am 2. Tage linlis total, reagirt rechts ungeachtet der Krämpfe. 3. Tag: bis auf einen nasalen Streifen vorhanden. 4.-6. Tag: Sebstörung noch vorhanden, doch wegen mangelhafter Reaction nicht genügend abzugrenzen. Vom 8. Tage an keine Sehstörung mehr. Gegen Licht: indifferent bis zum 8. Tage, an diesem Tage links nichts, rechts blinzelt er, am 10. Tage gleichgültig, schnappt nach der Flamme; indifferent bis zum 13. Tage, an diesem Tage erst gleichgültig, schnappt dann nach der Flamme, verbrennt sich, darauf heftig schenend. Später bis zu Ende beiderseits gleiche, mebr weniger starke Reaction.

Optische Reflexe: Bis zum 4. Tage links fehlend, rechts sehr deutlich; an diesem Tage auch rechts fehlend, dann bis zum 8. Tage rechts schwach vorhanden, bis zum 10. Tage rechts immer deutlich, links fehlend, von diesem Tage an auch links schwach bis zum 13. Tage; von da an beiderseits gleich, manchmal links etwas schwächer, mehr weniger deutlich vorhanden.

Nasenlidreflex: Links abgeschwächt bis zum4. Tage, an diesem Tage beiderseits fehlend, am 5 . Tage links fehlend, rechts angedeutet. Vom 7. bis 13. Tage links abgeschwächt v.orhanden, von da an beiderseits gleich, manchmal links etwas schwächer.

Gestorben am 36. Tage.

Section: Häute sonst normal, links einige zarte, leicht lösliche Verwachsungen zwischen Dura und Pia. Im Gebiet des Gyrus sigmoides fehlt beiderseits die Rinde. Verwachsung mit der die Knochenlücke schliessenden narbigen Membran. Auf beiden Seiten hier, kesonders links tiefergehende Erweichungsherde; links fast die innere Kapsel errejchend, rechts klejner, durch Blutfarbstoff bräunlich verfärbt. 
D. Skarificationen.

\section{Beobachtumo: 30 .}

Kleines, junges Thier. Aufdeckung im Gebiete des Gyrus sigmoides links, auf sagittal 16, frontal $14 \mathrm{~mm}$. Oberflächliche Skarification (immer ca. $2 \mathrm{~mm}$ tief) der ganzen vorliegenden Rinde.

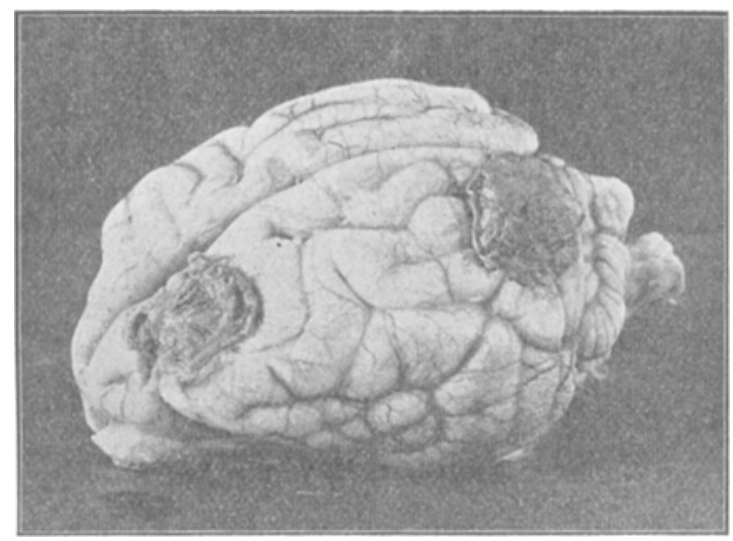

Fig. 34 .

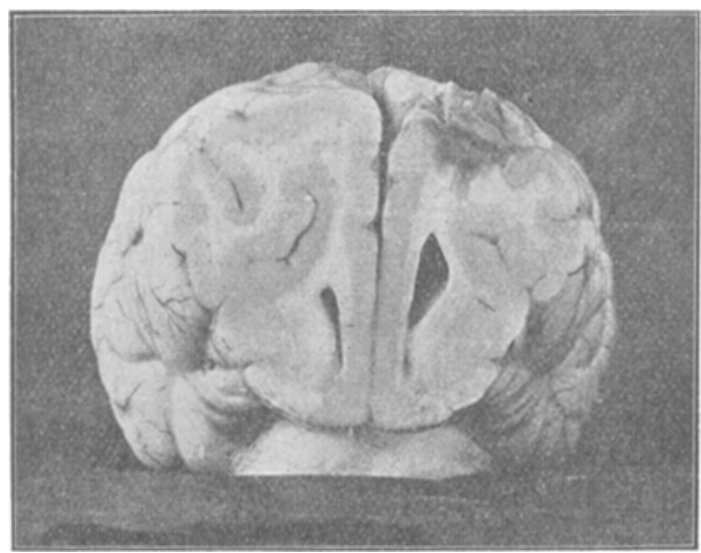

Fig. 35.

Motilitätsstörungen: Hochgradig, mit Voltelanfen und Krümmung der Wirbelsäule beim Liegen nach rechts convex bis zum 4. Tage. Verlieren sich allmählich, nach $2 \frac{1}{2}$ Monaten noch spurweise.

In der Schwebe: Hängt lange Zeit gänzlich, nach 3 Monaten noch 
leicht gestreckt. Beim Begreifen fehlt Reaction $21 / 2$ Monate. gänzlich, nach 3 Monaten vorn noch stark abgeschwächt, hinten fehlend.

Sehstörung: Bis zum 3. Tage völlig blind; dann allmählich sich bessernd, am 15. Tage noch in breitem temporalen Streifen; am. 19. Tage nur ganz aussen unsicher, am 25. Tage beiderseits gleich. Gegen Licht immer beiderseits gleichgültig, nur am 10. Tage rechts schwächere Reaction.

Optische Reflexe: 2 Stunden nach der Operation beiderseits in geringem Maasse vorhanden. Vom 2. Tage an rechts fehlend, vom 16. Tage an allmählich wiederkehrend, nach 5 Wochen noch abgeschwächt, nach zwei Monaten normal.

Nasenlidreflex: Fehlt bis zum 5. Tage, nachher abgeschwächt, vom 10. Tage an beiderseits gleich.

Getödtet 4 Monate nach der Operation mit Curare, nachdem inzwischen. 3 Monate nach der Operation eine zweite Operation im Hinterlappen ausgeführt war.

Section: Vor der hinteren Operationsstelle leichte Verklebung zwischen Dura und Pia; sonst beide Häute normal. Die vordere Operationsstelle bedeckt den vorderen Schenkel des Gyrus sigmoides nach hinten bis zum Sulcus cruciatus, nach vorn noch wenig auf den Stirnlappen übergreifend, lateral an der 2. Urwindung abschliessend. Auf einem Durchschnitt sieht man einen etwa keilförmigen Herd von Narbengewebe, der sich allmählich verjüngend, sich etwa 2-3 $\mathrm{mm}$ in die weisse Substanz hineinerstreckt. Das Rindengrau fehlt im Gebietdes vorderen Schenkels des Gyrus. Der Seitenven trikel ist links erweitert und nach der Narbe zu ausgezogen.

\section{Beobachtung $\mathbf{3 1}$.}

Aufdeckung des vorderen Schenkels des Gyrus sigmoides links bis eben an den Sulcus craciatus, sagittal $16 \mathrm{~mm}$, frontal an der Tabula vitrea $12 \mathrm{~mm}$. Ca. 19 Einstiche in die freiliegenden erregbaren Stellen.

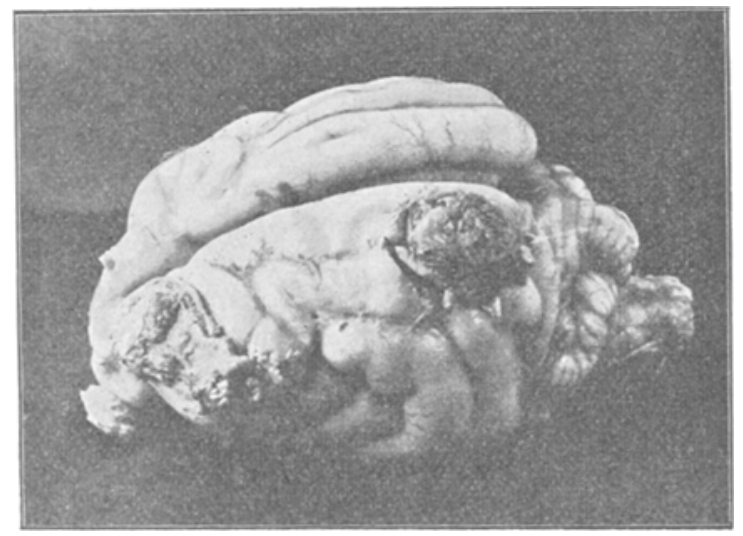

Fig. 36 . 
Motilitätsstörungen: Unmittelbar nach der Operation nachweisbar, aber unerheblich; weitere Notizen feblen.

Sehstörung: Am 2. Tage bis auf nasalen Streifen reactionslos, dann verschwunden. Gegen Licht am 2. und 3. Tage abgeschwächt.

Optische Reflexe: 5 Standen nach der Operation beiderseits rorhanden. Nur wenig und schwankend verändert bis zum 4. Tage.

$N$ asenlidreflex unverändert.

Getödtet $4^{1 / 2}$ Monate nach der ersten Operation. Da an der Stelle dieser noch eine zweite Operation vorgenommen ist; werden die Resultate der Section hier nicht angeführt.

\section{Beobachtmo: 3R.}

Junger Hund. Aufdeckung des linken Gyrus sigmoides auf sagittal 19, frontal $14 \mathrm{~mm}$. Ausgiebige Skarification des hinteren Schenkels und des lateralen Drittels des vorderen Schenkels.

Motilitätsstörungen: Deutlich, aber verhältnissmässig gering und schnell verschwindend. Am 14. Tage noch nachweisbar.

In der Schwebe: Hängt in der Regel mässig gestreckt, manchmal nur wenig anders als links. Reaction auf Begreifen fehlt während der ganzen Dauer der Beobachtung.

Sehstörung: Gegen Fleisch am 2. Tage auf temporalem Streifen; am 3. und 4. Tage dort vielleicht noch unsicher, dann normal. Gegen Licht am 2. Tage links scheuend, rechts nicht; später indifferent, jedoch am 11. Tage gegen oscillirendes Licht links häufiger Blinzeln als rechts.

Optische Reflexe: $31 / 2$ Stunde nach der Operation eher stärker, am 2. Tage fehlend, bis zum 10. Tage; rom 12. bis zum 15. Tage rechts noch abgeschwächt.

Nasenlidreflex am 2. und 3. Tage abgeschwächt, dann normal.

Hund gestorben 2 Monate na.eh der 1. Operation.

Wegen des Obductionsbefundes vergl. Beobachtung 29.

\section{Beobachtumo: 33.}

Aufdeckung links vorn sagittal 17 , frontal $15 \mathrm{~mm}$. Skarification des hinteren Schenliels und des lateralen Drittels des vorderen Sehenkels.

Motilitätsstörungen: Am 2. Tage recbt erheblich, am 6. Tage schon stark in der Abnabme; am 33. Tage noch Spuren, am 35. Tage nicht mehr nachweisbar.

In der Schwebe: Hängt mässig gestreckt, bald mehr, bald weniger bis zum 33. Tage. Beim Begreifen alsdann noch keine Reaction.

Sehstörung: Am 2. Tage bis auf nasalen Streifen vorhanden, am 3. Tage noch temporaler Streifen; am 4. Tage verschwunden. Gegen Licht beiderseits gleichgültig, nur am 11. Tage blinzelt er links häufiger als rechts.

Optische Reflexe: Am Operationstage, 6 Stunden nach der Operation rechts stärkere Reaction; fehlen dann rechts bis zum 13. Tage, von da an allmählich wiederkehrend; a.m 35 . Tage noch schwäeher als links. 
Nasenlidreflex: Am 2. Tage abgeschwächt, nachher normal. Getödtet 3 Monate nach der Operation.

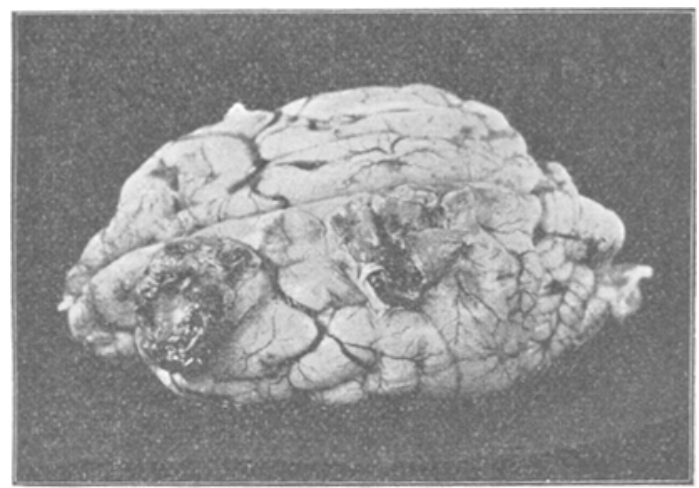

Fig. 37.

Section: Dura und Pia normal. Die Operationsstelle nimmt den ganzen Gyrus sigmoides ein, ohne auf die Nachbarwindungen überzugreifen. Der Durchschnitt zeigt nur eine ganz flache Zerstörung der Rinde, das Grau ist durch Narben gewebe flach ersetzt. Die weisse Substanz ist nicht mitverletzt.

E. Exstirpationen.

$\alpha$. Einseitige Operationen.

\section{Beobachtung 34 .}

Freilegung des linken Gyrus sigmoides, Umschneidung des hinteren und des hinteren Theiles des rorderen Schenkels desselben auf ca. $1 \mathrm{~cm}$ Tiefe, Abtragung der umschnittenen Partie nit dem Präparatenheber, mit Ausnahme der medialsten Partie, die unterschnitten wird. Knochenlücke sagittal $17 \mathrm{~mm}$, frontal $13 \mathrm{~mm}$. Ziemlich starke Blutung aus einer Knochenarterie und aus einer zwischen Dura und Pia verlaufenden Vene.

Motilitätsstörungen: Sebr hochgradig, steht anfänglich gewöhnlich auf dem Dorsum des rechten Vorderfusses, das rechte Hinterbein stark dislocirt, liegt mit dem Rücken nach rechts convex; vom 10. Tage an langsam abnehmend, am 14. Tage (Tag der 2. Operation) noch hochgradig.

In der Schwebe: Anfänglich keine Differenzen zwischen beiden Seiten, beiderseits ziemlich gestreckt. Vom 4. Tage zunehmend stärkere Streckung der rechten Extremitäten, so dass diese sich vom 6 . Tage an kreuzen. Vom 6. Tage an bei passiven Bewegungen häufig, nicht immer, Muskelwiderstand, besonders schnellt auch der Fuss nach passiver Beugung im Fussgelenk in die Streckstellung zurück. Nach Pumpbewegungen wird das vorher gestreckte 
Vorderbein gelegentlich gebeugt. Vom 2. bis 6. Tage Schnauzenspitze nach rechts, am 8. Tage nur noch Wirbelsäule nach rechts.

Sehstörung: Gegen Fleisch: an den ersten beiden Tagen nur insofern angedeutet, als er langsamer reagirt. Nachher fehlend. Gegen Licht: beiderseits indifferent,

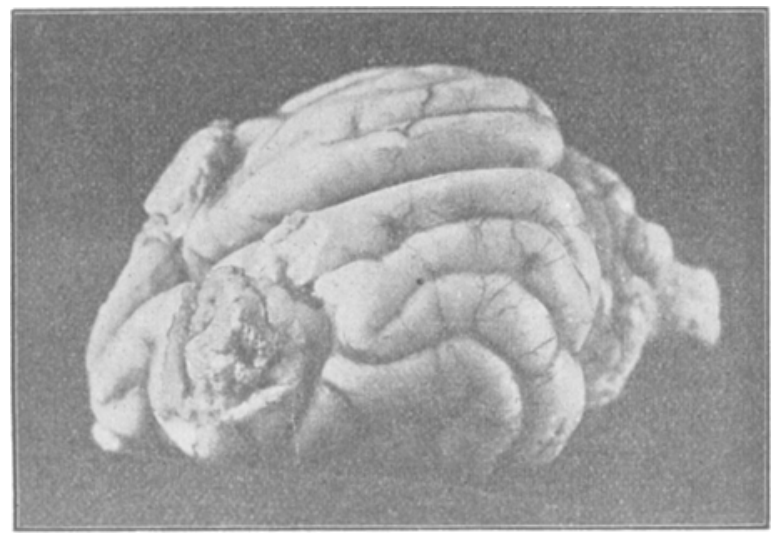

Fig. 38.

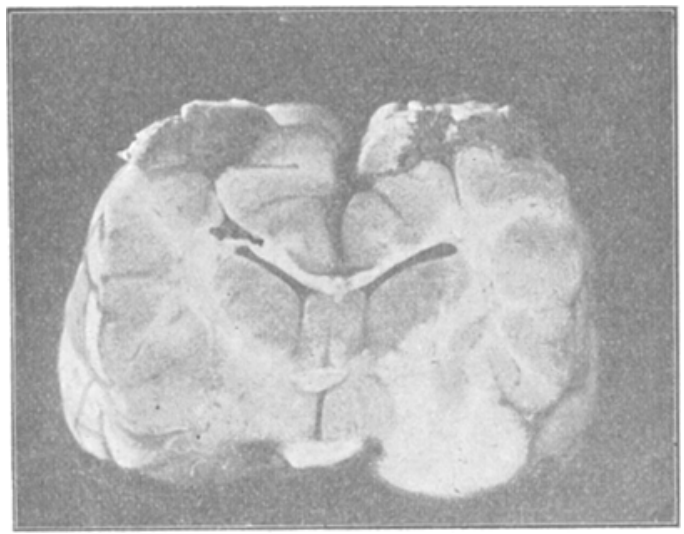

Fig. 39. 2. Durchschnitt.

Optische Reflexe fehlen bis zum 17. Tage, dann noch 4 Tage abgeschwächt.

Nasenlidreflex: Am 2. und 3. Tage gegen Bestreichen abgeschwächt, gegen Beklopfen normal.

Getödtet nach ungefähr 6 . Wochen. 
Section: Die Narbe bedeckt den ganzen Gyrus sigmoides mit Ausnahme des Ursprungs des Stirnlappens aus seinem vorderen Schenkel und eines schmalen medialen Streifens, die mediale Kante stark einziehend; lateral etwas auf die 2. Urwindung übergreifend. Durchschnitt circa durch die Mitte der Narbe: Hirnnarbe ist verhältnissmässig flach, Gyrus erscheint zusammengezogen, so dass die 2. Urwindung der Medianspalte etwas näher als normal liegt. Die Unterschneidung reicht bis zur Medianspalte, es steht aber medial noch eine schmale, allerdings narbig veränderte Rindenbrücke. Von der Narbe geht ein feiner strichförmiger Erweichungsstreifen in der Markleiste des Gyrus einige Millimeter basalwärts. Der linke Ventrikel ist vielleicht ein wenig erweitert. 2. Durchschnitt $2 \mathrm{~mm}$ weiter nach vorn als der erste: Von der Narbenkappe erstreckt sich ein ziemlich breiter Erweichungsstreifen, der mit einem etwa $2 \mathrm{~mm}$ grossen Erweichungsherd am Fuss des Stabkranzes unmittelbar am Uebergang in den Balken endigt, derart in die Tiefe, dass er die ganze Verbindung der Balkenstrahlung an dieser Stelle unterbricht. Auf dem dritten Durohschnitt, noch $2 \mathrm{~mm}$ weiter nach vorn, ist die narbige Veränderung etwas grösser geworden.

\section{Beobachtung 35.}

Aufdeckung des Gyrus sigmoides links. Unterschneidung des ganzen Gyrus mit dem Präparatenheber, Abtragung desselben mit der Schere.

Motilitätsstörungen: Anfänglich hochgradig, vom 8. Tage an allmählich abnehmend.

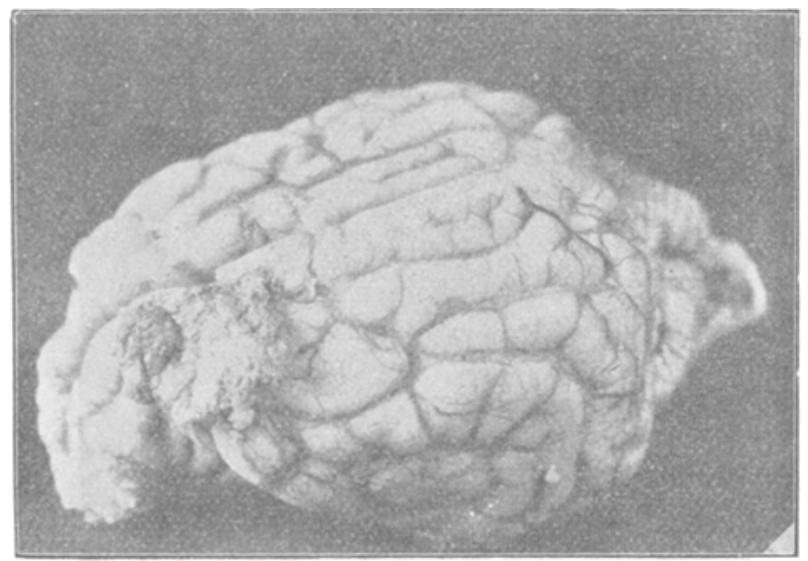

Fig. 40.

In der Schwebe: Hängt rechts vorn gestreckt, nach aussen deviirend, schlaff, beim Pumpen gegen den 11. Tag öfter Spreizen der Zehen. Beim Begreifen keine Reaction. 
Sehstörung: Gogen Fleisch wegen Aengstlichkeit des Thieres nicht zu untersuchen; gegen Licht bis zum 11. Tage rechts indifferent, links scheut er stark and beisst nach dem Licht; nachher krank.

optische Reflexe fehlen, gegen Schluss der Beobachtung vielleicht manchmal gegen flache Hand angedeutet.

Nasenlidreflex ungestört.

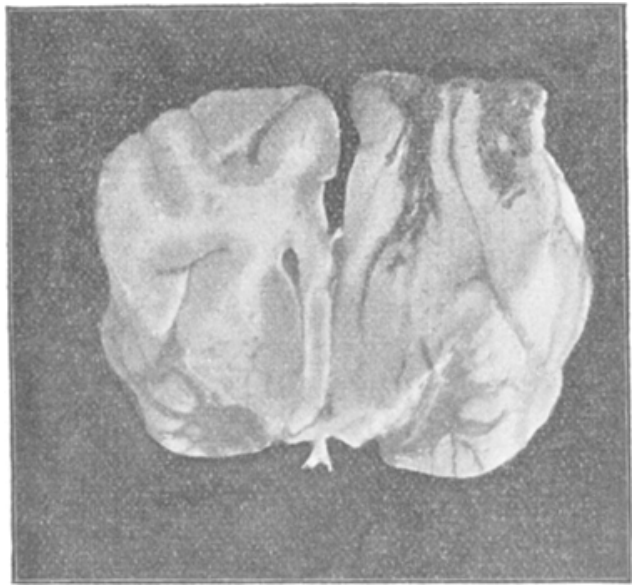

Fig. 41. 1. Durchschitt. H

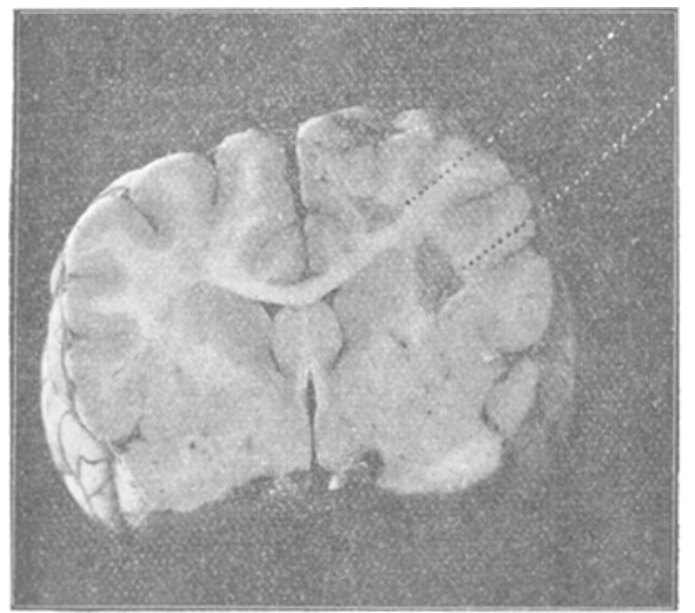

lig. 42. 2. Durchschnitt. HH. Herde.

Gestorben nach 3 Wochen.

Section: Pia zart und glatt. Auf dem linken Gyıus sigmoides sitzt, denselben vollkommen bedeckend, eine $20 \mathrm{~mm}$ sagittal and $15 \mathrm{~mm}$ frontal 
messende Narbenkappe auf, die medial bis zur Medianspalte reicht. Die Grenzen des Gyrus werden nicht überschritten. Der ganze vordere Abschnitt der Hemisphäre erweist sich als verschmälert und nach der Narbe zu zusammengezogen. 1. Durchsohnitt durch die Mitte der Narbe, dem Sulc. cruc, entsprechend. Rechte Hemisphäre: Grösste Breite $21 \mathrm{~mm}$, linke $18 \mathrm{~mm}$. Von der Narbe auf der linken Hemisphäre ziehen blutig verfärbte Erweichungsstreifen basalwärts, bis zum oberen Winkel des dort beginnenden Seitenventrikels. 2. Durchschnitt 2-3mm hinter dem hinteren Rande der Narbe: Im oberen Theil der inneren Kapsel findet sich ein leicht blutig verfärbter, etwa linsengrosser Erweichungsherd, der sie fast völlig durchtrennt und nur medial und lateral ganz schmale Streifen Markweiss intact lässt. Ein zweiter kleiner Herd findet sich im medialen dorsalen Bezirl des Centrum semiovale. Der Querschnitt, namentlich sein dorsaler Theil, ist stark atrophisch.

\section{Beobachtung: $\mathbf{3 6}$.}

Mittelgrosser Hund. Aufdeckung des Gyrus sigmoides links. Schädellücke sagittal-medial 24, lateral 19, frontal 14,5 mm. Der Gyrus wird mit dem Präparatenheber an den äusseren drei Seiten auf ca. $1 \mathrm{~cm}$ tief umstochen, dann bis zur Falx unterschnitten und endlich mit der Schere abgetragen. Nicht. erhebliche, aber anbaltende Blutung, so dass längere Zeit mit einigen Stückchen Feuerschwamm tamponirt werden muss.

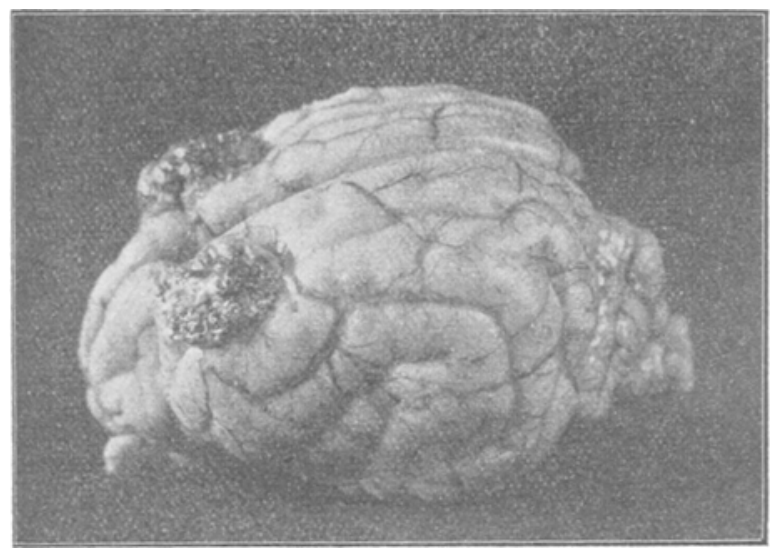

Fig. 43 .

Motilitätsstörungen: Sehr hochgradig, : bleibt unter anderem mit beiden rechten Beinen auf dem Dorsum stehen, wenn man ein linkes Bein aufhebt; hebt man beide linken Beine auf, fällt er um (vergl. Fig. 13). Sehr allmähliche Abnahme der Motilitätsstörung rom 9. Tage an; am 13. Tage (2. Operation) noch selor deutlich. 
In der Schwebe (vergl, Beobachtung 8): Beim Begreilen rechts gleich Null; links hinten starke Reaction, links vorn giebt er die Pfote.

Sehstörung: Am 2. Tage maximal, reagirt gegen Fleisch erst auf dem Nasenrücken, gegen Licht nicht; am 3. Tage ist der nasale Streifen etwas. breiter geworden, im nnteren medialen Quadranten wird Fleisch regelmässig. bemerkt; am 4. Tage fehlt Reaction gegen Fleisch nur noch bis zur Mitte. Am

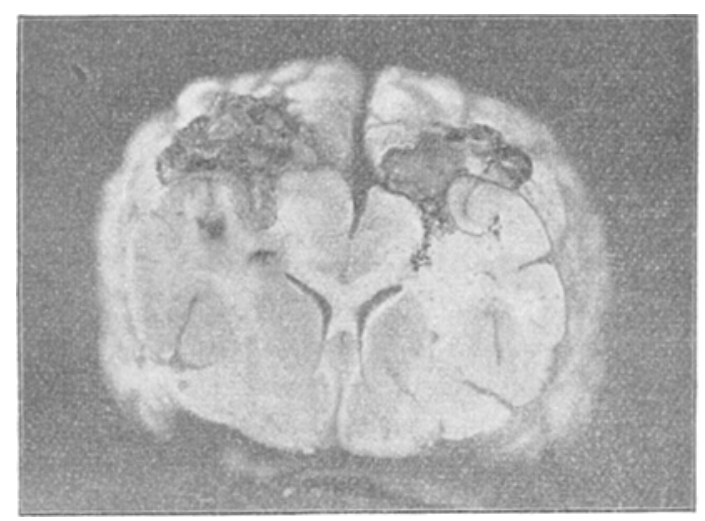

Fig. 44. 1. Durchschnitt.

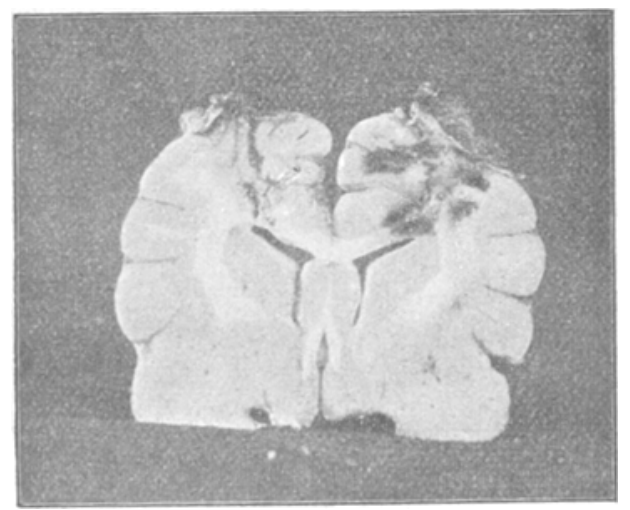

Fig. 45. 2. Durchschnitt.

6. Tage überall Reaction auf Fleisch, auch die bis dahin fehlende Reaction auf Licht ist vorhanden, jedoch bis zum Ende der Beobachtung (12. Tag) abgeschwächt. 
Optische Reflexe: Fehlen gänzlich bis zum 23. Tage, dann noch 5 Tage (bis zum Tode) abgeschwächt.

Nasenlidreflex (auch Sensibilität in der Nase) ungestört.

Getödtet nach 4 Wochen.

Section: Häute normal. Die etwa $25 \mathrm{~mm}$ im sagittalen und frontalen Durchmesser grosse Narbe bedeckt den ganzen Gyrus sigmoides und reicht bis an die hier etwas eingezogene mediale Kante desselben. Vorderer Durchschnitt ungefähr durch den Sulcus cruciatus: Die Narbenkappe sitzt noch etwas auf der 2. Urwindung auf, die Rinde ist dort etwas abgeblasst. Rinde des Gyrus sigmoides und darunterliegendes Markweiss zerstört. Von der Narbe zieht ein Erweichungsstreifen bis auf $2 \mathrm{~mm}$ an die Spitze des Seitenventrikels heran, ebenso ein feiner Streifen in die Markleiste der 2. Urwindung. Hinterer Durchschnitt am hinteren Ende der Narbe: Der Gyrus ist stark verschmälert, nur der mediale Theil ist erhalten, in die Lücke hat sich die 2. Urwindung hineingelegt. Die Narbe zieht sich yon der Oberfläche bis in den Balken hinein, der noch in seinem lateralen ventricularen Theile von kleinen Erweichungsherden durchsetzt ist.

\section{Beobachtung 37 .}

Ziemlich kleiner Hund. Aufdeckung des Gyrus sigmoides links. Schädellücke sagittal 21, frontal $10 \mathrm{~mm}$. Umschnejdung des Gyrus etwa $1 \mathrm{~cm}$ tief und Abtragung von hinten her mit der breiten Seite des Präparatenhebers.

Motilitätsstörungen: Am zweiten Tage zeigt er beim Umberlaufen deutliches Voltelaufen nach links, dreht sich auch oft fast auf der Stelle

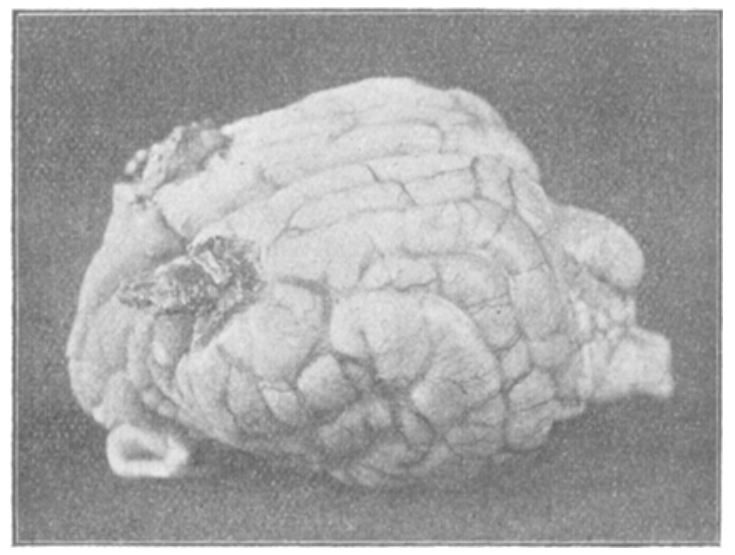

Fig. 46.

links berum, sogar beim Fressen aus dem Teller; Voltelaufen gelegentlich noch am 12, Tage. Anderweitige Motilitätsstörungen mässig hochgradig, öfter durch Ortsbewegungen des von jeher lebhaften Thieres theilweise verdeckt. 
In der Schwebe: Hängt stets rechts mehr oder weniger stark gestreckt. Die Streckung nimmt beim Begreifen und passiven Bewegungen häufig, beim Zeigen von Fleisch vom 6. Tage an zu. Die Muskulatur zeigt in der Regel keinen, an einzelnen Tagen aber vorübergehend einen mehr oder minder starken Widerstand gegen passive Bewegungen.

Sehstörung: Gegen Fleisch am 2. Tage Reaction nur im schmalen, nasalen Streifen, am 4. Tage in der medialen Hälfte des Gesichtsfeldes, in der unteren Partie besser; am 6. Tage zweifelhaft, ob noch vorhanden, vom 7. Tage an fehlend. Gegen Licht: Reaction tehlend am 2. Tage, vom 4. Tage an sehr deutlich vorhanden.

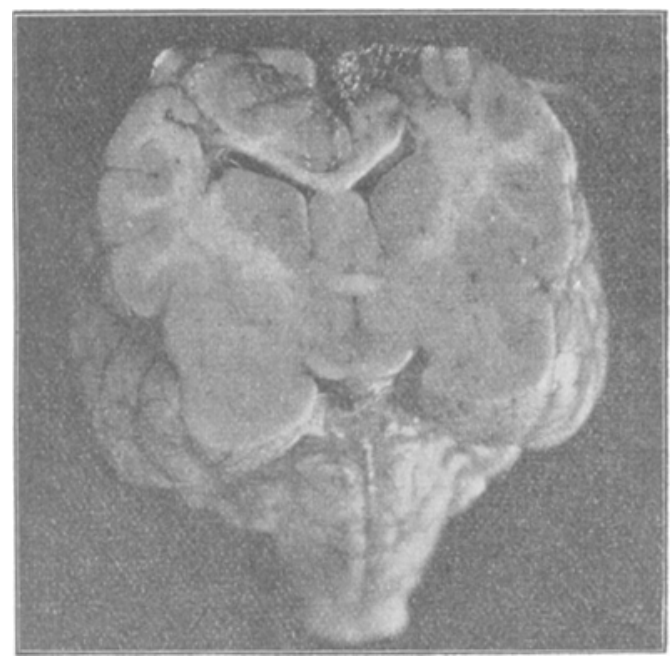

Fig. 47 .

Optische Reflexe: Fehlen bis zum Schluss der Beobachtung gänzlich, obwohl sie am 11. und 12. Tage anscheinend nachweisbar gewesen waren. (Gelireuzter Reflex?) Links waren sie stets sehr lebhaft.

Getödtet nach 27 Tagen.

Section: Pia zart und glatt. Unterhalb der Operationsstelle findet sich ein flaches, derbes, bereits ziemlieh entfärbtes, der Innenfläche der Dura anhaftendes, mit der Pia nicht verklebtes Blutcoagulum, das sich bis zur Basis herunterzieht, ebenso in die Medianspalte des Gehirns zwischen den beiden Operationsstellen bis nach dem vorderen Pol der Stirnhöhle sich erstreckt. Die ca. $20 \mathrm{~mm}$ sagittal und $13 \mathrm{~mm}$ frontal messende Narbe sitzt dem Gyrus sigm. auf, ihn in seiner ganzen Ausdehnung zerstörend. Die Zerstörung reicht bis zur: Medianspalte des Gehirns, die Kante ist hier nach der Narbe zu eingezogen. Durchschnitt etwa durch den Sulc. cruc.: Das Rindengrau und die ganze darunterliegende Marksubstanz im Gebiet des Gyrus ist vollständig zer- 
stört, von der Narbe aus ziehen Erweichungen nach dem Balken zu und unter dem Sulc. coronalis weg in die 2. Urwindung. Der Querschnitt ist verzogen und stark verkleinert.

\section{Beobachtung $\mathbf{3 8}$.}

Aufdeckung des linken Gyrus sigmoides auf $18 \mathrm{~mm}$ sagittal und $16 \mathrm{~mm}$ frontal. Lateral ist ein schmaler Abschnitt der 2. Urwindung freigelegt. Vorn ist der Ursprung des Stirnlappens aufgedeckt. Unterschneidung und Abtragung des freiliegenden Theiles des Gyrus sigmoides von hinten her und thunlichste Zerstörung der schmalen medialen, nicht mit aufgedeckten Partie. Mässige Blutung.

Motilitätsstörungen: Dreht und zwar noch am 5. Tage nach links. Anderweitige Motilitätsstörungen hochgradig, noch am 5. Tage maximal, am 9. Tage erheblich abgenommen; ist der Hund etwas lebhaft, so setat er bei jeder Berührung das rechte Vorderbein fort, lässt auch nicht mit dem Dorsum aufsetzen. Legt man ihm aber die Hand mit sanftem Druck anf den Rücken, so lässt er aufsetzen und dislociren. Am 19. Tage hebt er auf dern Tisch beim Fressen bei der leisesten Berührung das rechte Vorderbein in die Höhe. Rech-

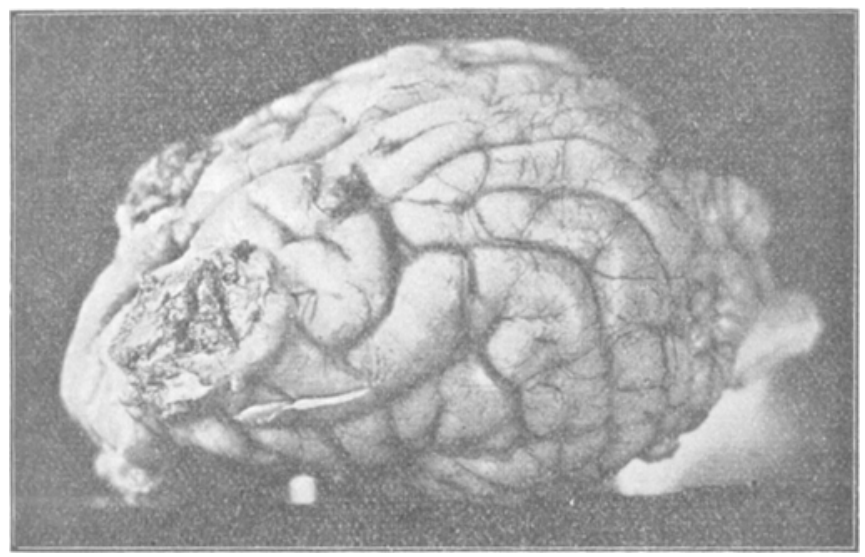

Fig. 48.

tes Vorder- und Hinterbein kann man noch mit dem Dorsum aufsetzen, beide Beine rutschen noch aus, lassen sich dislociren, aber nur, wenn der Hund ganz beruhigt ist und man einen leisen Druck auf den Rücken ausübt, dabei und später spontanes Ausrutsehen mit den rechten Extremitäten.

In der Schwebe: Hängt vom 2. Tage an dauernd gestreckt und schlaff. Auf Pumpbewegungen beugt sich gelegentlich das rechte Hinterbein stärker; so dass es sich mit dem Vorderbein kreuzt.

Sehstörung: Gegen Fleisch am 2. Tage nicht zu untersuchen, am 3. Tage laterale Hälfte, am 4. Tage in der Schwebe ein nicht sehr breiter late- 
raler Streifen, der auf dem Tische breiter erscheint. Am 5. Tage, wenn überhaupt, dann nur noch geringe Sehstörung. Der untere laterale Quadrant hellte sich früher auf. Gegen Licht bis zum 9. Tage beiderseits indifferent, an diesem T'age beiderseits scheuend.

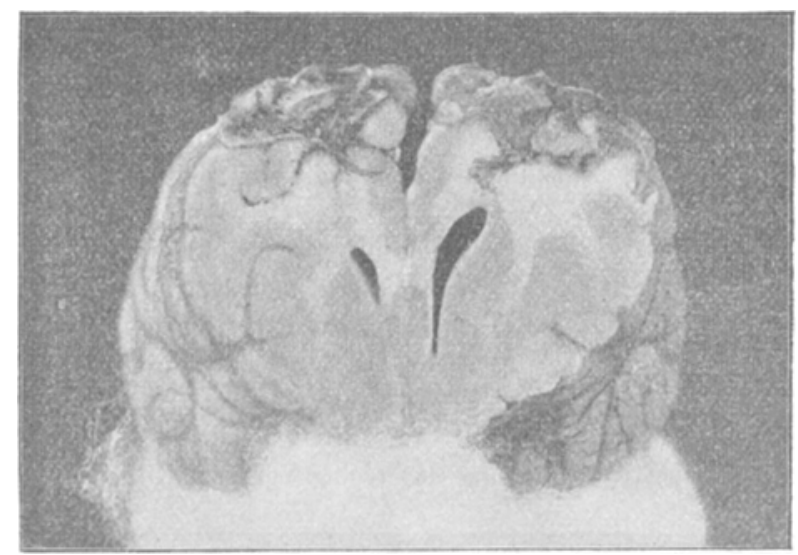

Fig. 49.

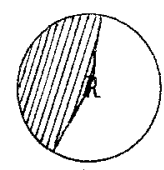

3.
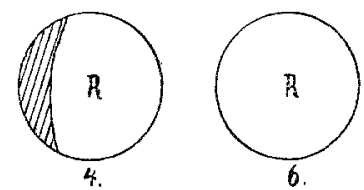

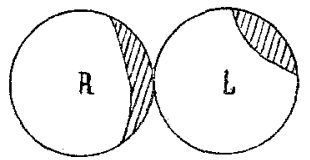

2.

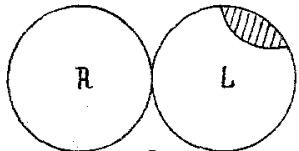

s.

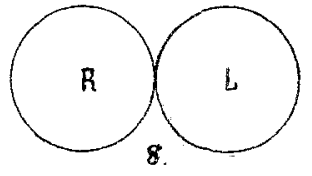

8.

Fig. 50. Die 1. Reihe der Gesichtsfelder bezieht sich auf Beob. 38, die 2. Reihe auf Beob. 42.

Optische Reflexe: Fehlen anfangs gänzlich, beginnen rom 7. Tage an zurückzukehren, am 13. Tage beiderseits gleich.

Nasenlidreflex: Stets lebhaft, obwohl am 2. und 3. Tage etwas abgeschwächt.

Getödtet nach ca. 10 Wochen nach einer 2. Operation.

Section: Häute normal. Die Auflagerung misst $18 \mathrm{~mm}$ sagittal, frontal in der Mitte $13 \mathrm{~mm}$. Sie nimmt den ganzen vorderen Schenkel und einen grossen Theil des hinteren Sohenkels des Gyrus sigmoides ein; der mediale Rand der Hemisphäre ist stark eingezogen. Durchschnitt mitten durch den Sulcus cruciatus: Die Stelle des Gyrus sigmoides ist dureh ein narbiges Ge- 
webe eingenommen, an das sich eine grössere Anzahl von grau-röthlichen Erweichungsherden in der weissen Substanz anschliesst. Die Erweichungsherde erreichen aber nioht den nach oben stark ausgezogenen. Ventrikel.

\section{B. Operationen der zweiten Seite.}

\section{Beobachtumo $\mathbf{3 9}$.}

Derselbe Hund von Beob. 34. Freilegung des rechten Gyrus sigmoides, Knochenlücke $14 \mathrm{~mm}$ sagittal, $15 \mathrm{~mm}$ frontal. Exstirpation des Gyrus sehr tief und ausgiebig mit Präparatenheber. Aus dem Grunde der Wunde entleert sich anscheinend Cerebrospinalflüssigkeit. Geringe Blutung.

Notilitätsstörungen: Links maximal bis zum 16. Tage, auch rechts immer sehr hochgradig, dann allmählich abnehmend, am 29. Tage bei Schluss der Beobachtung beiderseits noch sehr deutlich.

In der Schwebe: Hängt beiderseits während der ganzen Beobachtungsdauer mit den Vorderextremitäten stark gestreckt, schlaff, nur am 6. Tage links vorn im Fussgelenk federnder Muskelwiderstand.

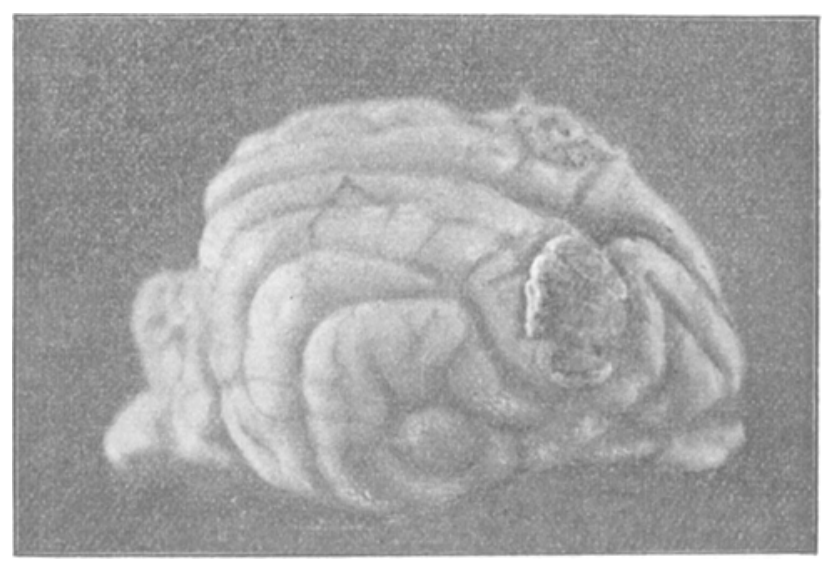

Fig. 51.

Sehstörung: Gegen Fleiseh: Hund sehr apathisch, in der Schwebe nicht zu untersuchen, auf dem Tisch vom 2. Tage an Sehstörung nachweisbar, aber nicht immer abzugrenzen, am 3. Tage breite temporale Sehstörung, unten weniger ausgesprochen; am 6 . Tage ca. ein Drittel, dann nicht mehr nachweisbar. Gegen Licht: fehlt Reaction bis zum 8 . Tage, dann beiderseits indifferent bis zum 12. Tage, wo er beiderseits deutlich, rechts stärker, scheut. Am 17. Tage beiderseits gleich, schon weit aussen schenend. Zwischendurch indifferent.

Optische Reflexe: beginnen vom 6 . Tage an sich rechts schwach einzustellen, links am 29. Tage die ersten Spuren.

Nasenlidreflex dauernd links abgeschwächt. 
Hund immer sehr stumpf, apathisch, in der Schwebe für Fleisch nicht mehr zu fixiren.

Getödtet am 29. Tage.

Section: Der linken Seite entsprechend, nur reicht die Narbenkappe etwas weiter nach vorn and nicht bis zur medialen Kante, wohl aber ist diese auch hier stark eingezogen. Durchschnitt (wie links): der Defect dringt keilförmig in die Hirnmasse vor, die an dieser Stelle durch dichtes Narbengewebe ersetzt wird. Er reicht nicht, auch nicht in Gestalt einer Unterschneidungsspalte, bis an die Medianspalte, doch ist dieser Theil der Rinde stark abge. blasst. Im Marklager dicht über der Spize des Nucleus càudatus findet sich ein, mehrere Millimeter grosser Erweichungsherd, der einen Zapfen noch in den Balken hinüberschickt. Der Ventrikel ist auf diesem Durchschnitt nicht verletzt. Die angrenzenden Rindenpartien, besonders der 2. Urwindung und die des einschneidenden Sulc. coronalis sind stark abgeblasst. Die 2. Urwindung ist auch hier medial verzogen, der Querschnitt des Gyrus sigmoides verschmälert. Auf dem II. Durchschnitt, $2 \mathrm{~mm}$ vor dem ersten ist die narbige Veränderung etwas kleiner geworden.

\section{Beobachtung 10 .}

Derselbe Hund von Beob. 36. Aufdeckung des Gyrus sigmoides rechts. Der hintere Schenkel liegt nicht ganz frei. Abtragung des Gysus auf ca. I cm Tiefe, wie bei der vorigen Operation thunlichst weit nach der Mittellinie zu. Bald nach der Operation kriecht der Hund auf dem Bauche nach rechts im Kreise herum.

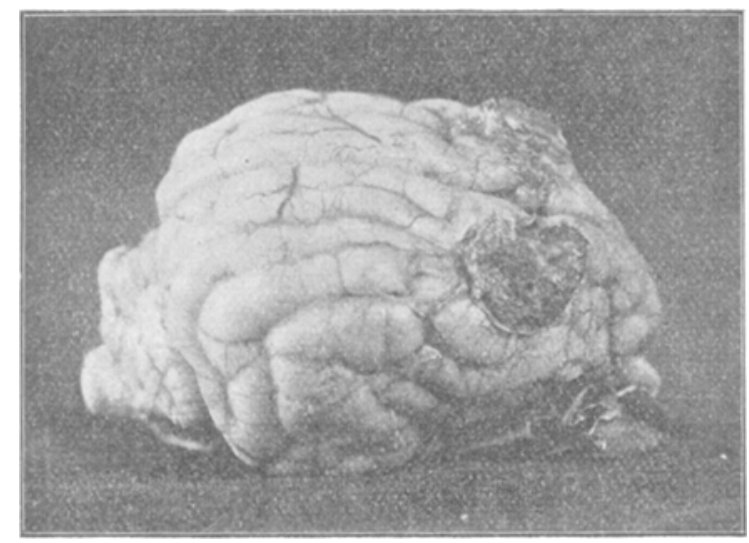

Fig. 52.

Motilitätsstörungen: Am 2. Tage hochgradige Motilitätsstörung links, die rechtsseitige hat nicht zugenommen. Liegt nach links convex, Schnauzenspitze nach rechts. Die Motilitätsstörungen bleiben, abgesehen von 
einer geringen Abnahme vom 7. Tage an, bis zum Schlusse der Beobachtung unverändert.

In der Schwebe: Am 2. Tage hängt er beiderseits mässig gestreckt. Am 3. Tage hängt er links schlaff herab, aber nicht extrem gestreckt, rechts leicht gebeugt, streckt rechts aber sofort, wenn man ihm Fleisch vorhält. Vom. 5. Tage an streckt er beide Beine beim Vorhalten von Futter, ein Symptom, welches linkerseits in den nächsten Tagen noch zunimmt. Die Extremitäten zeigen dabei gegen passive Bewegungen keinen Widerstand. Beim Begreifen niemals Reaction.

Sehstörung: Fehlt gegen Fleisch am 2. Tage wahrscheinlich, rom 3. Tage an sicher. Gegen Licht verhält er sich beiderseits indifferent.

Optische Reflexe: Feblen links, stellen sich rechts allmählich, nicht alle Tage gleich, wieder ein, so dass sie gegen Ende der Beobachtung dort auch gegen schmale Hand öfter nachweisbar sind. Zu dieser Zeit beginnen sie auch linlrs wiederzukebren.

Nasenlidreflex unverändert.

Der Hund wurde nach der zweiten Operation blödsinnig, wurde aber nicht bösartig und zeigte keinen vermehrten, sondern eher einen verminderten Bewegungsdrang.

Getödtet am 15. Tage.

Section: Häute normal. Die runde $15 \mathrm{~mm}$ im Durchmesser messende Narbe bedeckt wie links den Gyrus sigmoides bis auf einen etwa $3 \mathrm{~mm}$ breiten, aber eingezogenen medialen Streifen. Vorderer Durehschnitt (ungefähr durch den Sulcus cruc.): Rinde des Gyrus und ein grosser Theil des darunterliegenden Markes durch eine ziemlich derbe braune Narbe ersetzt, die sich aber weniger zusammengezogen hat als linkerseits, so dass der Gyrus weniger stark verschmälert erscheint als dort. Auch der mediale, nicht von der Narbe bedeckte Theil zeigt sich unterschnitten, das Grau hier abgeblasst. Von der Narbe zieht ein blutig durchsetzter Zaplen medialwärts. Ausserdem. fanden sich dicht über dem oberen Winkel des Nucl. caud. ein Erweichungsherd und ebenso unter dem Sule. coronalis im Marlweiss. Hinterer Durehsehnit am hinteren Ende der Narbe: Das Markweiss des Gyrus sigmoides und eines Theiles der 2. Urwindung bis herunter zum Eintritt des Balkens and das laterale Ende dieses sind blutig durchsetzt and narbig verändert. Die Rinde des Gyrus bis auf den abgeblassten medialen Theil völlig zerstört.

\section{Beobachtung 11.}

Derselbe Hund von Beob. 37. Ausgedehnte Freilegung des rechten Gyrus sigmoides, der dann mit Präparatenheber und Schere in der Tiefe von ca. $1 \mathrm{~cm}$ abgetragen wird. Die Zerstörung erstreckt sich auchi unter die Knochenränder der Lücke und nach der Falx zu ausgiebig.

Votilitätsstörungen: Am 2. T'age ziemlich hocbgradig, am Schluss der Beobachtung (12. Tag) noch sehr deutlich. Am 2. Tage Voltelaufen. Der Bewegungsdrang ist, wenn auch noch rorhanden, entschieden weniger hochgradig als vor der Operation. 
In der Schwebe: Hängt während der ganzen Beobachtungszeit beiderseits gleichmässig gestreckt, am 2. Tage rechts mehr als links; meist schlaff, gelegentlich in Folge von massenhaften Bewegungen leichten Muskelwiderstand zeigend. Auf Pumpen und Begreifen während der ganzen Beobachtungszeit keine Reaction.

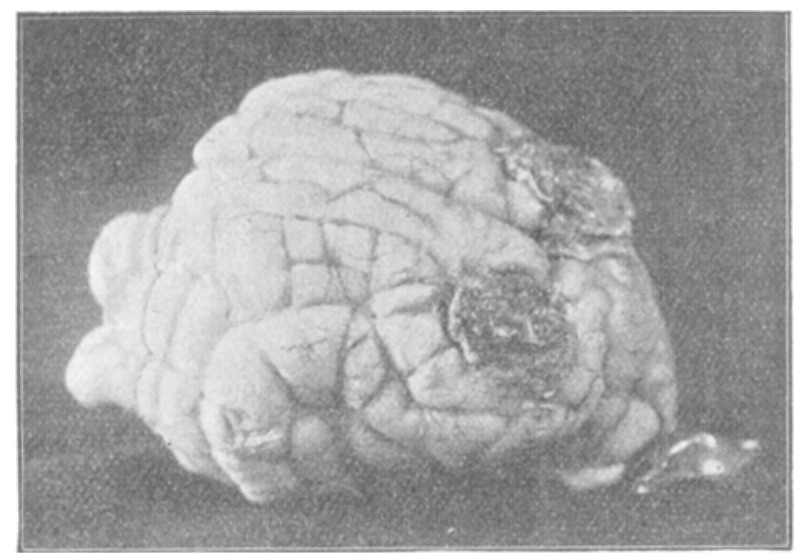

Fig. 53.

Sehstörung: Am 2. Tage so hochgradig, dass er mit der linken Seite des Kopfes überall anstösst, den Fleischteller links nicht sielt etc. Am 3. Tage und später gegen Fleisch gar keine Sehstörung mehr. Gegen Licht am 2. Tage rechts nicht, links stark scheuend, vom 3. Tage an gleichmässige Reaction, vom 4. Tage an regelmässig derart, dass er, sobald er des Lichtes ansichtig wird (rechts wie links), zu heulen beginnt, die Nase hineinsteckt, zurückfährt, um gleich darauf die Nase wieder hineinzustecken.

Optische Reflexe fehlen beiderseits bis zum Schlnss der Beobachtung.

Nasenlidreflex ungestört.

Getödtet am 12. Tage nach der Operation.

Section: Die $15 \mathrm{~mm}$ sagittal und $23 \mathrm{~mm}$ frontal messende Narbe sitzt dem Gyrus sigm. derart auf, dass sie lateral bis an den Sulc. coronalis reicht, nach vorn und hinten mit dem Gyrus abschliesst, aber nach medial eine ca. $6 \mathrm{~mm}$ breite Fläche freilässt. Durchschnitt: Rinde des Gyrus und ein grosser Theil der Marksubstanz zerstört, auch das nicht von der Narbe bedeckte Stück erweist sich als unterschnitten; der ringsum erweichte Spalt geht bis zur Medianspalte des Gehirns. Von der Narbenkappe zieht ein breiterErweichungsstreifon nach dem Balken und dem oberen Winkel des Nucl, caud. und ein feiner in die Markleiste der 2. Urwindung. 


\section{Beobachtung 4 .}

Derselbe Hund von Beobachtung 38. Aufdeckung vorn rechts über Gyrus sigmoides auf $20 \mathrm{~mm}$ sagittal, $17 \mathrm{~mm}$ frontal. Abtragung der Dura, doch so, dass ein Abschnitt der 2. Urwindung, der mit freigelegt war, von ihr bedeckt bleibt. Das freiliegende Rindenstück wird mit dem Präparatenheber umstochen, dann herausgehoben und etwa $8 / 4 \mathrm{~cm}$ tief mit der Schere abgetragen. Auch die von der medialen Brücke bedeckte Rinde wird mit dem Präparatenheber thunlichst herausbefördert. Ziemlich erhebliche Blutung aus der Arteria cruciata, die aber mit Penghawar Yambee sofort steht.

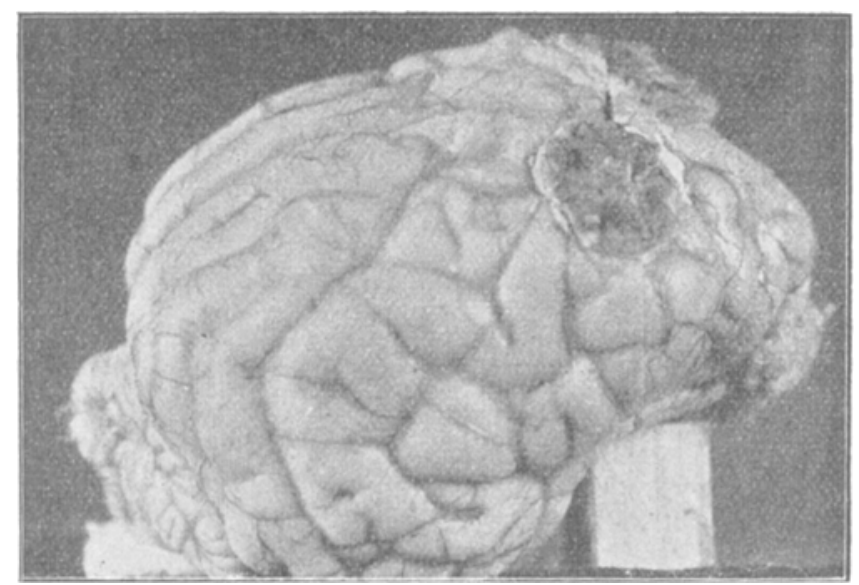

Fig. 54.

Wunde nie geschwellt oder empfindlich, dagegen wird an 5. und 6. Tage eine mässige Menge einer blutig gefärbten, nicht eitrigen Flüssigkeit durch Druck entleert und die Wunde alsdann wieder mit Jodoformcollodium verschlossen.

Motilitätsstörungen: Bevorzugt bis zum 12. Tage die Drehung nach rechts. Motilitätsstörungen mässig hochgradig, immerhin so, dass er bei Dislocationsversuchen des rechten Vorderbeins umfällt, allmählich abnehmend. Die Motilitätsstörungen der rechten Seite haben in Folge der 2. Operation nicht zugenommen.

Am 21. Tage doppelseitiger, links stärkerer Anfall von Facialiskrampf, durch Klysma von 2,0 g Chloral coupirt.

In der Schwebe werden eine Reihe von Beobachtungen gemacht, auf die hier nicht näher eingegangen werden soll.

Sehstörung: Gegen Fleisch: am 2. Tage rechts ein schmaler nasaler Streifen, links lateral oben ein amblyopischer Fleck. Am 5. Tage Sehstörung rechts verschwunden, links der amblyopische Fleck kleiner geworden. Am 
8. Tage auch dieser Fleck verschwunden. Gegen Licht verhält sich der Hnnd beiderseits indifferent.

Optische Reflexe: Fehlen anfänglich gegen schmale Hand, gegen flache Hand immer beiderseits nachweisbar, vom 7. Tage an beiderseits gleich. Getödtet nach ca. 5 Wochen.

Section: Hänte normal. Die Auflagerung misst $10,5 \mathrm{~mm}$ sagittal, $12 \mathrm{~mm}$ frontal. Sie sitzt auf dem vorderen Schenkel des Gyrus sigmoides und auf dem vorderen Theil des hinteren Schenkels. Der mediale Rand ist stark eingezogen. Beide Auflagerungen sind genau symmetrisch, nur erstreckt sich die linke roun und hinten etwas weiter als die rechte und noch ein wenig auf die 2. Urwindung. Durchschnitt mitten durch den Sulcus cruciatus: zeigt ein sehr ähnliches Bild wie Beob. 38, nur ist der Ventrikel bei Weitem weniger ausgezogen, dagegen erscheint die ganze Hemisphäre stärker atrophisch. In der Umgebung der Narbe ist die Rinde stark abgeblasst.

\section{F. Doppelseitige frontale Durchtrennung des vorderen Schenkels des Gyrus sigmoides.}

\section{Beobachtung 13.}

Doppelseitige Aufdeckung der lateralen $3 / 4$ des Gyrus sigmoides. Verticale Abtrennung der nach vorn gelegenen Rinde dieses Schenkels mit dem Präparatenheber.

Motilitätsstörungen: Am 2. Tage leichte Motilitätsstörungen an den rechten Extrernitäten. Am 3. Tage rechts wie am 2. Tage, links hochgradiger. Am 4. Tage Zunahme der Motilitätsstörungen rechts, rutscht mit allen vier

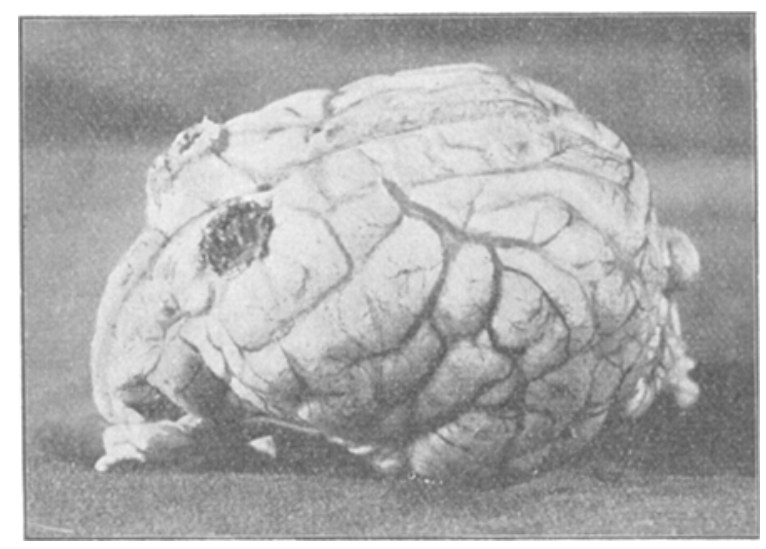

Fig. 55.

Extremitäten auseinander. Abnahme der Störungen vom 12. Tage an, am 17. Tage nicht mehr nachzuweisen. 
In der Schwebe: Am 2. Tage hängt er rechts vorn stark, im Uebrigen mässig gestreckt. Beim Begreifen rechts rorn nichts, sonst wenig. Am 3. Tage hängt er rechts vorn nur mässig, links vorn stark gestreckt, hinten beiderseits gestreekt. Beim Begreifen vorn nichts, hinten wenig. Am 4. Tage hängt er links vorn stark gestreckt, rechts vorn mässig angezogen. Links zeigt

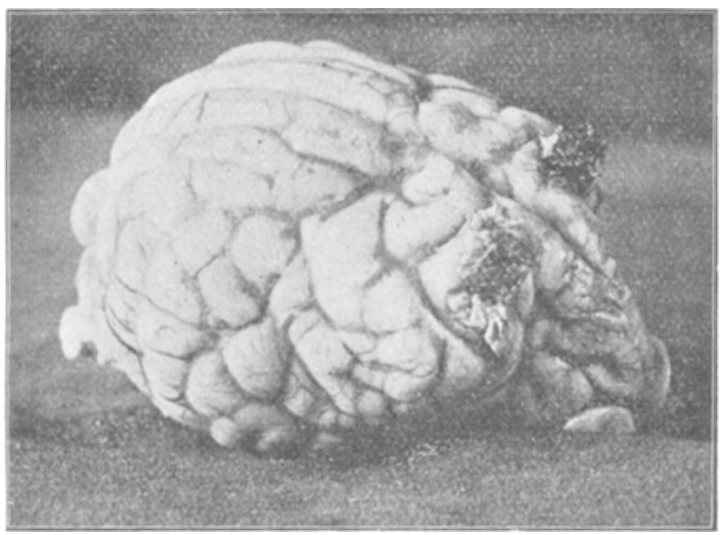

Fig. 56.

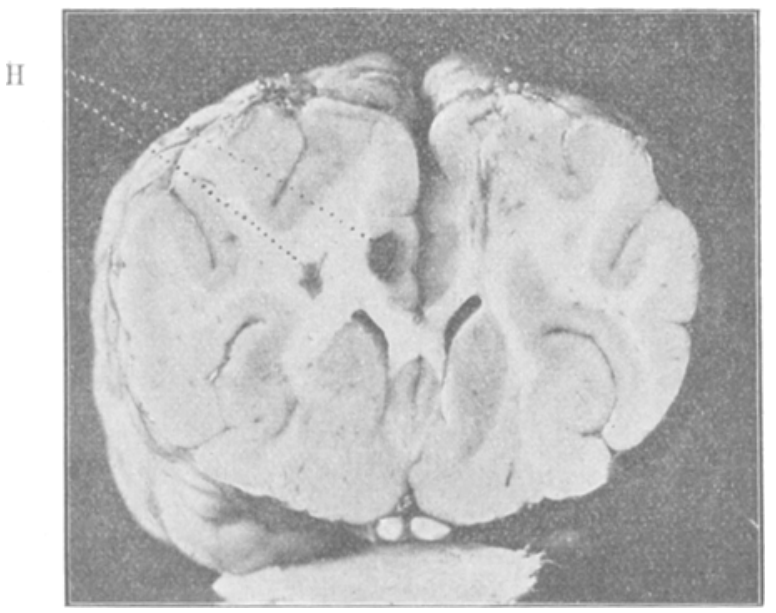

Fig: 57. H. Erweichungsherde.

sich im Gegensatz z $a$ rechts, bei passiven Bewegungen im EJlenbogengelenk leichter Muskelwiderstand bei Flexion. Vom 17. Tage an beim Begreifen überall schwache Reaction, keine Anomalien der Haltung mehr. 
Sehstörung: Gegen Fleisch: an vielen Tagen wegen Unruhe des Hundes nicht oder nicht deutlich zu bestimmen. Am 3. Tage links bochgradig, fehlt rechts, am 4. Tage links fast völlig blind, rechts etwa bis zur Mitte; am .10. Tage beiderseits noch hochgradig, links mehr als rechts. Am 12. Tage beiderseits Sehstörung, die aber nicht mehr sehr hochgradig sein kann. Am 15. Tage noch nachweisbar, nachher nicht mehr. Gegen Licht: am 2. Tage beiderseits wenig, aber gleich reagirend, am 3. Tage rechts scheuend, links indifferent, am 4. Tage beiderseits wenig scheuend.

Optische Reflexe: Febler links gänzlich bis zum 10. Tage, dann gegen flache Hand vorbanden. Am 12. Tage normal. Rechts abgeschwächt bis zum 28. Tage.

Nasenlidreflex ungestört.

Getödtet nach 5 Wochen.

Section: Keine meningitischen Veränderungen. Linke Hemisphäre: Auf dem vorderen Schenkel des Gyrus sigmoides sitzt die etwa $8 \mathrm{~mm}$ in jedem Durchmesser grosse Narbe auf. Dieselbe reicht medial fast bis zur Medianspalte, nach hinten und vorn schliesst sie mit der hinteren resp. vorderen Grenze des Schenkels ab. Durchschnit durch die hintere Hälfte der Narbe dicht vor dem Sulcus cruciatus: Vom medialen Rand der Narbe geht eine blutig durchsetzte Spalte $12 \mathrm{~mm}$ basalwärts, über der Ausstrablungsstelle des Balkens endend, ohne die imnere Kapsel zu erreichen. Zu beiden Seiten der Spalte finden sich punktförmige, blutig verfärbte Erweichungen im Markweiss. Rechte Hemisphäre: Narbe liegt genau symmetrisch. Durchschnitt wie links: Mitten im Markweiss etwas nach oben und aussen vom oberen Ende der inneren Kapsel liegt ein etwa $2 \mathrm{~mm}$ im Durchmesser grosser, unregelmässig gestalteter Erweichungsherd, ohne sichtbare Communication mit der Narbe. Schräg nach oben medial davon, fast ganz im medialen Rindengrau liegt ein etwas grösserer ein Blutcoagulum enthaltender Erweichungsherd.

1. Sehstörungen: In den 21 vorstehend mitgetheilten Beobachtungen fanden sich Sebstörungen verschiedener Art und verschiedener Dauer $20 \mathrm{mal}$; sie fehlten nur in 1 Falle (Beob. 40), welcher eine 2. symmetrische Exstirpation betraf, gänzlich. Im Uebrigen muss die Reaction der Hunde gegen Fleisch und Licht, welche sich, ganz abgesehen davon, dass die Hunde sich vielfach, wie früher erwähnt, gegen Licht überhaupt indifferent verhalten, keineswegs gleichmässig gestaltet, einer gesonderten Betrachtung unterzogen werden.

Dauer der Störung. aa) Die Reaction gegen Fleisch war beeinträchtigt nur am 2. Tage in 1 Falle (Beob. 27 erstmalige Unterschneidung des ganzen Gyrus), und zwar in unsicherer Weise, in einem 2. Falle (Beob, 34 erstmalige tiefe Exstirpation des hinteren Schenkels und des hinteren Theiles des vorderen Schenkels) durch einseitig ver- 
langsamtes Ergreifen des Fleisches, in ejnem 3. Falle (Beob. 31 Skarification des vorderen Schenkels) durch totale Amblyopie, in einem 4. Falle (Beob. 41 Exstirpation des ganzen Gyrus der 2. Seite) durch totale Blindheit; sie war beeinträchtigt 3 Tage in 1 Falle (Beob. 33 Skarification des hinteren Schenkels und des lateralen Drittels des vorderen Schenkels); 4 Tage in 2 Fällen (Beob. 25 erstmalige Untérschneidung des hinteren Schenkels und des lateralen Drittels des vorderen Schenkels und Beob. 32 Skarification des hinteren Schenkels und des lateralen Drittels des vorderen Schenkels); 5 Tage in 2 Fällen (Beobb. 36 und 38 erstmalige Exstirpationen des ganzen Gyrus); 6 Tage in 3 Fällen (Beob. 24 Anätzung des ganzen Gyrus, Beob. 37 erstmalige Exstirpation des ganzen Gyrus und Beob. 39 Exstirpation des ganzen Gyrus der 2. Seite); 7 Tage in 2 Fällen (Beob. 29 Unterschneidung des hinteren Schenkels und des lateralen Theiles des vorderen Schenkels der 2. Seite und Beob. 42 Exstirpation des ganzen Gyrus der 2. Seite) (gleichseitiges Auge 4 Tage); 11 Tage in 1 Fall (Beob. 26 erstmalige Unterschneidung des hinteren Schenkels und des lateralen Theiles des vorderen Schenkels); 13 Tage in 1 Falle (Beob. 23 Anätzung des hinteren Schenkels und der hinteren Hälfte des vorderen Schenkels); 14 Tage ebenfalls in 1 Falle (Beob. 28 Unterschneidung des ganzen Gyrus der 2. Seite). 15 Tage in 1 Falle (Beob, 43 doppelseitige frontale Durchtrennung des vorderen Schenkels des Gyrus sigmoides; links Sehstörung hochgradiger als rechts, wo sie bis incl. 3. Tag fehlt); 24 Tage in 1 Falle (Beob. 30 Skarification des vorderen Schenkels des Gyrus sigmoides). In 1 Falle, in dem eine Sehstörung gegen Licht nachweisbar war (Beob. 35 erstmalige Exstipation des ganzen Gyrus) war die Reaction gegen Fleisch wegen Aengstlichkeit des Thieres nicht zu prüfen.

Hiernach war eine Sehstörung also vorhanden bei 2 Anätzungen je 6 und 13 Tage, bei 3 erstmaligen Unterschneidungen je 2, 4 und 11 Tage, bei 4 Skarificationen je 2, 3, 4 und 24 Tage, bei 5 erstmaligen Exstirpationen je 2, 5, 5 und 6 Tage, während die Reactiou gegen Fleisch in einem Falle nicht zu untersuchen war, bei 2 Unterschneidungen der 2. Seite je 7 und 14 Tage, bei 4 Exstirpationen der 2. Seite je 2, 6 und 7 Tage, während in einem Falle überhaupt keine Sehstörung nachzuweisen war; bei einer doppelseitigen frontalen Durchtrennung des vorderen Schenkels des Gyrus sigmoides 15 Tage.

bb) Die Reaction gegen Licht war beeinträchtigt 2 Tage lang in 1 Falle (Beob. 41 Exstirpation des ganzen Gyrus der 2. Seite); 3 Tage lang in 2 Fällen (Beob. 37 erstmalige Exstirpation des ganzen Gyrus und Beob. 31 Skarification des vorderen Schenkels, abgeschwächt); 5 Tage in 1 Falle (Beob. 27 erstmalige Unterschneidung des ganzen Archiv f. Psychiatrie. Bd. 36. Heft 1. 
Gyrus); 6 Tage (mindestens) in 1 Falle (Beob. 23 Anätzung des hinteren Schenkels und der hinteren Hälfte des vorderen Schenkels); 8. Tage (mindestens) in 1 Falle (Beob. 29 Unterschneidung des hinteren Schenkels und des lateralen Theiles des vorderen Schenkels der 2. Seite); in 1 Falle (Beob. 26 erstmalige Unterschneidung des hinteren Schenkels und des lateralen Theiles des vorderen Schenkels) 9 Tage, die letzten 5 Tage abgeschwächt; 10 Tage in 2 Fällen (Beob. 25 erstmalige Unterschneidung des hinteren Schenkels und des lateralen Drittels des vorderen Schenkels and Beob. 30 Skarification des vorderen Schenkels); 11 Tage in 3 Fällen (Beobb. 32 und 33 Skarificationen des hinteren Schenkels und des lateralen Drittels des vorderen Schenkels und Beob. 35 (hier mindestens 11 Tage) erstmalige Exstirpation des ganzen Gyrus); 12 Tage in 2 Fällen (Beob. 36 erstmalige Exstirpation des ganzen Gyrus: 5 Tage fehlend, dann abgeschwächt und Beob. 39 Exstirpation des ganzen Gyrus der 2. Seite: 7 Tage fehlend, dann mindestens bis zum 12. Tage abgeschwächt); 14 Tage in 1 Falle (Beob. 28 Unterschneidung des ganzen Gyrus der 2. Seite; 3 Tage fehlend, nachher abgeschwächt). Hieran schliesst sich noch die eine besondere Stellung einnehmende Beob. 43 (doppelseitige frontale Durchtrennung des vorderen Schenkels des Gyrus sigmoides), bei der die Reaction nur am 3. Tage linksseitig fehlte. In 5 Fällen (Beob. 24 Anätzung des ganzen Gyrus, Beob. 34 erstmalige Exstirpation des hinteren Schenkels und des hinteren Theiles des vorderen Schenkels, Beob. 38 erstmalige Exstirpation des ganzen Gyrus, Beob. 40 Exstirpation des ganzen Gyrus der 2. Seite und Beob. 42 Exstirpation des ganzen Gyrus der 2. Seite) verhielten die Hunde sich gegen den Lichtreiz indifferent.

Zur Würdigung dieser Resultate muss die höchst verschiedene Reaction der Hunde auf Licht noch etwas eingehender berührt werden. Ich habe bereits wiederholt erwähnt, dass es Hunde giebt, welche überhaupt in keiner Weise auf den Lichtreiz reagiren; es ereignet sich aber auch durchaus nicht selten, dass solche Hunde, welche früher in lebhafter Weise vor der Flamme zurückscheuten, an einzelnen oder an mehreren aufeinanderfolgenden Tagen keinerlei Reaction auf Licht erkennen lassen, ohne dass sie dabei krank wären oder dass man sonst einen anderen Grund für dieses Verhalten ermitteln könnte. Dann fangen sie plötzlich wieder an, in irgend einer Weise ihre Abneigung gegen die Blendung zu erkennen zu geben. Dieses Verhalten tritt besonders stark in der Schwebe hervor, aber im Princip verhalten sich die Hunde alych unter anderen, ihnen geläufigeren Existenzbedingungen nicht anders. Nach der Schilderung von Goltz hätte der Hund überhaupt einen Abscheu vor glänzenden Gegenständen, z. B. vor Glasflaschen. Dies betrifft nun 
keineswegs alle Hunde, wenn äberhaupt die Majorität. Ich finde z. B., dass die Hunde sich viel mehr entsetzen, wenn man ihnen plötzlich die Innenseite eines Hutes vorhält. Ebensowenig ist die Darstellung von L oeb zutreffend, nach dem der Abscheu vor dem Stocke gleichsam zu den angeborenen Charaktereigenschaften eines Hundes gehört, so dass er auch, wemn er niemals einen solchen zu Gesichte bekommen hat, davor entflieht. Ich kann versichern, dass es zahlreiche Hunde giebt, sogar solche, die schon Prügel genug bekommen haben, die das Erscheinen einer Hundepeitsche oder eines Stockes in ihrem Gesichtsfelde diurchaus kalt lässt, während eine drohende Armbewegung mit oder ohne Reitpeitsche sie sofort verängstigt in einen Winkel verscheucht. Dieses Verhalten der Hunde gegen ihnen mehr oder minder unerfreuliche Gesichtsobjecte verringert natürlich den Werth der fraglichen Untersuchungsmethoden und macht sie erheblich unsicherer als die gleichfalls mit allerlei Mängeln behaftete Untersuchungsmethode mit Fleisch, auf die ich noch zurückkomme. Wenn die Hunde aber reagiren, so geschieht dies auch wieder in sehr verschiedener Weise. Ich habe bereits in der II. dieser Abhandlungen angeführt, dass ich mich nicht davon überzengen könnte, dass die Ansicht von Boensel, nach der der Hund niemals mit Blinzeln reagire, zutreffend sei. In der That finden sich in den vorstehenden Beobachtungen 3 Fälle, in denen der Hund auf der nicht geschädigten Seite den Reiz des oscillirenden Lichtes mit Blinzeln beantwortete, während der Orbicularis des geschädigteu Auges sich einmal gar nicht, die beiden anderen Male in verlangsamtem Tempo in Bewegung setzte; diese drei Fälle stehen in meiner Sammlung von Beobachtungen keineswegs vereinzelt da. Jedoch ist es richtig, dass sie Ausnahmen bilden. In anderen Fällen wendet der Hund den Kopf mit grösserer oder geringerer Energie ab oder er scheut mit dem mimischen Ausdruck des Entsetzens zurück, oder er beginnt Schwimmbewegungen zu machen, oder er beisst nach dem Licht. Gelegentlich kann man auch beobachten, dass der Huna mit der Pfote das Licht ausschlägt. In einem Falle steckte der blödsinnig gewordene Hund unter jämmerlichem Geheul die Schnauze in das Licht. Loeb würde dieses Verhalten vielleicht als eine Umwandlung des negativen in den positiven Heliotropismus bezeichnen. Auf die Deutung dieser Bewegungserscheinungen werde ich erst später eingehen.

Inzwischen erinnere ich aber daran, dass die Angaben der Reaction meiner Hunde auf Licht bei Weitem nicht in allen Fällen den Zeitpunkt treffen, zu dem die normale Lichtempfindlichkeit der Netzhaut, soweit wir dieselbe überhaupt zu untersuchen vermögen, wiederhergestellt war, vielmehr war sie sicher in vielen Fällen noch länger abge- 
schwächt, als dies festgestellt werden konnte. Vergleichen wir nach diesen Vorbemerkungen das Verhältniss der Reaction gegen Licht und Fleisch mit einander, so ergiebt sich, dass in den Beobb. 27, 33, 25, 32, 36 und 39 der Verlust oder die Abschwächung gegen Licht in ausgesprochener Weise länger anhielt als der totale oder partielle Ausfall der Reaction gegen Fleisch. Ansserdem differirten diese beiden Zablen in der fraglichen Richtung in 2 Fällen noch um je einen Tag.

Umgekehrt währte der totale oder partielle Ausfall der Reaction gegen Fleisch 4 mal, nämlich in den Beobb. 26, 30, 37 und 43 länger als die Beeinträchtigung der Reaction gegen Licht. In zwei ferneren Fällen, Beobb. 41 und 28 dauerte die Sehstörung gegen Fleisch und Licht gleich lang und in den übrigen 7 Fällen war eine Vergleichung aus den früher angeführten Gründen nicht möglich, -

Bei der Vornahme der angeführten Untersuchungen leitete mich u. A. die Absicht, den Einfuss von solchen Eingriffen zu studiren, denen eine verschieden grosse roizende oder lähmende Kraft zugeschrieben werden durfte. Während die lähmende Kraft naturgemäss um so grösser sein musste, je grösser das ansgeschaltete Areal war, wenn dieses thatsächlich eine Art von Sehcentrum darstellte, hatte ich mir die Vorstellung gebildet, dass die reizende Kraft unter sonst gleichen Umständen am geringsten sein würde bei Unterscbneidungen, grösser bei Exstirpationen, dan bei Skarifieationen und am grössten bei Anätzungen. Ich dachte mir, dass es auf beiden Wegen gelingen würde, überzengend nachzuweisen, ob die auf frontale Fingriffe erscheinende Sehstörung als Folge einer Lähmung oder einer Reizung corticaler oder anderer Centren aufzufassen sei. Der Versuch hat den letztgedachten Voraussetzungen in keiner Weise Recht gegeben. Ein wesentlicher Unterschied zwischen den Folgen der einzelnen Eingriffe fand sich nicht. Nur in der erstgedachten Richtung geht aus diesen Versuchen mit Sicherbeif hervor, dass direete Beziehungen $z$ wischen der Grösse des ausgeschalteten Areals und der Beeinträchtigung des Sehactes nicht existiren. Die Dauer und die Intensität der Sehstörung war keineswegs immer am grössten, wenn der ganze Gyrus ausgeschaltet worden war und sie war namentlich in dem Falle keineswegs immer am grösten, wenn dann auch der 2. Gyrus sigmoides ausgeschaltet wurde. Ebensowenig kam es in dieseu Tällen zu einem Wiederaufleben der bereits verschwundenen Sehstörung des gleichseitigen Auges; ja, dex einzige Fall, in demeine Sehstörung überhaupt nicht nachgewiesen werden konnte (Beob. 40), betraf gerade eine solche totale Exstirpation des Gyrus der 2. Seite. 
Eine Vergleichung dieser Beobachtungen mit den analogen des I. Kapitels dieser Abhandlung ergiebt jedoch, der Voraussetzung entsprechend, dass auf die jetzt geschilderten Eingriffe im Allgemeinen eine Sehstörung von grösserer Intensität und von längerer Dauer folgte; als in jenen Fällen, bei denen nur die Pia freigelegt war. Während damals die Sehstörung und zwar mit dem ungefähren Charakter der sogenannten Seelenblindheit nur in 1 Falle 22 Tage, in allen anderen Fällen 8 Tage oder weniger anhielt, dauerte sie hier in zahlreichen Füllen erheblich länger, in maximo jedoch auch nur 24 Tage.

Eine singuläre Stellung nimmt bei alledem der Versuch 43 - doppelseitige frontale Durchtrennung des vorderen Schenkels des Gyrus sigmoides nahe seinem vorderen Rande - insofern ein, ais die am 3. Tage rechts noch fehlende Sebstörung am 4. Tage und später deutlich nachweisbar war. Ich habe auf Grund einer Anzahl von anderen Versuchen hinreichende Veranlassung zu der Annahme, dass der Eintritt von Sehstörungen überhaupt nicht auf die Verletzung des grösseren Theiles des vorderen Schenkels, sondern auf die Ausbreitung des Trauma auf die von mir sogenannte erregbare Zone zu beziehen ist. Indessen kann ich an dieser Stelle auf diesen Punlst nicht näher eingehen.

Charakter und Verlauf der Sehstörung. Die Sehstörung trug der Art nach denselben Charakter wie bei den im I. Kapitel mitgetheilten analogen Versuchen; dem Grade nach aber war sie, wie vorauszusehen, in einer Anzahl von Fällen ausgesprochener als bei jenen. Sie hatte also, insofern sie überhaupt eintrat, den hemianopischen Charakter. Indessen waren die Hunde in einer grösseren Anzahl von Fällen auf dem der geschädigten Seite zukommenden Theil des Gesichtsfeldes entweder total blind, sodass sie sogar mit der entsprechenden Seite des Kopfes anstiessen, oder sie reagirten doch auf keinen der angewandten Reize. Ja, das Sehvermögen erschien sogar auf dem nasalen Streifen des Gesichtsfeldes, mindestens mit Bezug auf den Ortssinn geschädigt; erschien dort ein Stück Fleisch, so schnupperten die Hunde wohl in der Luft herum, aber sie vermochten nicht, es so im Raume zu localisiren, dass sie es erschnappen konnten. Die Sehstörung besserte sich dann ausnahmslos so, dass sie entweder plötzlich gänzlich verschwand, was auch bei solchen Fällen vorkam, bei denen sie am 2. Tage das ganze zugehörige Gesichtsfeld eingenommen hatte, oder dass sie mehr allmählich von der nasalen nach der temporalen Seite zurückwich. In einigen Fällen konnte dieses Zurückweichen derart verfolgt werden, dass der Hund auf einem mehr nasalwärts gelegenen Grenzstreifen Fleisebstücke zuerst wahrnahm, ohne sie identifiziren zu können, während er sie dawn am nächsten Tage auf diesem Streifen erkannte.. 
Von besonderem Interesse ist die Wiederholung der bereits in 4 Fällen der I. Serie gemachten Beobachtung, dass der untere innere Quadrant des Gesichtsfeldes entweder von vornherein weniger betroffen war oder sich früher aufhellte, sowie, dass die Sehstörung überhaupt sich in der unteren Hälfte des Gesichtsfeldes schneller von der Nase nach der Schläfe zu zurïckzog, als in der oberen Hälfte. Die Gesichtsfeldschemata zu den Beobb. 38 und 42 können ein ungefähres Bild von diesem Verhalten geben. Genaueres darüber werden wir später noch erfahren. Das fragliche Verhalten ist in den Beobb. 36, 37, 38, 39 and 42 ausdrücklich fixirt worden.

2. Die optischen Reflexe. Daver. Die optischen Reflexe waren abgeschwächt, ohne aber gänzlich zu fehlen, in 1 Falle (Beob. 31) 4 Tage und in einem 2. Falle (Beob. 42) 6 Tage. Sie fehlten gänzlich in 1 Falle (Beob. 28) 2 Tage und waren dann noch 1 Tag abgeschwächt; in 1 Falle (Beob. 38) 6 Tage und waren dann noch 6 Tage abgeschwächt; in einem anderen Falle (Beob. 27) 7 Tage; in 2 Fällen (Beobb. 23 und 29) 9 Tage und waren dann noch mindestens je 2 und 4 Tage abgeschwächt; in 2 Fällen (Beobb. 32 und 40) 10 Tage und waren damn noch je 5 und 4 Tage abgeschwächt; in 2 Fällen (Beobb. 24 und 41) (hier mindestens) 11 Tage; in 1 Falle (Beob. 33) 12 Tage, Abschwächung noch 23 Tage; in 1 Falle (Beob. 30) fehlten sie 15 Tage und waren dann (unbestimmt wie lange) abgeschwächt; in 1 anderen Falle (Beob. 34) 16 Tage, dann noch 4 Tage abgeschwächt; in einem Falle (Beob. 25) 20 Tage, dann noch 4 Tage abgeschwächt; gleichfalls in 1 Falle (Beob. 35) 21 Tage; in 1 Falle (Beob. 36) 23 Tage, Abschwächung noch 5 Tage; in je 1 Falle (Beob. 37) 27 Tage und (Beob. 39) 28 Tage und in 1 Falle (Beob. 26) fehlten sie 35 Tage. Endiich ist zu erwähnen, dass bei der eine doppelseitige Operation betreffenden Beobachtung 43 die Reffexe linkerseits 9 Tage fehlten, dann noch 2 Tage abgeschwäcbt waren, rechterseits aber 27 Tage nur abgeschwächt waren.

Wenn sich also auch aus den früher angeführten Gründen eine genaue Bestimmung der Dauer des Symptoms nicht geben und deshalb eine Vergleichung dieser Dauer zwischen den beiden parallelen Versuchsreihen nicht anstellen lässt, so erwächst doch der bestimmte Eindruck, dass auch dieses Symptom, sowohl was die gänzliche Aufhebung, als auch was die darauffolgende Abschwächung des Lidreflexes angeht, hier entschieden ausgesprochener war, als bei jener ersten Reihe von Versuchen.

Der Verlauf bot in 4 Fällen (Beobb. 30, 31, 32 und 33) insofern ein besonderes Interesse, als das Symptom bei ihnen 2-6 Stunden nach der Operation jedenfalls fehlte, während der Reflex bei zweien von 
diesen (Beobb. 32 und 33) zu der gedachten Zeit sogar stärker als auf der anderen Seite vorhanden war. In allen 4 Fällen fehlte er nachher gänzlich, oder war doch (in 1 Falle) 4 Tage abgeschwächt.

3. Das Verhältniss der Sẻhstörungen zu den optischen Reflexen ergiebt sich am besten aus der nachstehenden Tabelle.

Tabelle I. $\left.{ }^{1}\right)$

\begin{tabular}{|c|c|c|c|c|c|}
\hline $\begin{array}{l}\text { No. der } \\
\text { Beob. }\end{array}$ & Art der Operation & $\begin{array}{l}\text { Sehstör } \\
\text { Fleisch }\end{array}$ & $\begin{array}{l}\text { Ing gegen } \\
\text { Licht }\end{array}$ & $\begin{array}{l}\text { Optische } \\
\text { Reflexe }\end{array}$ & $\begin{array}{l}\text { Nasenlid- } \\
\text { reflex }\end{array}$ \\
\hline 23 & Anätzung & 13 & $\begin{array}{l}6 \text { min- } \\
\text { destens }\end{array}$ & $9 \quad 2)$ & $8 \quad(3)$ \\
\hline 24 & Anätzung & 6 & - & 11 dauernd & (11 dauernd): \\
\hline 25 & Unterschneidung & 4 & 10 & 20 (4) & (4) \\
\hline 26 & Unterschneidung & 11 & 9 & 35 dauernd & (35 dauernd) \\
\hline 27 & Unterschneidung & 2 & $\check{\partial}$ & 7 & (5) \\
\hline 28 & $\begin{array}{l}\text { Unterschneidung der } 2 \text {. } \\
\text { Seite }\end{array}$ & 14 & 14 & & 0 \\
\hline 29 & $\begin{array}{l}\text { Unterschneidung der } 2 \text {. } \\
\text { Seite }\end{array}$ & 7 & 8 & 9 (4) & (13) \\
\hline 30 & Skarification & 24 & 10 & 15 (?) & $5(4)$ \\
\hline 31 & Skarification & 2 & 3 & $(4)$ & 0 \\
\hline 32 & Skarification & 4 & 11 & $10 \quad(5)$ & (3) \\
\hline 33 & Skarification & 3 & 11 & $12(23)$ & (2) \\
\hline 34 & Exstirpation & 2 & - & 16 (4) & (3) \\
\hline 35 & Exstirpation & 一 & 11 & 21 & 0 \\
\hline 36 & Exstirpation & 5 & 12 & $23(5)$ & 0 \\
\hline 37 & Exstirpation & 6 & 3 & 27 & - \\
\hline 38 & Exstirpation & 5 & - & $6 \quad(6)$ & (3) \\
\hline 39 & Exstirpation der 2. Seite & 6 & 12 & 28 dauernd & (28 dauernd): \\
\hline 40 & Exstirpation der 2. Seite & 0 & - & 10 & 0 \\
\hline 41 & Exstirpation der 2. Seite & 2 & 2 & $\begin{array}{l}11 \text { min- } \\
\text { destens }\end{array}$ & 0 \\
\hline 42 & Exstirpation der 2. Seite & 7 & - & (6) & - \\
\hline 43 lints & Doppelseitige : frontale & 15 & ? & $9(2)$ & 0 \\
\hline 43 rechts & $\begin{array}{l}\text { Durchtrennung des vor- } \\
\text { deren Schenkels des } \\
\text { Gyrus sigmoides }\end{array}$ & 15 & $?$ & (27) & 0 \\
\hline
\end{tabular}

Hiernach waren die optischen Reflexe in allen Fällen geschädigt und zwar auf die Dauer von 14 Tagen auch in dem einen Falle, in dem. keinerlei Sehstörung zu beobachten war. Ein Fall, bei dem das Sehvermögen geschädigt, die optischen Reflexe aber intact gewesen wären, kam also nicht zur Beobachtung. In dieser Bezielung führte die 2. Reihe unserer Beobachtungen also genau zu denselben Resultaten wie

1) Die in Klammern gesetzten Zahlen bedeuten eine Abschwächung oder eine fernere Abschwächung um die Daver der betreffenden Zahlen in Tagen. Wegen der Bedeutung der Fragezeichen wird auf den Text verwiesen. 
die 1. Reihe, dagegen ergaben sich 2 scheinbare Abweichungen mit Bezug auf die relative Dauer der zu vergleichenden Symptome. Die Störung der optischen Reflexe, also das motorische Symptom, währte freilich mebr oder minder erheblich länger als die Sehstörung, also das optische Symptom, in 15 Fällen und in 4 Fällen (Beobb. 23, 27, 31 und 42) verschwanden beide Symptome annähernd gleichzeitig, aber in 2 anderen Fällen (Beobb. 28 und 43 links) hielt die Sehstörung je 11 und 4 Tage länger an als die Störung der optischen Reflexe. Indessen waren in beiden Fällen die Hunde mit Bezug auf die Sehstörung schlecht zu untersuchen und ausserdem war sie, wenn überhaupt noch vorhanden; auf eine laterale Zone zurückgewichen.

4. Die Störungen des Nasenlidreflexes haben zunächst ein Interesse mit Rücksicht anf die Localisation des Eingriffs.

Betrachten wir erst diejenigen 8 Fälle, bei denen jede Störung desselben während der ganzen Dauer der Beobachtung fehlte, so ergiebt sich, dass in den Beobb. 28 und 43 rechts und 43 links die II. Urwindung an der Läsion nicht betheiligt war, während in den anderen 4 Beobachtungen (bei Beob. 31 fehlt die Section) eine Betheiligang entweder ihrer Rinde oder ihrer Markstrahlung, wohl mehr noch des mittleren als des hinteren Drittels der uns beschäftigenden Region sicher nachzuweisen oder mit Wahrscheinlichkeit anzunehmen war. In der Beob. 35, in der eine ausgiebige Exstirpation vorgenommen war, überschritt die Narbe zwar nicht die Grenzen des Gyrus sigmoides, gleichwohl zeigte der Durchschnitt neben einem grossen Erweichungsherd, der ibre Projectionsfasern nicht ungeschädigt gelassen haben konnte, erhebliche Zerstörungen der II. Urwindung. In dem Fall 36 - gleichfalls eine ausgiebige Exstirpation - bedeckte nicht nur die Narbe einen Theil der II. Urwindung, sondern es zog sich auch noch ein feiner Erweichungsstreifen in deren Substanz hinein. Bei der Beob. 40 - Exstirpation der 2. Seite - zeigte sich eine sehr erhebliche Nebenverletzung der II. Urwindung, nicht nur war ihre Rinde stellenweise abgeblasst, sondern auch ein Theil ihres Markweisses war blutig durchsetzt und narbig verändert. Auch bei der Beob. 41, bei der der Sitz der Narbenkappe sich auf den Gyrus sigmoides beschränkte, zog ein feiner Erweichungsstreifen in die II. Urwindung hinein. Jedenfalls geht aus diesen Beobachtungen hervor, dass die II. Urwindung und zwar in Theilen verletzt sein kann, welche mit zu dem Areal gehören, durch das die unteren Aeste des Facialis innervirtwerden, ohue dass der Nasenlidreflex darunter zu leiden braucht. Bemerkenswerth ist, dass die optischen Reflexe ungeachtet dessen sehr lange, bis zur Dauer von 28 Tagen geschädigt sein konn- 
ten. Ja diese Schädigung dauerte in 1 Falle (Beob. 43 rechts) 27 Tage, obwohl die Verletzung in diesem Falle gerade am allerweitesten vom Orbiculariscentrum entfernt, nämlich am vorderen Rande des vorderen Schenkels des Gyrus sigmoides angebracht war.

Fassen wir die 10 uns zu Gebote stehenden Fälle, bei denen der Nasenlidreflex geschädigt war (in 2 ferneren Fällen Beobb. 23 und 24 war die Section nicht zu verwerthen), in's Auge, so können wir daraus eine 1. Gruppe, bestehend aus 6 Fällen, absondern, bei der das Symptom nur ganz kurze Zeit, bis zu 5 Tagen, zu beobachten war. Von diesen 6 Fällen war bei den Beobb. 25, 27 und 34 die Hineinbeziehung der II. Urwindung in den Bereich des Trauma mit mehr oder weniger Sicherheit nachweisbar, in 3 Fällen (32, 33 und 38) war sie nicht nachweisbar. Gleichwohl glaube ich, dass alle diese Fälle zusammengehören. Ich habe bereits früher wiederholt darauf aufmerksam gemacht, dass benachbarte Windungen sich in die Lücken, welche durch Eingriffe in die Substanz des Gehirns entstehen, hineinzudrängen und dadurch in ihrer Integrität geschädigt zu werden pflegen. Diesem Umstande ist auch die hier wiederholt gemachte Erfahrung zuzuschreiben, dass der nicht mitaufgedeckte mediale Theil der II. Urwindung mit in den Bereich der narbigen Auflagerung hineingezogen war. Die beobachtete geringfügige Schädigung des Nasenlidreflexes lässt sich in allen diesen Fällen also sehr wohl als ein durch ein indirectes Trauma bedingtes Nachbarschaftssymptom deuten. Die 2. Gruppe setzt sich aus 4 Fällen zusammen. Bei der Beob. 26 fand sich das Orbiculariscentrum zum Theil zerstört, während der Reflex mindestens 35 Tage fehlte. Bei der Beob. 39, bei der der Reflex gleichfalls bis zum Tode (28 Tage) fehlte, fanden sich ebenfalls deutlich sichtbare, wenn auch nicbt so grobe Veränderungen der II. Urwindung, ausserdem ein Herd im Fusse des Stabkranzes. Bei den Beobb. 29 und 30, bei denen der Reflex 13, bezw. 9 Tage fehlte, war jedoch wieder keine Betheiligung der 2. Urwindung nach eisbar; ob dennoch eine solche vorhanden war, muss ich dahingestellt sein lassen.

Ein ferneres Interesse hat die Störung des Nasenlidreflexes in ihrem Verhältniss zur Störung der optischen Reflexe. Dieses Verhältniss wird aus Tabelle I. ersichtlich.

Es ergiebt sich aus ihr, dass der Nasenlidreflex gestört war:

1. in keinem Falle länger als die optischen Reflexe und zwar in 8 Fällen überhaupt nicht;

2. gleich lang in 5 Fällen;

3. kürzer als die optischen Reflexe in 7 Fällen.

Sehen wir uns die Gruppe unter 2 näher an, so finden wir, dass 
ihre 5 Fälle in der später zu erörternden Frage des Zusammenhanges beider Symptome überhaupt nichts beweisen können. Ausserdem wurden 2 dieser Thiere (Beobb. 24 und 26) vor Ablauf dieser Symptome einer neuen Operation unterworfen, der 3. Hund (Beob. 39) aber vorher getödtet.

Es zeigt sich also, dass, abgesehen von dem 4. und 5. Falle (Beobb. 23 und 29), in allen 7, überhaupt in Betracbt kommeuden Fällen ausnahmslos der Nasenlidreflex früher wiederkehrte als der optische Reflex.

5. Für den $Z$ weck, den ich in diesem Kapitel verfolge, ist die Erörterung der Frage, ob die Störung des Nasenlidreflexes auf den Eingriff in den Gyrus sigmoides oder auf eine Nebenverletzung zu beziehen sei, erst in zweiter Linie von Interesse. In erster Linie interessirt der ursächliche Zusammenhang $z$ wischen den Störungen des Sehactes und der durch den Opticus und sodann auch der durch den Trigeminus angeregten Reflexthätigkeit.

Ich habe den Standpunkt, auf dem die Autoren die erstere Frage gelassen haben, bereits in meiner II. Abhandlung ${ }^{1}$ ) übersichtlich dargelegt. Ich hebe daraus nur hervor, dass alle Forscher, insofern sie sich überhaupt etwas eingehender mit dem Studium dieser Reflexe befasst haben, aus dem Ausbleiben der optischen Reflexe ohne Weiteres auf die Existenz einer Sehstörung schlossen; nur Exner und Paneth wollten es unentschieden lassen, ob das Symptom "der Störung der Function des Facialis oder der Sehstörung angehöre." Nach den theoretischen Auseinandersetzungen von Hunk dagegen kanu es sowohl durch eine Sehstörung als durch eine Störung in der Function des corticalen Uebertragungsapparates bedingt sein. Werfen wir nun einen Blick auf die in dem vorigen und in diesem Kapitel vorgetragenen Untersuchungen, so ergiebt sich zunächst aus jener ersten Reihe, dass die optischen Reflexe während der ganzen, 6 Tage dauernden Beobachtung 9 gänzlich fehlten, während auch nicht die Spur einer Sebstörung zu constatiren war und dass auch in mebreren der übrigen dort angeführten Beobachtungen die Störung der Reflexthätigkeit erheblich länger anhielt, als die Störung des Sehvermögens.

Auch in der jetzt vorgetragenen Reihe von Untersuchungen findet sich 1 Fall (Beob. 40), bei dem eine Sehstörung überhaupt nicht nachzuweisen war, während die optischen Reflexe 10 Tage lang gänzlich fehlten und dann noch 4Tage lang eine Abschwächung erfahren hatten.

1) E. Hitzig, Historisches, Kritisches und Experimentelles etc. Dieses Archiv Bd. 35. Heft 2. S. 335-340. 
Entsprechend überdauerte die Störung der optischer Reflexe, wie bereits oben erwähnt, die Sehstörung fast immer nm ein sehr erhebliches Zeitmaass. Indem ich im Lebrigen auf die Tabelle verweise, hebe ich aus ihr nur die 4 ausgesprochendsten Fälle hervor: Beob. 26: 11 zu 35. Beob. 30: 24 zu 35. Beob. 33: 11 zu 35. Beob. 36: 12 zu 28. Dabei habe ich immer noch dasjenige Zeitmaass als Dauer der Sehstörung angenommen, welches dem längsten Fehlen der Reaction, gleichviel ob gegen Fleisch oder gegen Licht entsprach.

Wenn also die optischen Reflexe fehlen können, während keine Sehstörung vorhanden ist, oder jemals vorhanden war, so folgt daraus, 1. dass eine Störung in dem zwischen Opticus und Facialis eingeschalteten Uebertragungsapparat unabhängig von einer Sehstörung eintreten kann. 2. dass es unzulässig ist, von dem Nachweise einer Störung der optischen Reflexe auf das Vorbandensein einer Sehstörung zu schliessen.

Aus der 2. Reihe jener Untersuchungen liessen sich zwar aus den dort angeführten Gründen weitergehende Schlüsse nicht ziehen, indessen ergab sich aus ihnen doch die Thatsache, dass bei den dort vorgenommenen Schädigungen der Convexität des Hinterlappens die Störung der optischen Reflexe gegen die Störung des Sehvermögens derart zurücktrat, dass die ersteren ungeachtet vorhandener Sehstörung entweder vorhanden, oder in nur unerheblichem Grade geschädigt waren. Hieraus lässt sich schliessen, dass die Störung der optischen Reflexe keine nothwendige Folge einer corticalen Sehstörung ist und dașs, wenn sie überhaupt in allen Fällen von der Schädigung der Rinde direct abhängig sein sollte, der optische Theil des corticalen Uebertragungsapparates an den von mir angegriffenen Stellen der Convexität des Hinterlappens seinen Sitz nicht hat.

6. Die Motilitätsstörungen waren selbstverständlich entsprechend der Grösse der Eingriffe in den jetzt mitgetheilten Fällen mehr weniger ansgesprochen als in der frühex mitgetheilten Serie. Die Intensität der sie zusammensetzenden Symptome steht aber nicht durch-. gehends in g]eichem Verhältniss zu der Intensität der Sehstörung, so dass ein näheres Eingehen auf diesen Punkt nicht geboten erscheint, nur die Beob. 43 bietet nach dieser Richtung insofern ein grösseres Interesse, als bei ihr die Sehstörung mit der gleichzeitigen Zunabme der Motilitătsstörung ebenfalls erst eintrat, bezw. eine Zunahme erfuhr. Etwas ganz Aehnliches hatte ich bereits anlässlich der Besprechung der Beobb. 14 und 15 hervorgehoben.

7. Die Sectionsbefunde. Von den mitgetheilten 21 Beobacb- 
tungen fehlt die Section in 3 Fällen, weil bei ihnen an der gleichen Stelle noch andere Operationen vorgenommen worden sind; 3 andere Fälle sind inhaltlich der Sectionsbefunde, nämlich 2 Verwachsungen der Häute (Beobb. 26 und 32) und eine subdurale Blutung (Beob. 37) als nicht rein zu betrachten. Wenn man sie also ausschalten will, so habe ich nicht das Geringste dagegen einzuwenden. Ich habe ibre MittheiIung aber dennoch für nützlich befunden, damit der Leser sich ein Bild von der Gruppirung und dem Ablauf der Symptome auch in solchen Fällen machen kann.

Betrachten wir diese 3 Fälle näher, so ergiebt sich, dass bei der Beob. 26, welche eine feste Verwachsung der Häute erkennen liess, eine sebr lange (3ó Tage) dauernde Störung der optischen Reflexe und des Nasenlidreflexes zu beobachten war, während die Sehstörung nicht besonders lange anhielt. Man könnte diese längere Dauer der Störung der Reflexthätigkeit also wohl auf die nachgewiesene Meningitis beziehen, aber doch nur die längere Dauer, denn die gleicheu Störungen und zwar gelegentlich von fast gleicher Dauer wurden in zahlreichen anderen Fällen, bei denen nicht die Spur meningitischer Erscheinungen nachzuweisen war, gleichfalls beobachtet. In dem 2. Falle (Beob. 32), bei dem eine lockere Verwachsung der Häute gefunden wurde, waren bei einer Sehstörung von mässiger Dauer auch die optischen Reflexe nur mässig lange (15 Tage) gestört und der Nasenlidreflex sogar nur sehr kurze Zeit ( 3 Tage) beeinträchtigt. Die gewonnenen Resultate werden also durch diese beiden Beobachtungen in keiner Weise alterirt. Von der etwaigen Einwirkung der subduralen Blutung in dem 3. dieser Fälle ist es wirklich sehr schwer sich eine Vorstellung zu bilden. Der Hund wurde allerdings blödsinnig, aber doch erst nach der 2., rechtsseitigen Operation, während hier von der 1 . linksseitigen die Rede ist. Die Sehstörung dauerte nur verhältnissmässig kurze Zeit und nur die Störung der optischen Reflexe trat mit einer Dauer von 27 Tagen mehr in den Vordergrund.

Auf die Localisation der Hirnverletzung auf die einzelnen Windungen werde ich später noch zurückkommen.

b) Laterale Nachbarwindungen des Gyrus sigmoides.

Es gab zwei Wege zur Lösung der Frage, ob die Einflüsse, welche durch einen Eingriff in den Gyrus sigmoides auf die Function des Auges ausgeübt werden, mit Nothwondigkeit die Verletzung seiner Rinde voraussetzen oder ob die Beschädigung eines Theiles der Markstrahlung genügt? Der eine konnte in frontaler Durchtrennung der von ihm ausgehenden 
Bahnen bestehen, indem man als Einstichspunkt eine der Nachbarwinduugen dieses Gyrus wählte. Auf dem anderen Wege konnte man Unterschneidungen der Rinde dieser Windungen vornehmen oder diese Rinde in anderer Weise zerstören und dann abwarten, wie tief der primäre Fingriff reichen und ob, event. mit welchen Folgen sich Erweichungsherde in der llarkstrahlung einstellen würden.

Der erste dieser Wege, den ich, übrigens auch noch zur Erreichung. eines anderen Zweckes einschlug, hat mich nach vielen Bemühungen zu keinen mich befriedigenden Resultaten geführt; die Ergebnisse, welche ich auf dem anderen Wege erlangte, werden uns in dem nachfolgenden Abschnitte beschäftigen. Diese Versuchsreihe witre schon deshalb unrermeidlich gewesen, weil der von mir mitgetheilte Versuchsplan ohnehin die Erforschung jenes Tbeiles der Rinde mit Rücksicht auf ihre Beeinflussung der Functionen des Auges in sich schloss. Natürlich wurde sie es aber umsomehr, wenn man von diesen Gebieten aus die Markstrahlung anderer Gyri untersuchen wollte. Vorbedingung war in diesem Falle natürlich, dass die isolirte Verletzung der Riode jener Windungen selbst mindestens nicht zu Sehstörungen führte.

Unsere Kenntrisse von den Functionen der frontalen Schenkel der 2.-4. Urwindung sind noch bei Weitem weniger klar umfassend und gesichert, als die von den Functionen des Gyrus sigmoides.

Bereits in der yon Fritsch und mir ${ }^{1}$ ) veröffentlichten Arbeit findet sich auf Grund von Reizversuchen die Angabe, dass der Facialis von dem mittleren Theile der 2. Urwindung innervirt sei. Es heisst da: „die betreffende Stelle übertrifft häufig an Ausdehnung $0,5 \mathrm{~cm}$ und erstreckt sich von der Hauptknickung oberhalb der Sylvi'schen Grube aus nach vor- und abwärts." In einer anderen Abhandlung aus dem Jahre 1873 hatte ich $^{2}$ ) nachgewiesen, dass der von uns damals gefundene Innervationsherd für den Orbicularis palpebrarum gleichzeitig der Innervation der contralateralen geraden Augenmuskeln diene. Ausserdem ergab sich damals die Abhängigkeit der unteren Aggregate des Facialis von einem mehr lateral und basal gelegenen Theile jener Windungen (II. und III. Urwindung). Ferrier ${ }^{3}$ ) hat sodann angegeben, dass die vorderen und basaien Theile jener Gegend mit Schliessbewegungen des Unterkiefers, Verziehung der Mundwinkel, Oeffnung der Schnauze, Bewegungen der Zunge und verschiedenen anderen Reizeffecteu antworten. Seine

1) E. Hitzig, Untersuchungen über das Gehirn. 1874. S. 13.

2) E. Hitzig, Ebenda S. 42 ff.

3) Ferrier, ExperimentaI Researches in cerebral Physiology etc. The West Riding lunatic asylum Medical Reports. Vol. III. 1873. 
Angaben stützten sich jedoch der Hauptsache nach auf einen einzigen Versuch; sie waren so widerspruchsvoll und die ihnen zu Grunde liegende Faradisirung der Hirnrinde war mit so starken Strömen ansgeführt worden, dass man dem. Urtheil, welches andere englische Autoren über sie aussprachen, er habe wobl die Region, aber nicht die Foci der Repräsentation jener Bewegungen aufgedeckt, nur beistimmen kann. Ich selbst ${ }^{1}$ ) hatte bei einer Nachprüfung der Untersuchungen Ferrier's dieselben nur zu einem Theile bestätigen können und übrigens diejenigen Punkte angegeben, deren Reizung mit dem Zuckungsminimum Bewegungen der Zunge, der Kiefer, des Restes der Gesichtsmuskeln und der vorderen Halsmuskeln hervorbringt. Auch hatte ich bei dieser Gelegenheit auf die Doppelseitigkeit des grösseren Theiles dieser Bewegungen, insbesondere der Zungenbewegungen, aufmerksam gemacht.

Munk ${ }^{2}$ ) hat zuerst in seiner Mittheilung rom 15. März 1878 die uns bier interessirenden Windungen als "Kopfregion" bezeichnet, ohne dass er jedoch bei diesem Anlass mittheilt, welche besonderen Störungen in Folge von Verletzungen dieser Region eintreten. In seiner nächsten Mittheilung vom 29. November 1878 hat er sodaun den Namen „Kopfregion" für den vorderen Theil dieser Sphäre reservirt, den hinteren Theil aber mit einem dahinter liegenden, bisher freigelassenen, von der IV. Urwindung bis zur Medianebene reichenden und senkrecht auf ihr stehenden Streifen mit dem Namen "Augenregion" bedacht. Von der letzteren Region erfahren wir (a. a. 0. S. 50 ff.), dass ibre Exstirpation zwar die Blinzbewegungen des Auges gegen Berührungen intact lässt, aber das sonst ,jedesmal" auf Annäherung des Fingers oder der Faust erfolgende Blinzeln aufhebt, dass ferner die Augenbewegungen eine Beeinträchtigung erfahren, sowie dass manchmal, nicht immer, Ptosis eintritt, und dass endlich die sonst bei Reizung der Conjunctiva zu beobachtenden mimischen und Abwehrbewegungen in Fortfall kommen. Ueber die "Kopfregion" heisst es sodann (S. 53): "Nach Exstirpation der Kopfregion habe ich Seelenbewegungslosigkeit der gegenseitigen Zungenhälfte und der dort um den Mund herum gelegenen Muske]n bestehen sehen; ausserdem waren beim Hunde die Druckgefühle der gegenseitigen Gesichtshälfte verschwunden. Die Zungenlähmung habe ich immer nur bei weit nach unten reichender Exstirpation gefunden. Ich möchte glauben, dass die weitere Untersuchung diese Kopfregion noch in mehrere Regionen wird zerfällen lassen."

Ich habe diese Darstellung Munk's stets mit Verwunderung ge-

1) E. Hitzig, Untersuchungen über das Gehirn. 1874. S. 63-113.

2) H. Munk, Gesammelte Mittheilungen. 1890. S. 33. 
lesen. Zunächst ist mir die Abtrennung einer "Augenregion" von der einmal "Kopfregion” getauften Sphäre nicht verständlich geworden.

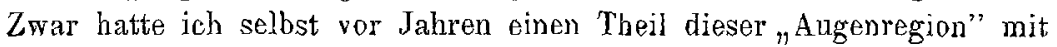
Rücksicht auf die gercinschaftliche Function als "Centrum für Bewegung und Schutz des Auges" bezeichnet. Wenn man aber schon einmal von einer "Kopfregion" sprechen will, so sehe ich nicht ein, weshalb die Augen und der Orbicularis palpebrarum, welche doch ebenso gut am Kopfe liegen, wie der Rest des Facialis incl. Frontalis, die Muskeln der Zunge, der Kiefer etc. eben nicht zu dieser „Kopfregion” gehören sollen. Sodann erfahren wir weder bei dieser, noch bei einer anderen Gelegenheit, in welchen Beziehungen die einzelnen Theile jenes breiten, sich quer über die Hemisphäre erstreckenden Streifens zil den Bewegungen und Empfindungen innerhalb dieser sogenannten "Augenregion" stehen und ebensowenig sagt uns Munk irgend etwas mit Bezug auf diesen Punkt über denjenigen Bezirk, in dem ich das Centrum für die Fress- und Sprechmuskeln (Untersuchungen S. 135) localisirt hatte. Wir bören nur, er glanbe, dass die weitere Untersuchung diese „Kopfregion” moch in mehrere Regionen wird zerfällen Iassen. Allerdings Jag Veranlassung genug zu einem solchen Glamben in den von mi" soeben angeführten Untersuchuugen. Indessen hätte $M u n k$ dann freilich erwähnen müssen, dass ich selbst durch den Reizversuch schon vor ihm eine derartige Abgrenzung der centralen Innervationsstätten für die ganze hier in Frage kommende Muskulatur vorgenommen hatte. Ich muss bedauern, dass er dies unterlassen und sogar auf Kosten derjenigen Bestätigung seiner Exstirpationsversuche unterlassen hat, welche ihnen aus meinen Reizversuchen erwachsen wasste, Sehr fraglich muss es überhaupt, wegen der Kleinheit der Theile, erscheinen, ob eine solche weitere Zerfällung beim Hunde durch Lahmungsversuche mit der gleichen Genauigkeit wie durch die Reizversuche möglich ist. In dieser Beziehung sind die Reizversuche, wie ich früher bereits ausgefübrt habe, den Lähmungsversuchen entschieden überlegen und um so mehr bätten sie angeführt werden sollen. Vollkommen im Unklaren lässt uns Munk an dieser Stelle auch darüber, was er unter "Seelenbeweguagslosigkeit der gegenseitigen Zungenhälite" verstanden wissen will. Zeigte die Zunge etwa eine Deviation und nach welcher Seite war eine solche gerichtet? Naheres über die Art dieser Störung theilt $\mathrm{Mlnk}^{1}$ ) erst im Jahre 1882 anlässlich der Beschreibung der zufälligen Nachbarschaftswirkungen der doppelseitigen Exstirpation des Stirnlappens mit. Wenn die Entzündung sich in diesen Fällen nach hinten verbreitet,

1) H. Munk, Gesammelte Mittheilungen, 1890. S. 149. 
fassen die Hunde ungefähr während der Dauer der ersten Woche Fleischstücke ungeschickt mit den Kiefern und vermögen mit der Zunge nur zu lecken, nicht aber, namentlich feste Nahrung in den Schlund zu befördern. An einer anderen Stelle (ebenda S. 174) hebt er noch ausdrücklich hervor, dass diese Fressstörungen nur bei symmetrischer Zerstörung dieser Regionen zu beobachten sind, so dass noch beute Unklarheit darüber" herrscht, was Munk unter der "einseitigen Seelenbewegungslosigkeit der Zunge" damals verstanden wissen wollte. Inzwischen hatte Schiff bereits im Jahre 18731) einseitige Fressstörungen in der Weise beschrieben, dass die Thiere diejenigen Theile von Knochen und Speisetheilen überhanpt, welche der geschädigten Seite entsprechen, aus dem Maule verlieren und dass ihnen Speisetbeile in den Backentaschen und zwischen den Zähnen zurückbleiben. Goltz's) hatte zwei Jahre nach jener Mittheilung von Munk den doppelseitigen Fressstörungen wohl die ausführlichste Beschreibung gewidmet; aber beide Forscher haben diese als Gegner der Localisationslehre selbstverständlich nicht auf die fraglichen Regionen localisirt: insbesondere begreift die Beschreibung von Goltz nicht nur die durch die Ataxie der Fressmuskeln, sondern auch die durch die Ataxie der Nackenmuskeln bedingten Störungen in sich. Man sieht, dass ein rechter Grund zu einem Prioritätsstreit, wie er sich zwischen Goltz und Munk erhoben hat, eigentlich gar nicht vorlag. Die wenigen Beobachtungen, welche ich bei diesen Versuchen über Fressstörungen gemacht habe, geben mir keine Veranlassung an dieser Stelle auf dieselben zurückzukommen.

Die Autoren der italieniscben Schule Luciani im Verein mit Tamburini und Sepilli, Bianchi und Tonnini haben, wie wir bereits in der III. dieser Abhandlungen ${ }^{3}$ ) gesehen haben, dem vorderen Schenkel der II. Urwindung, insbesondere auch deren Sylvi'scher Region besondere Beziehungen zum Sehvermögen zugeschrieben und sich dabei namentlich auch auf das Ausfallen der optischen Reflexe gestützt. Ich möchte hier nur noch hervorheben, dass Luciani bei seinen mit Sepilli publicirten Versuchen $1 \mathrm{mal}$ (Hund $\mathrm{H}$ ) und bei seinen mit Tamburini publicirten Versuchen $4 \mathrm{mal}$ (Versuche II, XI, XV, XVII) vorübergehend eine Erweiterung der contralateralen Lidspalte beobachtete, ohne aber diesem Symptom besondere Beachtung zu schenken.

1) M. Schiff, Lezioni di fisiologia sperimentale sul sistema nervoso encefalico. p. $538 \mathrm{f}$. Vergl. auch Gesammelte Beiträge pp. Bd. 3. S. 517.

2) Fr. Goltz, Ueber Verrichtungen des Grosshirns, 5. Abhandlung. Pflüger's Archiv Bd. 34. S. $468 \mathrm{ff}$.

3) E. Hitzig, Historisches, Kritisches etc. Dieses Archiv Bd. 35. H. 2. S. $302 \mathrm{ff}$. 
Den gleichen hier in Betracht kommenden Fall hat Eckhard ${ }^{1}$ ) einer Untersuchung unterzogen. Er fand keinen constanten Unterschied in der Weite der Lidspalten oder in den Berührungsreflexen (Conjunctiva, Cilien, Haut der Lider oder der Wange) oder in den spontanen Lidbewegungen. "Das Orbicularisfeld hat keinen Einfluss auf die reflectorische und spontane Thätigkeit des subcorticalen Centrums für die Lidbewegungen."

Endlich haben sich R. du Bois-Reymond und Silex') gleichfalls mit diesem meinem Centrum für die Bewegung und den Schutz des Auges beschäftigt. Sie bestätigten die Resultate meiner Reizversuche und die der eben erwähnten Eckhard'schen Lähmungsversuche, ausserdem fanden sie, dass der optische Reflex gegen flache Hand "bei einseitig operirten Hunden an dem geschädigten Auge in der Regel (also doch wohl nicht constant) häufiger ausblieb, als auf der anderen Seite." Beiläufig sei noch erwähnt, dass sich in der caudalsten Partie dieser Region Luciani's "Centrum der Centren" (vergl. Historisches, Kritisches etc. Dieses Archiv Bd. 35. H. 2. S. 302) befindet. -

Die nachstehenden Versuche habe ich in zwei Gruppen eingetheilt, solche, die ohne nennenswerthe motorische etc. Erfolge an den Extremitäten verliefen und solche, die mit derartigen Erfolgen verliefen.

\section{A. Versuche ohne motorische Folgen.}

\section{Beobachtung 4.1.}

Kleine Hündin. Trepanation $30 \mathrm{~mm}$ nach vorn von Lambdanaht links mit $14 \mathrm{~mm}$ Trepan. Die halbe Trepankrone auf Planum semicirculare. Reizung mit Inductionsströmen, während das Thier noch nicht ganz erwacht ist, erfolglos, nur einige zitternde Nachbewegungen im Orbicularis rechts. Aetzung mit 5 proc. Carbolsäure.

In der Folge werden weder motorische, sensible, optische, noch Reflexstörungen beobachtet.

Wegen der Section vergl. Beob. 45.

\section{Beobachtung 45 .}

Derselbe Hund von Beob. 44; 3 Wochen nach dieser Operation. Erweiterung der Trepanöffnung um ca. $6 \mathrm{~mm}$ lateralwärts. Pia hyperämisch. Skarification der blossgelegten Rinde mit feinem Messer und Aetzung mit 5proc. Carbolsäure.

1) G. Eckhard, Das sogenannte Rindenfeld des Facialis in seiner Beziehung zu den Blinzbewegungen. Centralbl. f. Phys. Bd. XII. No. 1.

2) R. du Bois-Reymond und Silex, Ueber corticale Reizung der Augenmuskeln. Archiv für Anatomie and Physiologie. 1899. S. $174 \mathrm{ff}$. 
In der Folge keine Spur von motorischen, sensiblen, optischen, noch Reflexstörungen.

Getödtet nach 13 Monaten, nachdem inzwischen noch 2 Operationen, die 3. im Gyrus sigmoides, die 4. im Hinterlappen ausgeführt worden waren. In

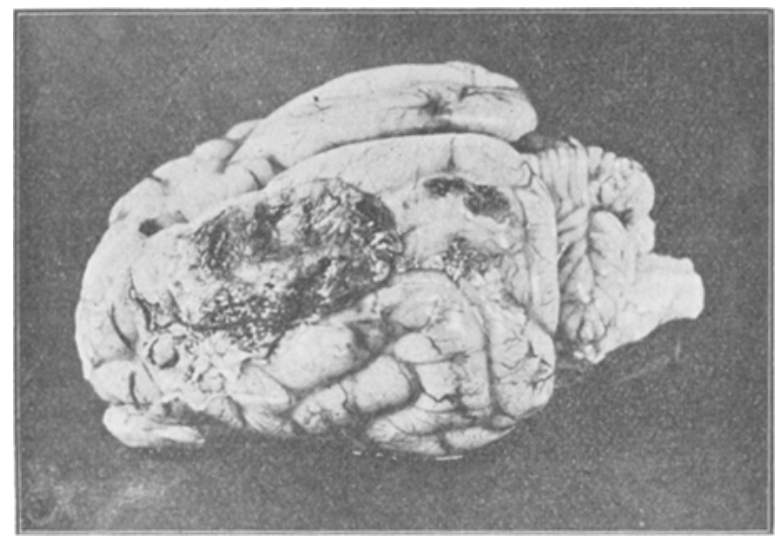

Fig. 58.

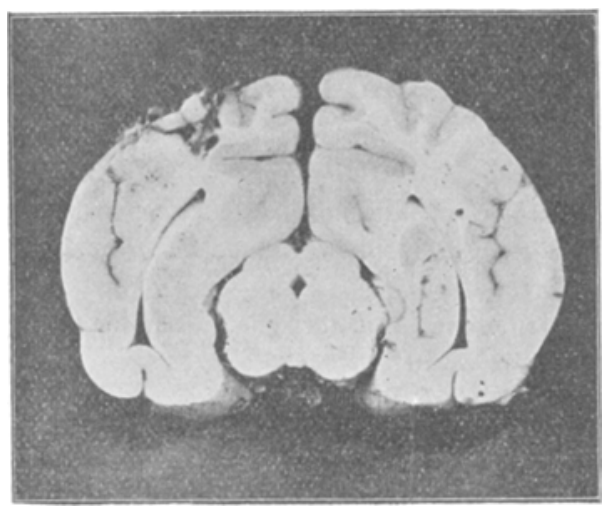

Fig. 59.

dem nachstehenden Sectionsbefunde ist die Beschreibung der Convexität vollständig wiedergegeben.

Dura nicht verdickt, mit Pia nur zwischen vorderer und hinterer Operationsstelle leicht verwachsen. Die Auflagerung reicht medial bis fast an die Längsspalte des Gehirns, nach vorn und lateral noch etwas über den vorderen Schenkel des Gyrus sigmoides binaus, nach lateral noch eben auf die III. Ur- 
windung übergreifend, nach hinten bis auf etwa $3 / 4 \mathrm{~cm}$ von der hinteren Operationsstelle entfernt bleibend. Vorn lațeral in der III. Urwindang findet sich ein flacher Erweichungsherd. Auf dem Durchschnitt zeigt sich Zerstörung des Rindengraus im Gebiete der aufsitzenden Narbenkappe. Das Narbengewebe dringt etwa $1 \mathrm{~cm}$ tief in das Mark hinein. Dort keine Erweichung. Der Ventrikel kaum ausgezogen. Hintere Operationsstelle: Die Operation hat genau die Munk'sche Stelle $A_{1}$ unterschnitten. Der Einstich ist noch etwas lateral von der lateralen Begrenzung dieser Stelle. Der Ausstich etwas lateraler als die mediale Begrenzung der Stelle. Von der vorderen Narbe gehört ca. die hintere Hälfte den beiden hier in Frage kommenden Operationen an. Sie bedeckt das von mir sogenannte Centrum für Bewegung und Schutz des Auges und medial davon einen Theil der von Munk sogenannten Augenregion.

\section{Beobachtung 46.}

Abtragung des Knochens ganz vorn und lateral bis zur Spitze des linken Planum semicirculare, dabei Durcbschneidung des Facialis. Dura am hinteren Rande der Lücke aufgeschlitzt. Unterschnejdung vornehmlich basal bis au den Knochen, doch auch nach vorn basal $2,5 \mathrm{~cm}$ lang mit dem Präparatenhebej unter seitlicher Abtrennung der unterschnittenen Theile derart, dass die seit: lichen Schneiden des Präparatenhebers an der medialen und lateralen Grenzè des unterschnittenen Theiles gegen den Knochen angedrückt. werden.

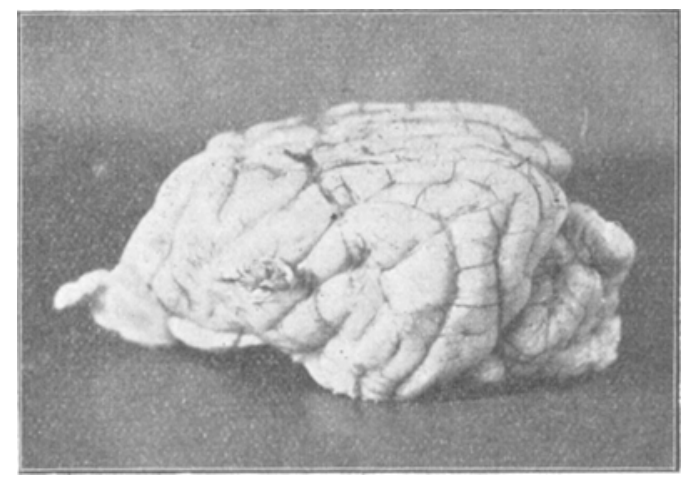

Fig. 60 .

In der Folge keine Spur von optischen, motorischẹn, sensiblen und Reflexstörungen, insbesondere auch keine Anomalieon der Zunge.

Gestorben nach ca. 21/2 Monaten, nachdem inzwischen eine 2. Operation. vorgenommen worden war.

Section: Häute normal. An der Operationsstelle eine scharf umschriebene narbige Verwachsung. Die ungefähr $7 \mathrm{~mm}$ breite und $12 \mathrm{~mm}$ lange Narbe sitzt in dem der II. und III. Urwindung gemeinschaftlichen Theil vorn $2 \mathrm{~mm}$; hinten $6 \mathrm{~mm}$ lateral vom lateralen Rande des Gyrus sigmoides. 1. Dureh- 
schnitt (2 mm vor dem hinteren Rande der Narbe): Von der Narbenkappe geht ein nicht ganz gerader, theilweise durch Erweichungen bis $1 \mathrm{~mm}$ breit erweiterter Spalt basalwärts bis zur basalen $\mathrm{Pia}$, ohne dieselbe zu durch-

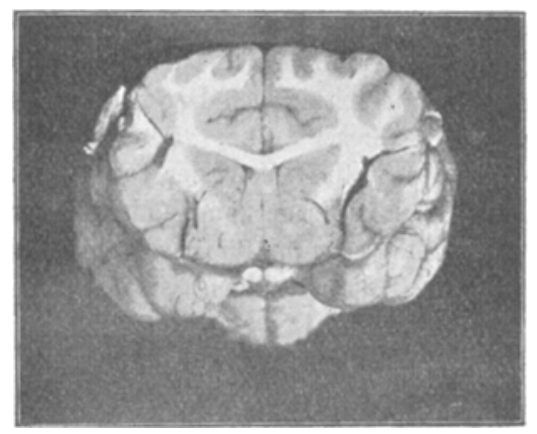

Fig. 61 .

schneiden. Der Spalt geht zwischen Rindengrau und innerer Kapsel entlang. Auf dem 2. Durchschnitt ( $8 \mathrm{~mm}$ weiter nach vorn) sieht man nichts mebr von dem Einstich.

\section{Beobachtumg 17 .}

Abtragung des Knochens auf linkem Planum semicirculare ganz yorn und lateral, auf $21 \mathrm{~mm}$ sagittal, $11 \mathrm{~mm}$ frontal, unter Durchschneidung des Facialis. Abtragung der Dura nur über der hinteren Hälfte. Unterschneidung nicht ganz bis an die vordere Spitze, ausserdem lateral und basalwärts.

Motilitätsstörungen: Gleich nach dem Einstich tonische Contractionen, wie es scheint ausschliesslich der Lendenmuskulatur, sonst ungestört. Sehstörung fehlt.

Optische Reflexe normal.

Nasenlidreflex ungestört.

Gestorben am 13. Tage ohne erkennbaren Grund. (Epileptischer Anfall?) Section: Häute normal, nur scharf an der Operationsstelle mit den weichen Bedeckungen verwachsen, Pia dort etwas höckrig und stellenweise etwas strichförmig narbig eingezogen. Die Narbe sitzt auf der II. und III. Urwindung. 1. Durchschnitt $\left(3^{1 / 2} \mathrm{~mm}\right.$ vor dem Einstich): Schnittförmiger Canal etwa $4 \mathrm{~mm}$ von der Rinde, parallel zur Oberfläche, Ränder mit einer schmalen Erweichungszone umgeben. Der Schnitt fällt 'senkrecht zur Markstrahlung der unterschnittenen Windung, so dass ein grosser Theil der Rinde von soinen subcorticalen Verbindungen abgetrennt ist. Das Rindengran ist auch im Ganzen etwas abgeblasst, stellenweise fast markweiss. Oberhalb und lateral rom Nucleas caudatus findet sich eine blutig suffundirte strichförmige Erweichungsstelle im Markweiss. 2. Durchschnitt (5 mm weiter nach roin): Stichcanal nicht ganz parallel zur Oberfläche, unten etwa $3 \mathrm{~mm}$, oben etwa 
$4^{1} / 2 \mathrm{~mm}$ entfernt. Da er hier etwa in die Richtung der Marlkstrahlung fällt, sind augenscheinlich wenig Fasern quer durchschnitten, das Rindengrau dar-

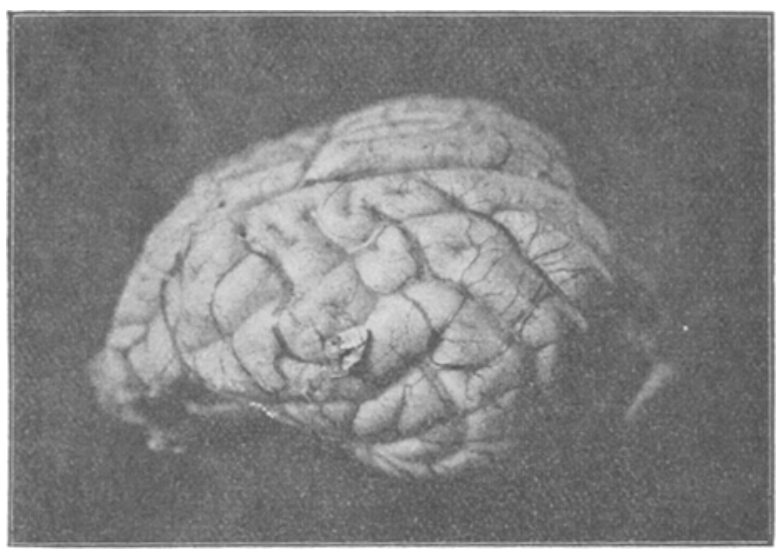

Fig. 62 .

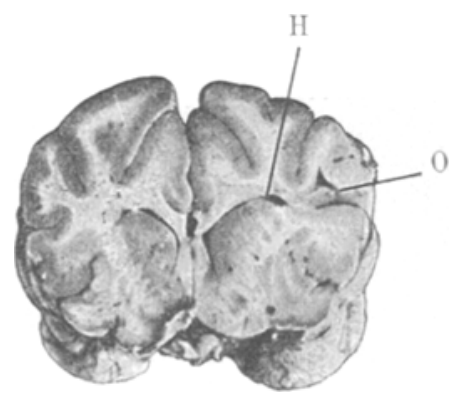

Fig. 63.

über auch kaum merklich aufgehellt. Etwa $11 / 2 \mathrm{~mm}$ weiter nach vorn endet der Stichcanal. Länge des Ganzen danach $10 \mathrm{~mm}$. (Vergl. Beob. 2.)

\section{Beobachtung 48.}

Trepanation ganz vorn, stark lateral auf dem Planum semicirculare links. Erweiterung mit Knochenzange auf $19 \mathrm{~mm}$ sagittal, $10 \mathrm{~mm}$ frontal. Abtragung der unverletzten Dura, bis auf einen schmalen Streifen rings herum und ein breiteres Stück im vorderen Drittel. Pia unverletzt. Einstich mit dem schmalen Ende des Präparatenhebers hinten und Unterschneidung der Rinde nach vorn in der Richtung der Knochenlücke bis an die vordere Schädelwand; dann wird unter noch zweimaligem Einführen des Präparatenhebers in einem Winkel 
die Rinde lateral und medial bis an die Pia ohne Verletzang derselben abgetrennt.

Motilitätsstörungen fehlen sonst; rechte Lidspalte 4 Tage weiter als linke.

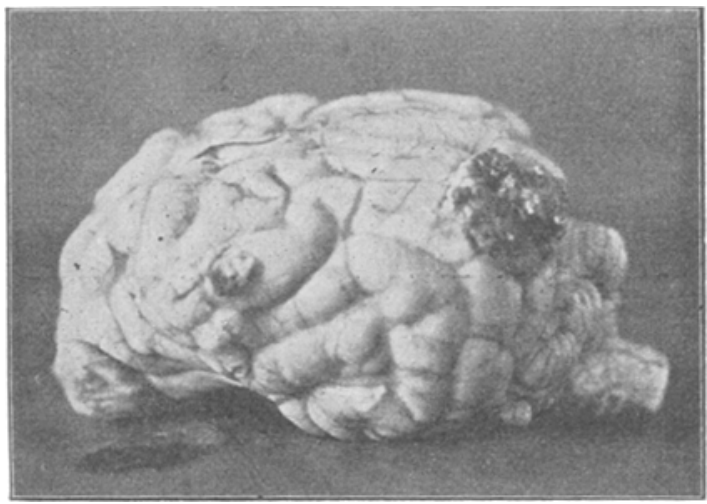

Fig. 64.

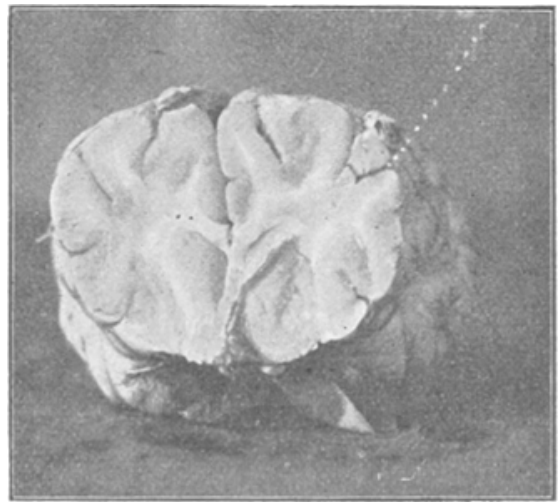

Fig. 65. 0: Unterschneidungsstelle.

In der Schwebe: Hängt am 2. Tage rechts gestreckt und reagirt auf Begreifen schwächer.

Sehstörung: Gegen Fleisch und Licht fehlend. Optische Reflexe normal.

Nasenlidreflex: Am 2. und 3. Tage vielleicht abgeschwächt.

Getödtet nach 7 Wochen; inzwischer eine 2. Operation im Hinterlappen. 
Section: Häute normal. Eine etwa $5 \mathrm{~mm}$ grosse Narbenkappe in der II. Urwindung dicht vor dem Centrum für Bewegung und Schutz des Auges, also etwas weiter nach hinten als bei der vorjgen Beobachtung. Durchschnitt ( $5 \mathrm{~mm}$ vor dem Einstich): Vom medialen Rand der Narbe ausgehend, erstreckt sich ein schnittförmiger Spalt der Pia11-12 mm nach vorn. Von diesem schon aussen in der Pia sichtbaren Schnitt geht eine Spalte quer durch das Rindengrau und Markweiss etwa $6 \mathrm{~mm}$ medial, um unten lateral umzubiegen und fast an die Pia heranzugehen. Länge dieser Unterschneidung etwa $15 \mathrm{~mm}$.

\section{Beobachtung 49.}

Knochenlücke ganz vorn $28,5 \mathrm{~mm}$ sagittal, $15 \mathrm{~mm}$ frontal auf Planum semicirculare links, $2-4 \mathrm{~mm}$ lateralwärts von der Linea semicircularis, unter Vermeidung des Gyras sigmoides, Unterminirung der vorderen Hälfte der freigelegten Stelle mit dem Dariel'schen Löffel.

Motilitäts-und Sensibilitätsstörungen fehlen.

In der Schwebe: Hängt beiderseits gleich. Beim Begreifen Reaction bis zum 6. Tage vorn rechts fehlend, am 7. Tage schwächer, an 8. Tage normal.

Sehstörung: Fehlt gegen Fleisch. Gegen Licht reagirt der Hund nicht.

Optische Reflexe: Beiderseits fehlend oder nur angedentet, aber ohne Unterschied.

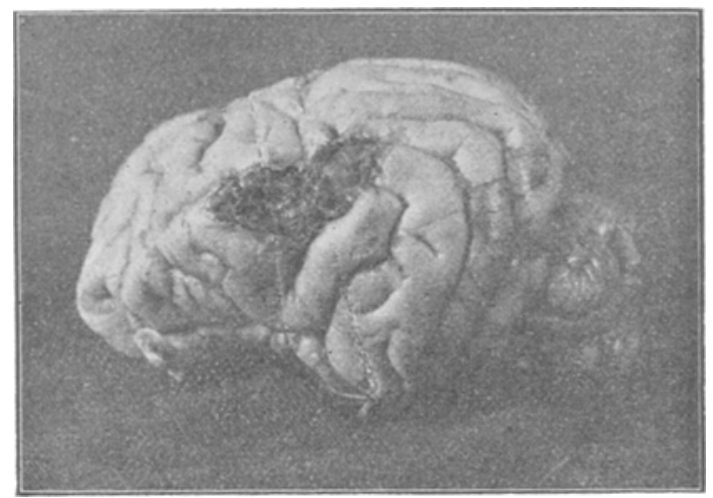

Fig. 66 .

Nasenlidreflex: Beiderseits überhaupt schwach, rechts aber theils ganz. fehlend, theils nooh schwächer bis zum 17. Tage. Später beiderseits gleich.

Cornealreflex unverändert.

Sensibilität der Zunge etc.: Verliert anfänglich oft Fleischstücke, sonst nichts nachweisbar. 
Getödtet nach $5 \frac{1}{2}$ Monaten; inzwischen eine 2. symmetrische Operation.

Section: Häute normal. Eine etwa $23 \mathrm{~mm}$ lange und $10 \mathrm{~mm}$ breite Narbe befindet sich lateral vom Gyrus sigmoides gerade den lateralen Rand desselben berührend, aber nicht darauf übergreifend. Vorn erstreckt sie sich etwa bis zum lateralwärts verlängerten Sulcus cruciatus, nach hinten $10 \mathrm{~mm}$

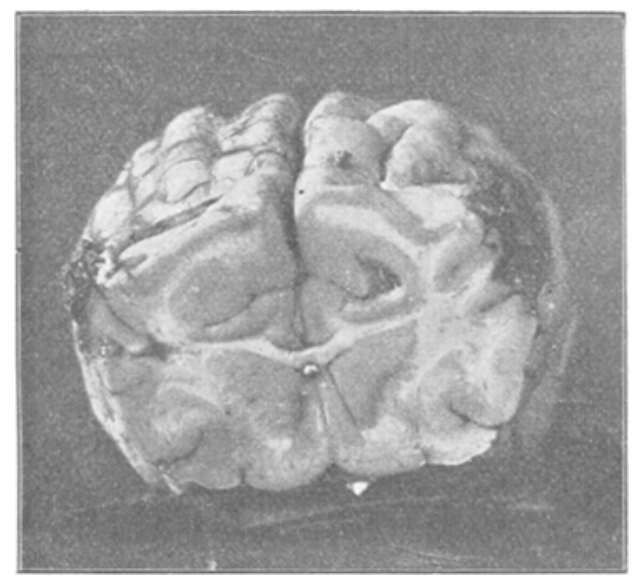

Fig. 67.

über den hinteren Schenkel des Gyrus sigmoides hinaus. Die Narbe liegt leicht schief von hinten medial nach vorn lateral, im Wesentlichen den hinteren Theil des vorderen Schenkels der II. Urwindung zerstörend. Durchschnitt (mitten durch den hinteren Schenkel des Gyrus sigmoides): Unter der Narbe ist die Rinde flach zerstört, das Rindengrau, soweit es die einschneidenden Sulci darunter amgiebt, ist jedoch erhalten.

\section{Beobachtung: $\mathbf{5 0}$.}

Aufdeckung auf dem Planum semicirculare links ganz vorn und ganz lateral auf $17,5 \mathrm{~mm}$ sagittal, $9,5 \mathrm{~mm}$ frontal. Unterschneidung der freigelegten Partie mit dem Präparatenheber von der hinteren Peripherie der Lücke her in der Richtung derselben nach rorn bis an den Knochen.

Motilitätsstörungen fehlen in den Extremitäten. Rechte Lidspalte 4 Tage erweitert.

Sehstörung fehlt.

Optische Reflexe: Gleich nach der Operation ungestört; vom 2. bis 4. Tage abgeschwächt, nach 5 Wochen noch abgeschwächt.

Nasenlidreflex abgeschwächt bis zum Schluss. (5 Wochen.)

Getödtet nach 7 Wochen; inzwischen eine 2. symmetrische Operation.

Section: Häute normal. Narbe von $11 \mathrm{~mm}$ Länge in der II. Urwin- 
dung, Mitte etwas nach vorn vom Sulcus cruciatus, hinterer Rand genau mit der Einstichstelle zusammenfallend, vorderer Rand genau da, wo im Gehirn die Unterschneidungsspalte aufhört. Durchschnitt $(6 \mathrm{~mm}$ vor dem Einstich):

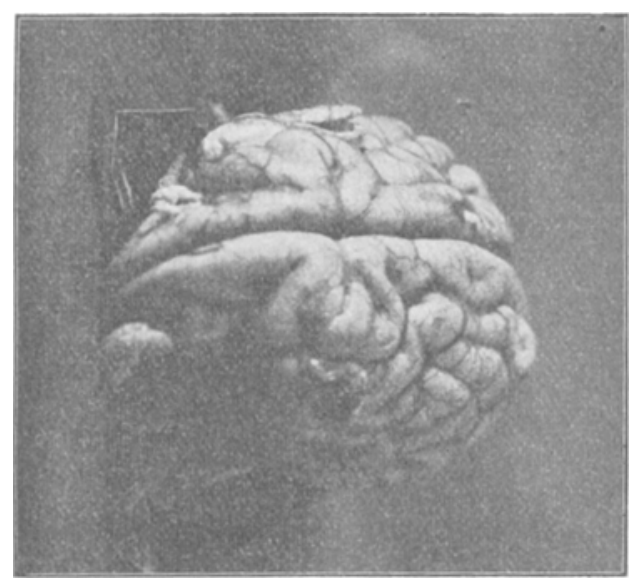

Fig. 68.

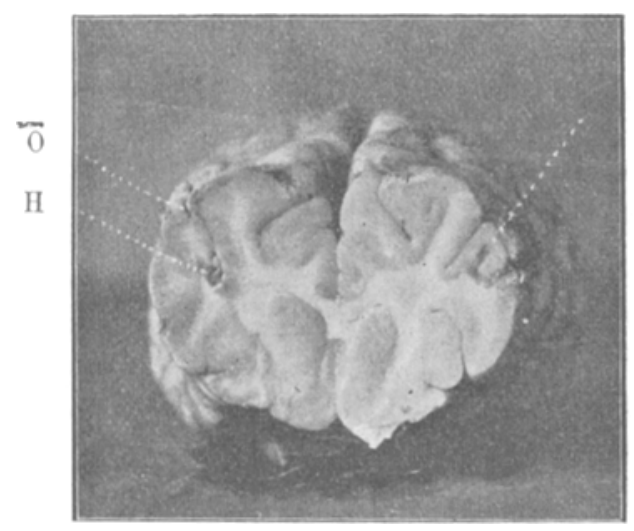

Fig. 69. 0: Operationsstelle; H: Erweichungsherd.

Die leicht blutig verfärbte Spalte liegt genau in der Längsrichtung der Markstrahlung, von dieser nicht viel übrig lassend. Rinde darüber ganz leicht abgeblasst. 


\section{Beobachtmo: 51.}

Derselbe Hund ron Beab. 50. Anfdeckung auf rechtem Planum semicirculare ganz vorn und lateral auf $2 \mathrm{~cm}$ sagittal. Unterschneidung wie bei Beob. 50.

Motilitätsistörungen fehlen.

Sensibilitätsstörungen fehlen, auch im Gesicht und in der Nase.

Sehstörung: Gegen Fleisch: Am 2. Tage im breiten temporalen Streifen, wo er zwar fixirt, aber nicht zuschnappt; am 3. Tage keine deutliche Sehstörung mehr, am 4. Tage sicher verschwunden. Gegen Licht: fehlend.

Optische Reflexe dauernd rechts schwächer.

Nasenlidreflex rechts schwächer.

Getödtet am 13. Tage.

Section: Häute normal. Auflagerung annähernd symmetrisch, etพas weiter nach hinten im Bereiche meines Centrums für Bewegung und Schutz des Auges. Dio Unterschneidung ist ganz flach, ungefähr an der Grenze von Rindengrau und Markweiss, der mediale Rand der Schneide hat dabei die Pia durchschnitten. Durchschnitt $(10 \mathrm{~mm}$ vor dem Einstich): Unterschneidungsspalte hat hier gerade noch die Rinde quer durchtrennt, der grösste Theil des Schnittes ist ausserbalb der Pia gefallen. In der Tiefe des Sulcus, der den Gyrus sigmoides lateral begrenzt (Sulcus coronarius), liegt ein blutig durchsetzter Erweichungsherd im Rindengrau. (Vergl. Beob. 1.)

\section{Beobachtung 5:.}

Kräftiger, mittelgrosser Hund. Aufdeckung im linken Planum semicirculare, vorderer Rand der Lücke $15 \mathrm{~mm}$ hinter der Spitze des Planum, auf ca.

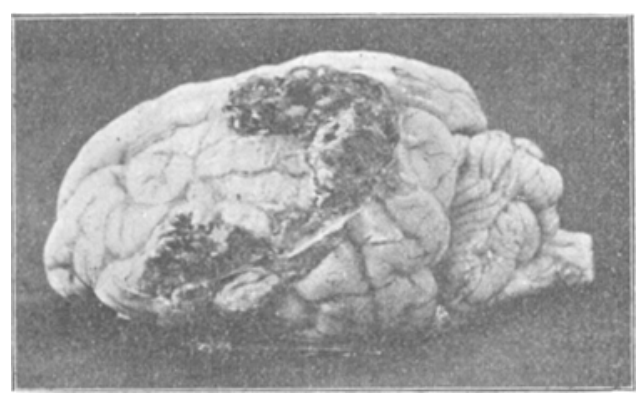

Fig. 70 .

$14 \mathrm{~mm}$. Faradjsche Reizung im vorderen unteren Wundwinkel ergiebt Schluss des Auges. Skarification dieses Abschnittes auf 2-3 mm Tiefe.

Motilitäts-und Sensibilitätsstörungen (auch in der Nase) fehlen. 
In der Schwobe: Hängt, aber nur am 2. Tage, rechts vorn etwas gestreckt.

Sehstörung: Gegen Fleisch: Am 2. Tage im oberen temporalen Quadranten Abschwächung der Reaction.

Optische Reflexe: 2 Tage lang fehlend, am 3. Tage unvollkommen, dann normal.

Nasenlidreflex: Fehlt am 2. Tage derart, dass man ohne Reaction bis an den Lidrand kommen kann, dort normale Reaction; abgeschwächt bis zum 16. Tage, nachber normal.

Getödtet nach ca. 7 Monaten; inzwischen eine 2. Operation im Hinterlappen.

Section: Die Narbe bedeckt das Centrum für Bewegung und Schutz des Auges und die nach vorn von diesem gelegenen Theile der II., sowie die nach hinten gelegenen Theile der III. Urwindung; von hier geht dann schief nach medial zur hinteren Stelle ein Streifen, wo die Dura unlösbar mit der Pia verwachsen ist. (Diese Verwachsung ist eine Folge der 2. Operation, da die Häute, wie damals ausdrücklich constatirt, zart und nicht verwachsen waren.) An der Durchschnittsstelle erscheint das Gehirn nur wenig und oberllächlich verändert.

\section{Beobachtung 53.}

Aufdeckung anf linkem Planum semicirculare $17 \mathrm{~mm}$ hinter der Spitze des Planum aul $18 \mathrm{~mm}$ sagittal und $13 \mathrm{~mm}$ frontal. Faradische Reizung im mittleren und vorderen Drittel ergiebt Lidschluss. Unterschneidung dieser Partie.

Der Hund frisst bereits ${ }^{3} / 4$ Stunden nach der Operation und ist im Allgemeinen gut zu untersuchen; Sehstörung scheint zu fehlen. Optische Reflexe

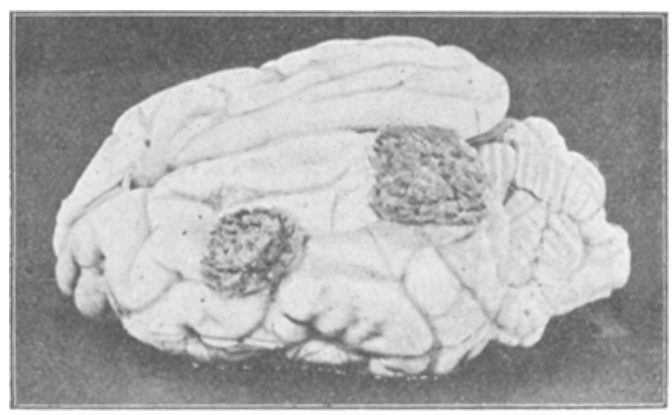

Fig. 71.

fehlon rechts, links vorhanden. Nasenlidreflex rechts abgeschwächt. Ciliarreflex beiderseits gleich. 
Motilitätsstörungen fehlen, nur am 3. Tage etwas "Defect der Willensenergie." Lidspalte weiter offen bis zum 23. Tage.

Sehstörung: Gegen Fleisch am 3. Tage Reaction durch Fixiren auf der temporalen, durch Zuschnappen auf der nasalen Hälfte des Gesichtsfeldes. Später geringere Energie beim Zuschnappen bis zur letzten Notiz am 33. Tage. Gegen Licht beiderseits sehr indifferent.

Optische Reflexe: Am 2. Tage schwächer, am 3. und 4. Tage fehlend. Dann fehlend oder schwächer mindestens bis zum 18. Tage.

Nasenlidreflex schwächer bis zum 14. Tage.

Getödtet nach 8 Wochen; inzwischen eine 2. Operation im Hinterlappen.

Section: Häute normal. Die Narbe bedeckt genau das Centrum für Bewegung und Schutz des Auges. Auf dem Durchschnitt zeigt sich eine medial-lateral verlaufende Unterschneidungsspalte, die lateral etwa $3 / 4 \mathrm{~cm}$ unter der Oberfläche endet. Die Rinde über dieser Spalte ist entfärbt.

Tabelle II. ${ }^{1}$ )

\begin{tabular}{|c|c|c|c|c|c|c|}
\hline \multirow{2}{*}{$\begin{array}{c}\text { No. } \\
\text { der } \\
\text { Beob. }\end{array}$} & \multirow{2}{*}{ Art der Operation } & \multirow[t]{2}{*}{ Motilitätsstörungen } & \multicolumn{2}{|c|}{$\begin{array}{l}\text { Sehstörung } \\
\text { gegen }\end{array}$} & \multirow{2}{*}{$\begin{array}{l}\text { Opti- } \\
\text { sche } \\
\text { Reflexe }\end{array}$} & \multirow{2}{*}{$\begin{array}{l}\text { Nasen- } \\
\text { lidre- } \\
\text { flex }\end{array}$} \\
\hline & & & Fleisch & Licht & & \\
\hline 44 & Anätzung & 0 & 0 & 0 & 0 & 0 \\
\hline 45 & $\begin{array}{l}\text { Skarification u. An- } \\
\text { ätzung }\end{array}$ & 0 & 0 & 0 & 0 & 0 \\
\hline 46 & Unterschneidung & 0 & 0 & 0 & 0 & 0 \\
\hline 47 & Unterschneidung & (Lendenmuskeln) & 0 & 0 & 0 & 0 \\
\hline 48 & Unterschneidung & $\begin{array}{l}\text { In der Schwebe: } 2 ; \\
\text { Lidspalte: } 4 \text { Tage }\end{array}$ & 0 & 0 & 0 & \\
\hline 49 & Unterschneidung & Begreifen: $6(1)^{\circ}$ & 0 & - & - & (16) \\
\hline 50 & Unterschneidung & Lidspalte: 4 Tage & 0 & 0 & $(35)$ & (35) \\
\hline 51 & $\begin{array}{l}\text { Unterschneidung der } \\
\text { 2. Seite }\end{array}$ & & & 0 & 0 & 0 \\
\hline 52 & Skarification & $\begin{array}{l}\text { Hängt am 2. Tage } \\
\text { vorn etw. gestreckt }\end{array}$ & 2 & — & $2(1)$ & $2(14)$ \\
\hline 53 & Unterschneidung & $\begin{array}{l}\text { Lidspalte: } 23 \text { Tage; } \\
\text { Defect d. Willens- } \\
\text { energie: } 3 . \text { Tag }\end{array}$ & 33 ? & - & $18 ?$ & (13) \\
\hline
\end{tabular}

1. Sehstörung fehlte in 7 von den 10 mitgetheilten Beobachtungen gänzlich. In der Beob. 52 fand sich am 2. Tage im oberen temporalen Quadranten eine dann verschwindende Abschwächung der Reaction gegen Fleisch; in der Beob. 53 war das Verhalten ein sehr eigenthümliches gewesen. Der Hund sah und erkannte, wie er durch

1) Die in Klammern gesetzten Zahlen bedeuten eine Abschwächung oder oine fernere Abschwächung um die Daner der betreffenden Zahlen in Tagen. Wegen der Bedeutung der Fragezeichen wird auf den Text verwiesen. 
Zuschnappen bewies, das Fleisch auf der nasalen Gesichtsfeldhälfte; auf der temporalen Gesichtsfeldhälfte sah er das Fleisch freilich auch von Anfang an, wie er durch Fixiren bewies, aber er erkannte es offenbar nicht, da er sich nicht bemühte, es zu ergreifen. Dieser Zustand war zwar am 4. Tage verschwunden, aber der Hund bekundete noch bis zum 33. Tage, bis zum Ende der Beobachtung, durch geringere Energie beim Zuschnappen, dass ihm das Bild des Fleisches weniger deutlich erschien. Etwas Aehnliches fand sich in der Beob. 51, aber nur am 2. Tage, an dem der Hund das in einem breiten temporalen Streifen erscheinende Fleisch auch nur fixirte, ohne aber zuzuschnappen. Am folgenden Tage bereits war das Phänomen nicht mehr deutlich zu erkennen.

2. Die optischen Reflexe waren in 6 Fällen überhaupt nicbt und in einem 7 . Falle, bei dem sie beiderseits nur schwach, aber gleichmässig nachweisbar waren, wahrscheinlich nicht alterirt. Sie waren also alterirt in den 3 Fällen der Beobb. 50, 52, 53. In der Beob. 50 gelang es gleich nach der Operation ihre Unversehrtheit nachzuweisen, daun aber waren sie während der ganzen Dauer der Beobachtung 35 Tage lang - abgeschwächt. In der Beob. 52 fehlten sie nur am 2. Tage und waren dann noch 1 Tag abgeschwächt; in der Beob. 53 endlich fehlten sie in einer ganzen Reihe von Tagen gänzlich, waren aber an anderen, dazwischen liegenden Tagen mehr oder minder stark abgeschwächt nachweisbar.

3. Der Nasenlidreflex war in 5 Fällen überhaupt nicht alterirt. In der Beob 48 war er drei Tage lang anscheinend, in der Beob. 49 16 Tage abgeschwächt, während er häufig ganz fehlte. Abgeschwächt war er auch bei den Beobb. 50 und 53 auf die Dauer von 35 bezw. 13 Tagen. In der Beob. 52 endlich fehlte er am 2. Tage vollständig und war dann noch 14 Tage lang abgeschwächt.

4. Motilitätsstörungen. Da in diese Reihe von Beobachtungen nur solche Fälle aufgenommen worden sind, bei denen nennenswerthe Störungen der Motilität and Sensibilität in den Extremitäten fehlten, so ist über diese natürlich nichts zu sagen. Immerhin hingen die Hunde der Beobb. 48 and 52 am 2. Tage etwas gestreckt, während die Hunde 48 und 49 auf Begreifen in der Schwebe, der erste am 2. Tage weniger, der andere bis zum 6. Tage gar nicht, am 7 . Tage schwächer als auf der anderen Seite reagirten. Der Hund der Beob. 53 endlich liess am 3. Tage die contralaterale Vorderextremität unter geringerem Widerstande dislociren, zeigte also das von mir "Defect der Willensenergie" genannte Symptom.

Eine Erweiterung der contralateralen Lidspalte zeigten 
3 von diesen Hunden. Bei den Beobb. 48 und 50 war das Symptom 4 Tage lang und bei der Beob. 5323 Tage lang wahrzunehmen.

Schliesslich ist noch zu erwähnen, dass der Hund der Beob. 47 bei der Operation ein sehr eigenthümliches, meines Wissens bisher nicht beschriebenes Symptom zeigte. Unmittelbar nach dem Einstich rerfielen die Muskeln der Lendenwirbelsäule beiderseits in einen ziemlich lange anhaltenden tonischen Krampf, an dem sich, dem Anscheine nach, andere Muskeln nicht betheiligten. Wahrscheinlich werden bei dem Einstich die betreffenden von vorn nach hinten ziehenden Bahnen verletzt worden sein.

5. Operationen und Sectionen. In jeder Hinsicht von besonderem Interesse ist die Beob. 46. Sie betraf den vordersten Theil der uns beschäftigenden Windungen; die Dura war nicht abgetragen, sondern nur am hinteren Ende der Knochenlücke aufgeschlitzt worden und darauf hatte ich eine sehr ausgiebige Unterschneidung der gesammten vorderen Partieen der basalen Windungen vorgenommen. Der erste durch die Narbe gelegte Querschnitt hatte die Unterschneidung in ihrer grössten Ausdehnung getroffen und zeigte, dass die III. und IV. Urwindung vollständig von der inneren Kapsel abgetrennt waren, und dass die innere Kapsel selbst jedenfalls auch eine schwere Schädigung erlitten hatte. Ich werde auf die klinische Bedeutung des Falles noch zurückkommen; hier möchte ich nur darauf aufmerksam machen, dass dieser Fall die Art und den Umfang der bei analogen Eingriffen gesetzten Zerstörungen deswegen besonders deutlich zeigt, weil der Schnitt gerade die richtige Stelle getroffen hat. Indessen ist der Umfang der Läsion auch in denjenigen Fällen, in denen sie durch den Frontalschnitt nicht in dieser Weise demonstrirt werden konnte, sicherlich nicht geringer ausgefallen. Von dem gleichen Interesse ist die Beob. 47, bei der die Narbe sich annähernd genau an der gleichen Stelle fand, während das Instrument, wie der Frontalschnitt zeigt, in die II. Urwindung eingedrungen war. Hier hatte es fast die ganze Markstrahlung dieser Windung durchtrennt, abgesehen von den Verwüstungen, die es sonst noch bei seiner Vorschiebung nach der Basis zu angerichtet haben muss. Ausserdem fand sich noch ein ziemlich grosser Erweichungsherd im Fusse des Stabkranzes, der ersichtlich die Stammstrahlung aus einem grossen Theile des hinteren Schenkels des Gyrus sigmoides neben einem Theile des von vorn nach hinten ziehenden sagittalen Markes durchtrennt hat. Bei der nächsten Beob. (48) war die gleiche Operation, nur etwas weiter hinten ausgeführt worden. Die Narbenkappe sass in der II. Urwindung an der unteren Grenze meines Orbiculariscentrums und die auf dem abgebildeten Frontalschnitt nur zum Theil sichtbare 
Durchtrennung reichte mit einem ca. $15 \mathrm{~mm}$ langen Stichcanal bis fast an die basale Pia, so dass auf diese Weise das Mark jener Windungen gleichfalls von der Verbindung mit dem anderweitigen Projectionssystem abgetrennt erscheint. Die nun folgende Operation (Beob. 49) hat die II. Urwindung wieder etwas weiter nach binten getroffen, so duss die Narbenkappe noch etwas über die hintere Grenze des von mir sogenannten Centrums für Bewegung und Schutz des Auges hinausreicht. Es war aber nur die vordere Hälfte des aufgedeckten Rindenbezirkes unterminirt worden. Bei der Beob. 50 sitzt die Narbe derselben Windung zwar etwas weiter nach vorn auf; indessen ist der Einstich hier an der hinteren Peripherie der Knochenlücke eingedrungen und hat von da aus so gut wie die ganze Markstrahlung der II. Urwindung vernichtet. Die Beob. 51 wnrde an der anderen Hemisphäre desselben Hundes in einer annähernd gleichen Weise ausgeführt, nur begann der Einschnitt noch etwas weiter nach hinten, so dass die Narbe der Hauptsache nach dem mehrerwähnten Orbiculariscentrum aufsass. Ausserdem fand sich wieder ein grosser Erweichungsherd, der einen Theil der Markstrahlung aus dieser Windung unterbrochen hat an ihrer Basis. Die mächste Beobachtung (Beob. 52) griff abermals einen etwas weiter nach hinten liegenden Theil der II. Urwinduug an, so dass nur der an dem vorderen Theil der Knochenlücke aufgedeckte Rindenbezirk, welcher auf den faradischen Reiz mit Schluss des Auges reagirte, skarifcirt wurde. Die Beob. 53 betrifft etwa die gleiche Region. Die Narbe sass genau dem Orbiculariscentrum auf, betheiligte den hinteren Rand des Gyrus sigmoides vielleicht um etwas. Unterschnitten waren aber nur die vorderen $2 / 3$ dieser Partie, welebe auf den faradiseben Reiz mit Lidschluss reagirten. Der Durchschnitt zeigte nur eine ca, $3 / 4 \mathrm{~cm}$ unter der Oberfäche liegende Unterscineidungsspalte. Am weitesten nach hinten liegen die beiden, an dem gleichen Hunde vorgenommenen Eingriffe der Beobb. 44 und 45 . Bei der ersteren dieser Beobachtungen war der medial und etwas nach hinten von mejnem Orbiculariscentrum liegende Theil der Munk'schen Augenregion, sowie der mediale Theil des Orbiculariscentrums selbst angeätzt worden. Bei der darauffolgenden Operation wurde der Rest dieses Centruons sikarificirt und geätzt (die vordere Narbe auf der Abbildung gehört nur in ihrer hinteren Hälfte zu diesen Operationen, die vordere Hälfte derselben bexieht sich auf zwei andere an dem gleichen Hunde im Gyrus sigmoides vorgenommene Operationen). Die Zerstörung drang in diesem Falle etwa um $1 \mathrm{~cm}$ tief in die Hirnsubstanz ein.

6. Das Verbältniss der Symptome zu dem Ort der VerJetzung. Von den vorliegenden 10 Beobachtungen betreffen die beiden 
letzten die hintere Grenze des vorderen Schenkels der II. Urwindung. Die anderen 8 Beobachtungea habe ich in der Weise angeordnet, dass sie so auf einander folgen, wie sie von vorn nach hinten gerechnet, die einzelnen Theile der II. Urwindung und deren laterale Nachbarwindungen treffen. Hierbei ergiebt sich nun, dass die einzelnen Symptome ibrer Zahl und ihrer Dauer nach im Allgemeinen um so mehr zunehmen, je weiter die Läsion nach hinten vorrückt. In den beiden Beobb. 46 und 47 war das Resultat des Eingriffes gänzlich negativ, obwohl in dem einen Falle die ganze Masse der lateralen Windungen von der inneren Kapsel unter Verletzung derselben abgetrennt war und obwohl sich in dem anderen Falle neben der Abtrennung des grösseren Theiles der Markstrahlung der II. Urwindung ein grosser Erweichungsherd vorfand, der dicht unter der Einstrahlung des Balkens die medialen $2 / 3$ des Fusses des Stabkranzes unterbrach. Nur ein für die Localisation unerhebliches Symptom, die tonische Contraction der Lendenmuskeln bei der Operation 47 wurde in dem letzten jener beiden Fälle beobachtet. Schon bei der nächst höher liegenden Beob. 48, welche die untere Grenze des Orbiculariscentrums nicht überschreitet, beginnen die Symptome mit einer 4 Tage dauernden Erweiterung der Lidspalte und einer annähernd ebenso lange (3 Tage) dauernden Abschwächung des Nasenlidreflexes. In der wieder etwas weiter nach rückwärts localisirten Beob. 49 , bei der die Narbe dem Gyrus sigmoides anlag, markirte sich dieser Umstand durch eine 7 Tage lang dauernde Störung der normalen Reaction auf Begreifen, während das auf die Oertlichkeit zu beziehende Symptom, die Störung des Nasenlidreflexes 16 Tage lang anhielt. Bei der nächstfolgenden Operation (50) stellte sich eine Erweiterung der contralateralen Lidspalte gleichfalls auf die Dauer von 4 Tagen ein, gleichzeitig aber zeigte sich eine 35 Tage dauernde Störung der optischen und des Nasenlidreflexes. Die nächstfolgende, den gleichen Hund betreffende Operation ergab bei annähernd gleicher Localisation der Verletzung und bei einem grossen Erweichungsherde am Fusse der II. Urwindung nur eine unerhebliche 2 Tage dauernde Sehstörung. Ueber die Beeinträchtigung der Reflexe war ein sicheres Urtheil nicht zu gewinnen, weil der Hund aus der 1. symmetrisehen Operation noch mit einer Abschwächung, sowohl des optischen als des Nasenlidreflexes in die 2. Beobachtung eintrat. Bei der Beob. 52 folgte auf eine Skarification des Orbiculariscentrums eine zweitägige Sehstörung mit einer ebenso lange dauernden Aufhebung des optischen Reflexes und des Nasenlidreflexes, eine 14 tägige Abschwächung des Letzteren und (wegen der Nachbarschaft des Gyrus sigmoides) ein schlafferes Herabhängen der contralateralen Vorderextremität am 2. Tage. Am ausgesprochensten 
waren die Erscheinungen bei der Beob. 53, beí der eine Unterschneidung des Orbiculariscentrums vorgenommen worden war. Neben einem unerheblichen "Defect der Willensenergie" zeigte dieser Hund 33 Tage lang die Erscheinungen einer Art von Seelenblindheit; die contralaterale Lidspalte war 23 Tage erweitert, die optischen Reflexe waren 18 Tage lang aufgehoben und der Nasenlidreflex 13 Tage lang abgeschwächt.

Endlich sei nur noch kurz erwähnt, dass die Anätzung bezw. Skarification und Anätzung des am meisten caudal gelegenen Abschnittes der II. Urwindung und der Nachbarregion innerhalb der sogenanuten Fühlsphäre des Auges absolut negativ verlief.

Ich habe die innerhalb dieser Region vorgenommenen Operationen um deswillen in zwei Gruppen geordnet, von denen die eine, soeben betrachtete diejenigen Fälle enthält, welche ohne deutliche Störungen in der Innervation der Extremitäten verliefen und eine zweite, welche Fälle enthält, die mit solchen Störungen verliefen, weil das Eintreten solcher Störungen stets den Verdacht auf eine Mitbetheiligung des Gyrus sigmoides oder seiner Projectionsbahnen erweckt. Für die uns beschäftigenden Fragen ist die soeben analysirte erste jener beiden Gruppen mit ihren negativen Ergebnissen entschieden von grösserer Wichtigkeit.

Ich hatte die Frage aufgeworfen, ob diese Windungen oder der darunter befindliche Markkörper in Beziehungen zu der nach Eingriff in das Frontalhirn auftretenden Beeinträchtigung des Sehactes stünde oder nicht. Wie bereits mehrfach erwähnt, batten - ganz abgesehen von Goltz und Loeb - die Italiener dem vorderen Schenkel der II. Urwindung ganz besonders nahe Beziehungen zum Sehacte zugeschrieben: Diese Auffassung muss nach den Ergebnissen der vorliegenden Untersuchungen mit aller Bestimmtheit abgelehnt werden. Wir haben gesehen, dass in 7 von jenen 10 Fällen auch nicht die Spur einer Sehstörung vorhanden war, so dass nur 3 Fälle mit Sehstörung übrig bleiben. Dies sind diejenigen 3 Fälle, bei denen die Verletzung dem Gyrus sigmoides am nächsten gerückt war und in der That liessen die Hunde der Beobb. 52 und 53 dadurch, dass der eine rechtsseitig einen Tag schlaffer hing, der andere ebenso lange das Symptom des "Defectes der Willensenergie" darbot, erkennen, dass dieser Gyrus nicht ganz unbehelligt geblieben war. Die Sehstörung dauerte denu auch in jenem 1. Falle nur bis zun 2. Tage, also so lange wie das motorische Symptom, in dem anderen Falle dauerte sie allerdings sehr viel länger (33 Tage), indessen war hierbei die Wahrnehmung des Gesichtsobjectes niemals aufgehoben, vielmehr hatte nur seine Identificirung an den Archiv f. Psychiatrie. Bd. 36. Heft 1 . 
beiden ersten Tagen und schliesslich nur die Energie, mit der der Hund auf dasselbe reagirte, gelitten. Ein ähnliches Symptom war bei der Beob. 51, aber nur auf die allerkürzeste Zeit, am 2. Tage zu beobachten gewesen. Unter diesen Umständen zwingt die gesammte Sachlage mit aller Entschiedenheit dazu, die geringfügige in diesen $3 \mathrm{Fäl-}$ len beobachtete Sehstörung nicht auf die direct angegriffenen Areale, sondern auf den Gyrus sigmoides oder auf die Ton diesem ausgehende Markstrahlung zu bezieben, wenn auch eine Schädigung dieser Gebilde nicht nachgewiesen werden konnte.

Bei einzelnen von diesen Versuchen war der Markkegel der ganzen Windung, bei anderen die Gesammtmasse der lateral-basalen Windungen von ihren Verbindungen mit dem Projectionssystem vollkommen abgetrennt, wobei einmal die ganze innere Kapsel eine schwere Schädigung: erlitten hatte und endlich hatte sicb, wenigstens in einem Falle ein grosser Erweichungsherd so im Fusse des Stabkranzes etablirt, dass der grössere Theil der dort passirenden Fasern unterbrochen sein mnsste. Hieraus lässt sich, wenn auch nicht mit absoluter Sicherheit, so doch mit der grössten Wahrscheinlichkeit der Schluss zieben, dass Eingriffe in die ganze nach vorn vom Gyrus sigmoides gelegene Partie des Markköpers ebensowenig direct zum Eintritt von Sehstörungen führen, wie die Verletzung der vorderen Schenkel der II.-IV. Urwindung. Auch das ventral vom vorderen Schenkel des Gyrus sigmoides gelegene Marklager scheint sich ebenso zu verhalten; jedoch will ich hierauf, ebenso wie auf die Frage des Verhaltens der medialen zwei Drittel dieses Schenkels bei dieser Gelegenbeit nicht näher eingehen. --

Die Beziehungen der II.-IV. Urwindung zur Innervation der Extremitäten. Es war mir bekanntlich im Verein mit Fritsch seiner Zeit gelungen durch elektrische Reizung die einzelnen Bewegungen auf ganz circumscripte Stellen der Hirnrinde zu localisiren. Ich hatte damals die Möglichkeit offen gelassen, dass diese Stellen - Centra nur Sammelplätze abgeben für die von weiteren Strecken der grauen Rinde zuströmenden Erregungen. Auch jetzt noch sehe ich nicht, dass diese Auffassung als irrig erwiesen worden wäre. Inzwischen hat ihr aber Bianchil) eine Ausdehnung gegeben, der ich nicht beipflichten kann. Er meint, von einer ausschliesslichen Beziehung bestimmter Punkte dieser Zone zu bestimmten Muskelgruppen lzönne keine Rede sein. Die centralen Elemente für die Innervation eines bestimmten

1) Bianchi, Sulle compensazioni funzionali della corteccia cerebrale. La Psichiatria. 1883. 
motorischen Organs seien vielmehr über die ganze motorische Zone zerstreut und fänden sich nur in wenigen Punkten dichter zusammengelagert, derart, dass sie auf diese Weise die erregbare Zone zusammensetzten. Aber diejenigen Muskeln, welche von hier aus erregt werden können, seien nicht nur hier, sondern auch in dem ganzen Rest der motorischen Zone repräsentirt.

Diese Ansicht stützt sich in der Hauptsache darauf, dass dauernde motorische Störungen nur dann eintreten sollen, wenn grössere, $d . h$. wohl solche Exstirpationen vorgenommen sind, die sich über den Gyrus sigmoides hinaus erstrecken.

Es war ursprünglich meine Absicht, diese Theorie von Bianchi zum Gegenstaud einer besonderen Arbeit zu machen und diese der vorliegenden Arbeit, deren eigentlicher Fragestellung sie fern liegt, nicht einzuverleiben. Auf diesem Wege wäre ich aber zu einer Reproduction der hier mitgetheilten Beobachtungen und auch sonst zu zahllosen Wiederholungen gekommen, sodass ich mich nachträglich entschlossen habe, den fraglichen Streitpunkt, soweit das uns jetzt interessirende Gebiet überhaupt in Betracht kommt, gleichzeitig mit den anderen dessen Function betreffenden Fragen, immerhin innerbalb der mir durch meine Versuche gezogenen Grenzen, mit wenigen Worten zu erledigen.

Ich möchte zunächst auf einige, der experimentellen Lösung der aufgeworfenen Frage entgegenstehende Schwierigkeiten aufmerksam machen. Nach meiner Ueberzeugung gehört der ganze hintere Schenkel und das laterale Drittel des vorderen Schenkels des Gyrus sigmoides mit Einschluss des in den Tiefen seiner Windungen liegenden Rindengraues, seine caudale Nachbarschaft und die vorderen Schenkel der II.-IV. Urwindung zur motorischen Zone. Eine richtige Vorstellung von den Folgen der vollständigen Exstirpation der für die Extremitäten bestimmten Centren, von denen hier allein die Rede sein soll, kann man nur dann gewinnen, wenn man das gesammte motorische Areal der I. Urwindung bis auf den Grand seiner Furchen ausschaltet. Operirt man aber in dieser Weise, so geht regelmässig ein grösserer oder geringerer Theil der Nachbarwindungen durch Erweichung zu Grunde. Ebenso ist eine partielle Zerstörung des wichtigsten Theiles des Gyrus sigmoides, seines lateralen Bogens allemal dann unvermeidlich, wenn man seine Nachbarwindungen bis auf ihren Grund ausrottet. Das Resultat ist also in beiden Fällen das gleiche: der Versuch ist unrein, man kann au, diese Weise die zu allererst zu beantwortende Frage nicht entscheidenf welche Theile der motorischen Zone bei dem unversehrten Hunde zur Innervation der Extremitäten beitragen. 
Die Frage schien mir deshalb so gestellt werden zu müssen: kann man durch hinlänglich vorsichtige Eingriffe in die Nachbarschaft des Gyrus sigmoides die bekannten Störungen in den Extremitäten hervor"bringen?' Als solehe Eingriffe konnten mir uur solche Operationen gelten, wie ich sie in den vorstehenden Beobachtungen gesclildert habe, Unterschneidungen der Rinde oder Durchschneidungen der Markstrahlung einer Windung, mehr oder weniger nahe ihrem Fusse, ausserdem die auf einige Fälle beschränkte Zerstörung der Rinde durch directe Abtragung ihrer oberflächlichsten Schichten oder durch Skarifizirung oder durch Anätzung mit 5 proc. Carbolsäure. Auf diese Weise wurde die Gefahr, Nachbarschaftssymptome hervorzubringen, erheblich vermindert, während doch unfehlbar motorische Erscheinungen in den Extremitäten hätten auftreten müssen, wenn diese in der Norm motorische Impulse von der fraglichen Windung bezogen.

Wir haben im Vorstehenden gesehen, dass die mitgetheilte Reihe von Versuchen, obwohl sie sämmitlich die motorische Region und zwar zum Theil in recht grosser Ausdehnung betrafen, der Hauptsache nach absolut negativ verliefen; uur in 3 Fällen waren unerhebliche und ganz vorübergehende Innervationsstörungen der contralateralen Vorderextremität, welche auf unerhebliche Traumen des Gyrus sigmoides zu beziehen waren, zur Beobachtung gekommen. In einer zweiten nachstehend folgenden Versuchsreihe waren solche Innervationsstörungen allerdings in mehr weniger ausgesprochener und anhaltender Form in die Erscheinung getreten. Da aber bei dieser Art von Versuchen nur diejenigen Beobachtungen entscheidend sind, welche mit der geringsten Summe von Störungen verlaufen, so ist die gestellte Frage hiermit, soweit es durch solche Versuche überhaupt möglich ist, entschieden. Mit anderen Worten, die lateral und basal von dem Gyrus sigmoides gelegenen Partieen der motorischen Zone bis in die Gegend der Spitze der Fossa Sylvii besitzen keinen directen Einfluss auf die motorische Innervation der Extremitäten.

Man könnte gegen die Beweiskraft dieser Versuche einwenden, dass bei einer Anzahl von ihnen die Rinde oder die von ihr ausgehenden Projectionsbahnen nur zum Theil zerstört worden seien, so dass der zurückgebliebene Rest ausgereicht hätte, um die Aufgaben der Function zu decken. Dieser Einwand würde berechtigt sein, wenn es sich bei diesen Versuchen um eine Frage der Restitution, nicht aber um die der Frkenuung eines primären Ausfalles der Functionen handeite. Ein solcher wäre aber nach der Analogie des Verhaltens aller anderen uns bekannten Rindenterritorien in Folge der hier vorgenommenen Fingriffe unvermeidlich gewesen und er bätte mit den uns geläufigen Methoden, 
insbesondere auch durch die Untersuchung der schwebenden Hunde unter allen Umständen erkannt werden müssen.

Allerdings kann die Frage, ob die bei diesen Versuchen theils zerstörten, theils von ihren Projectionsfasern abgetrennten Rindengebiete nach vorangegangener Zerstörung des Gyrus sigmoides nicht dennoch einen Einfluss auf die Innervation der Extremitäten gewinnen können, auf die angegebene Weise nicht entschieden werden. Indessen vermag jch mir die Art, wie dieser Einfluss wirksam werden könnte, anatomisch nur schwer vorzustellen. Durch den zerstörten Gyrus sigmoides könnte der Innervationsweg doch nicht gehen, gegen die Beschreitung eines directen Weges zwischen jenen Windungen und den spinalen Centren für die Extremitäten sprechen nicht nur die soeben angeführten Versuche, sondern auch die elektrischen Reizversuche und die Erfahrungen über die secundäre Degeneration; es bliebe nur der Weg durch die Haubenbahn übrig. Wie es sich damit verhält, lasse ich unentschieden. -

Die Besprechung eines Theiles der anderweitigen, nach Verletzung dieser Region eintretenden Symptome behalte ich mir für die alsbald folgende Serie von Untersuchungen vor.

\section{B. Versuche mit motorischen Folgen.}

Wir haben gesehen, dass die directe Verletzung des Gyrus sigmoides in der Regel zu Sehstörungen führt. Es versteht sich daher von selbst, dass kein Theil dieses Gyrus bei den in seiner Nachbarschaft vorgenommenen Operationen mit aufgedeckt werden darf; namentlich gilt dies von seinem lateralen Bogen, dessen Beleidigung allem Anscheine nach besonders häufig Sehstörungen im Gefolge hat. Einen sprechenden Beweis hierfür liefert die folgende Beobachtung.

\section{Beobachtung 54.}

Junger Hund. Aufdeckung im vorderen Winkel des linken Planum semicirculare auf $17 \mathrm{~mm}$ sagittal, $13 \mathrm{~mm}$ frontal. Medial liegt der laterale Bogen des Gyrus sigmoides und caudalwärts mindestens die vordere Hälfte des Orbiculariscentrums frei. Reizung mit dem gewöhnlichen Zuckungsminimum ergiebt faradisch und galvanisch Zuckungen in der Vorderpfote, Orbicularis palpebrarum, Nasen- und Schnauzenmuskeln. Exstirpation ca. $3 \mathrm{~mm}$ tief mit Schonung der Venen und der Nachbarschaft des Gyrus sigmoides. Die Hirnwunde bleibt ettra $2 \mathrm{~mm}$ vom Sulcus coronarius entfernt. Ausspülung mit 5 proc. Carbolsäure.

Motilitätsstörungen: Hochgradig in beiden Extremitäten; erst sehr langsam abnehmend, zunächst hinten; vier Monate nach der Operation nooh Spuren.

Sehstörung: Bis zum 10. Tage complett, dann abnehmend, verschwunden am 17. Tage. 
Optische Reflexe: Fehlen 4 Monate gegen flache Hand, noch nach 5 Monaten abgeschwächt.

Nasenlidreflex: Fehlt gänzlich bis zum 11. Tage, nach 4 Monaten noch abgeschwächt.

Gestorben nach 7 Monaten.

Section: $\mathrm{Da}$ inzwischen eine 2. Operation im Gyrus sigmoides gemacht worden war, bleibt nur zu bemerken, dass bei der 1. Operation eine genaue Zeichnung der aufgedeckten, sowie der exstirpirten Partieen gemacht worden war, mit der die Section in diesem Theile übereinstimmte. Die narbige Auflagerung nahm den ganzen vorderen Schenkel der II. Urwindung ein.

Wir sehen also, dass in diesem Falle, obschon der aufgedeckte laterale Rand des Gyrus sigmoides bei der Exstirpation selbst auf das Sorgfältigste geschont worden war, dennoch hochgradige und langanhaltende Motilitätsstörungen zu beobachten waren, und dass ausserdem, neben den auf die Verletzung der II. Urwindung zu beziehenden Symptomen, noch eine sehr ausgesprochene, 10 Tage lang sogar complette und im Ganzen 16 Tage nachweisbare Sehstörung eintrat.

\section{Beobachtung: 55.}

Aufdeckung auf Planum semicirculare links anf $14 \mathrm{~mm}$ sagittal und $15 \mathrm{~mm}$ frontal. Vorderer Rand der Lücke $15 \mathrm{~mm}$ von der Spitze des Planum entfernt. Bei faradischer Reizung R. A. $12,5 \mathrm{~cm}$ in der vorderen Hälfte der freigelegten Stelle contrahirt sich der contralaterale Orbicularis palpebrarum. (Leichte Stichverletzung mit Spitze des Zirkels am unteren Wundrand.) Aetzung der ganzen freigelegten Partie mit 5 proc. Carbolsäure.

Motilitätsstörungen: In der rechten Vorderpfote gering, am 4. Tage bereits verschwunden.

Sensibilitätsstörungen: In den Extremitäten ebenfalls gering, am 7. Tage bereits beim Begreifen keine Differenz mehr. Schmerzempfindung in der Nase abgeschwächt bis zum 11. Tage.

Sehstörung fehlt.

Optische Reflexe nicht beeinträchtigt.

Nasenlidreflex abgeschwächt bis zum 12. Tage.

Nach 10 Wochen todtgebissen.

Section in meiner Abwesenheit ausgeführt, unzuverlässig.

\section{Beobachtuno 56.}

Derselbe Hund von Beob. 46. Abtragung des Knochens ganz vorn und lateral bis zur Spitze des rechten Planum semicirculare aut $20 \mathrm{~mm}$ sagittal, $10 \mathrm{~mm}$ frontal, dabei Durchschneidung des Facialis. Dura am hinteren Rande der Lücke aufgeschlitzt. Es wird mit dem Präparatenheber eingestochen, die Schneide wird einmal basal- und lateralwärts bis auf den Knochen geführt; dann ein 2. Mal in der Richtung der Knochenlücke in der ganzen Länge der Schneide nach vorn. 
Motilitätsstörungen: In den Extremitäten vom 2. Tage an ziemlich hochgradig bis zum 4. Tage, dann nur noch vorn und allmählich abnehmend, am 27. Tage nur noch angedentet. Katzenbuckel und Unmöglichkeit die Lendenwirbelsänle zu drehen vom 2. Tage an; am 27. Tage noch angedeutet.

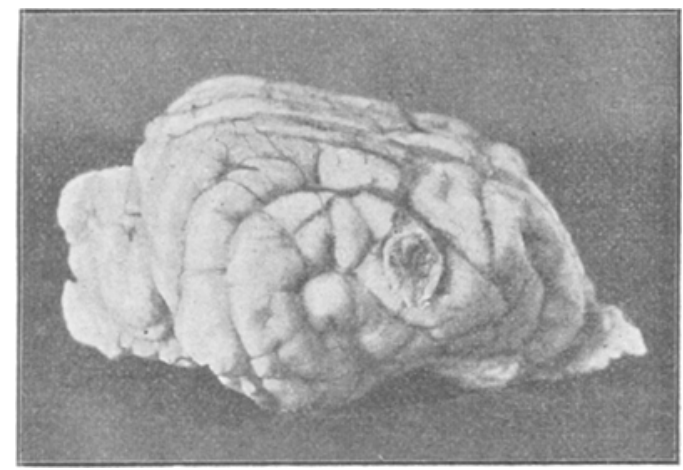

Fig. 72.

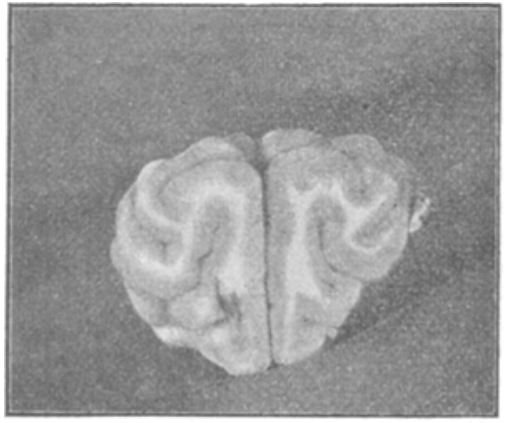

Fig. 73 .

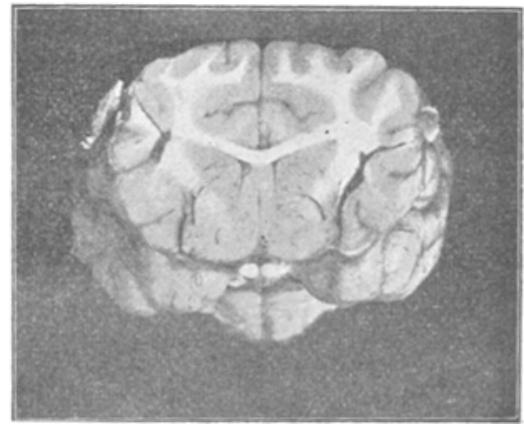

Fig. 74.

In der Schwebe: Hängt links dauernd gestreckt, beim Begreifen keine Reaction.

Sehstörung: fehlt.

Optische Reflexe: Fehlen zunächst wegen doppelter Facialislähmung gänzlich, am 16. Tage wieder schwach vorhanden. Ebeuso Nasenlidreflex.

Gestorben nach ca. 7 Wochen.

Section: Häute normal. An der Operationsstelle eine scharf umschriebene, narbige Verwachsung. Diese befindet sich auf der II. Urwindung nnmittelbar vor dem Centrum für den Orbicularis, den Sulcus coronalis nicht erreichend. 1. Durchschnitt (etwa $4 \mathrm{~mm}$ vor dem Einstich): $7 \mathrm{~mm}$ von der 
der Pia aufsitzenden Narbe sieht man einen parallel zur Oberfläche liegenden, durch Erweichung auf $4 \mathrm{~mm}$ erweiterten Spalt, welcher einen grossen Theil der inneren Kapsel von dem Fusse des Stabkranzes abgetrennt hat, nur die innere Partie ist erhalten geblieben. Von diesem Spalt zieht nach oben und lateralwärts bis zum oberen Rande der Narbe ein sehr feiner, scharfer Spalt gerade an der Grenze von Weiss und Grau der betreffenden Windung. 2. Durchschnitt ( $8 \mathrm{~mm}$ weiter nach vorn): Der Unterschneidungsspalt liegt hier viel weiter basalwärts, er ist v.on unregelmässigen Erweichungen umgeben und hat hier die weisse Substanz so gut wie rollständig zerstört.

\section{Beobachtung $5 \%$}

Derselbe Hund von Beob. 62. Aufdeckung rechts ganz vorn auf Planum semieirculare auf $20 \mathrm{~mm}$ sagittal und $13 \mathrm{~mm}$ frontal. Abtragung der Dura im hinteren Drittel der freigelegten Lücke auf $3: 7 \mathrm{~mm}$. Einstich mit Präpara-

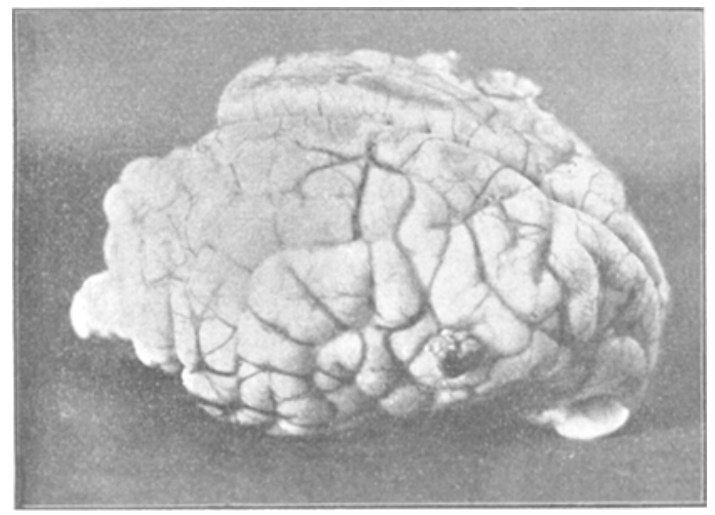

Fig. 75 .

tenheber in Längsrichtung der Lücke einmal nach hinten bis zum hinteren Rande der Knochenlücke, dann nach vorn in der ganzen Länge der Schneide. Umkippen derselben, so dass die Verbindungen mit der Rinde möglichst durchtrennt werden.

Motilitätsstörungen: Am 2. Tage mässig, bängt aber nicht gestreckt, am 3. Tage nur noch ganz gering, am 4. Tage selbst geringer als rechts, am 7. Tage nur noch spurweise, später nicht mehr nachzuweisen.

Sehstörung: Gegen Fleisch: Am 2. Tage nicht deutlich nachweisbar, später fehlend. Gegen Licht fehlend.

Optische Reflexe: Vom 2.-15. Tage fehlend, dann gegen flache Hand angedeutet, gegen schmale Hand fehlend bis zum Schluss der Beobachtung, 39. Tag.

Nasenlidreflex ungestört. 
Gestorben nach ca. 6 Wochen.

Section: Die etwa $5 \mathrm{~mm}$ grosse runde Narbe sitzt an der Grenze der II. und III. Urwindung, etwa entsprechend dem hinteren Rande des Gyrus sigmoides. 1. Durchschnitt (3-4 $\mathrm{mm}$ hinter der Narbe): $4 \mathrm{~mm}$ medial von der Oberfläche findet sich hier im Markweiss derIII. Urwindung eine klaffende kleine

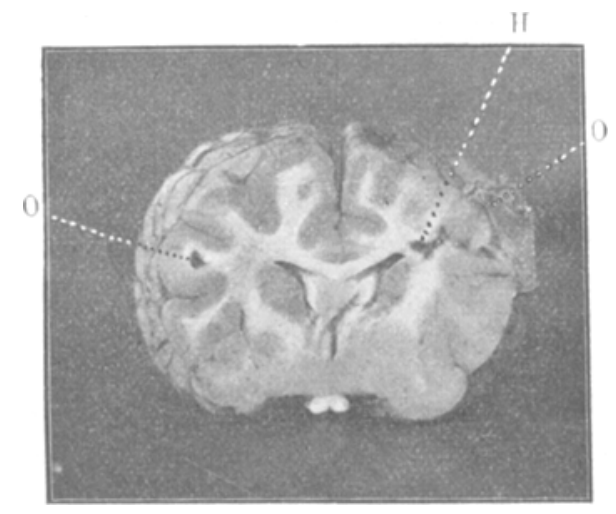

Fig. 76 .

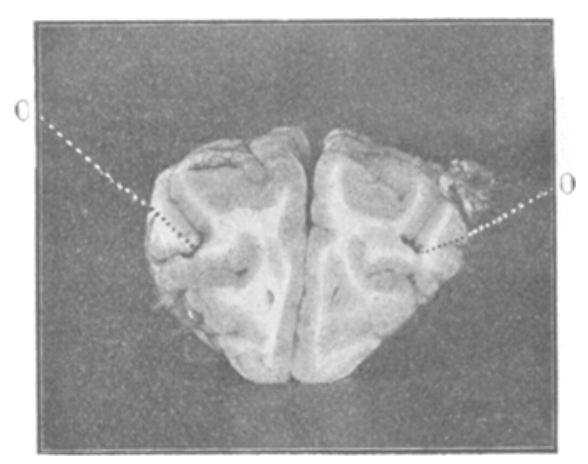

Fig. 77.

0: Operationsstelle; H: Erweichungsherde.

Spatte mit glatten scharfen Rändern (d. i. nach hinten gerichtete Unterschneis dung). II. Durchschnitt (12 mm weiter nach vorn, genau durch den Sulcucruciatus): Die keine Erweichung. zeigende Unterschneidungsspalte hat hier den vordersten Theil der II. Urwindung von seiner medialen Verbindung fast ganz getrennt, indem die Spalte Rindengrau und Markweiss quer durchschneidet. 


\section{Beobachtung 58 .}

Derselbe Hund von Beob. 49. Aufdeckung auf rechtem Planum semicirculare ganz vorn auf $24 \mathrm{~mm}$ sagittal, $11 \mathrm{~mm}$ frontal, vorn 4 , hinten $8 \mathrm{~mm}$ von der Linea semicircularis entfernt. Aufschlitzung der Dura im Bereiche der Knochenlücke. Eingehen mit Daviel'schem Löffel, subcorticale Unterschneidung ganz flach nach vorn. Durchschneidung des Facialis.

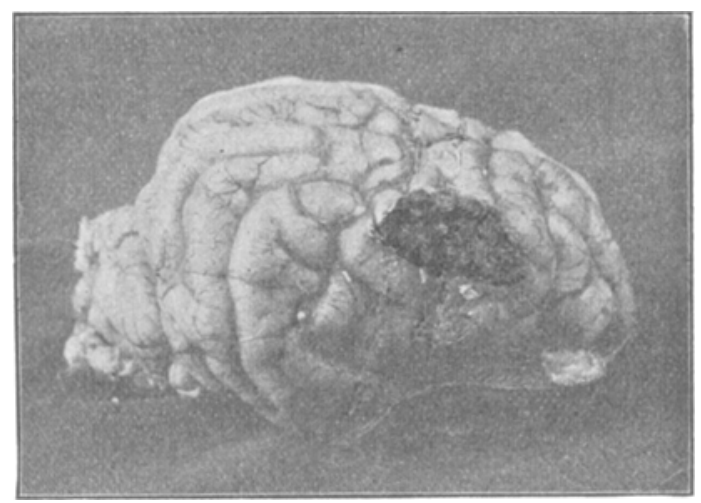

Fir. 78.

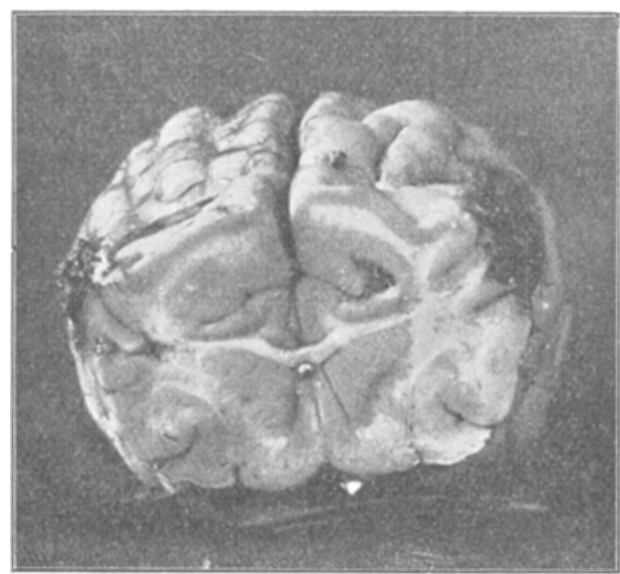

Fig. 79.

Motilitätsstörungen: In den ersten Tagen ziemlich hochgradig, am 6. Tage nur noch wenig, aber nach 4 Wochen noch angedeutet. 
Sehstörung: Gegen Fleisch: Ap_2. Tage unsicher, am 3. Tage sicher fehlend. Gegen Licht: Am 2. Tage deutich, am 3. Tage gering, am 4. Tage fehlend.

Optische Reflexe: Anfänglich nicht notirt, vom 6. Tage an gegen flache Hand deutlich vorhanden, gegen schmale Hand schwach; wegen der rechtsseitigen Facialislähmung Vergleich unmöglich.

Nasenlidreflex: Yorhanden, aber schwach, Vergleich wegen der rechtsseitigen Facialislähmung unmöglich.

Getödtet nach ca. 4 Monaten.

Section: Häute normal. Die $20 \mathrm{~mm}$ lange und $10 \mathrm{~mm}$ breite Narbe reicht medial bis an den Gyrus sigmoides, erstreckt sich nach vorn etwa bis zur lateralen Verlängerung des Sulous cruciatus, nach hinten etwa bis zum hinteren Ende des Centrums für den Orbicularis palpebrarum. Durchschnitt an gleicher Stelle wie links: Die Rinde unter der Narbe ist theilweise zerstört, theilweise abgeblasst, auch das den einschneidenden Sulcus umgebende Rindengrau ganz leicht. Von der Narbe erstreckt sich ein Erweichungsherd medialwärts bis etwa $2 \mathrm{~mm}$ vom oberen lateralen Winkel des Nocleus caudatus, so dass er den lateralen Theil der Stammstrahlung aus dem hinteren Schenkel des Gyrus sigmoides unterbricht, während die Balkenstrahlung intact erscheint.

\section{Beobachtunar $\mathbf{5 0}$.}

Aufdeckung auf dem linken Planum semicirculare ganz vorn lateral, so dass vorderer Rand der Lücke durch Linea semicircularis gebildet wird, auf $18 \mathrm{~mm}$ sagittal, $11 \mathrm{~mm}$ frontal. Abtragung der Dura nur im hinteren lateralen Theil. Unterschneidung und Unterminirung der Rinde nach unten lateral bis auf den Knochen. Dann nach vorn lateral mehr als 2,5 cm lang. Abtragung des vorliegenden Rindenstücks.

Motilitätsstörungen: Voltelaufen gleich nach der Operation, am 2. Tage nicht mehr; dreht aber meist nach links. In den Extremitäten hochgradig; am 2. Tage Wirbelsäule beim Stehen so nach rechts um die Längsachse gedreht, dass das rechte.Hinterbein so stark nach links gestellt wird, dass der Hund oft mit dem Hintertheil nach rechts umikippt; macht besonders mit den Hinterbeinen eigenthümliche, wie atactisch aussehende, ausfahrende Bewegungen beim Laufen; auch beim Liegen sind die Beine selten ruhig, besonders mit beiden Hinterbeinen macht er kurze schnelle Bewegungen. Am 3. Tage in der Schwebe Biegung der Wirbelsäule mit der Convexität nach links, so dass die stark gestreckten rechten Extremitäten sich in der Gegend des Hinterbeins berühren. 5. Tag: Etwas Abnahme der Motilitätsstörungen, schwankt mit den Hintertheilen nicht mehr so stark hin und her, Krümmung der Wirbelsäule beim Hängen nicht mehr so hochgradig. Unverändert bis zum 10. Tage.

Zunge leckt unmittelbar nach derOperation dauernd nach rechts, manchmal auch gerade, nie nach links.

Sehstörung: Gegen Fleisch: Am 2. Tage absolut, am 3. Tage in der Abnahme, am 4. Tage etwa ein Drittel, am 5. Tage in temporalem Streifen, 
am 6. Tage verschwunden. Gegen Licht indifferent. Stösst am 2. Tage mit dem Kopfe an.

Optische Reflexe: Gleich nach der Operation rechts fehlend, links deutlich, ebenso am 2. Tage; am 3. Tage auch rechts bereits deutlich vorhanden, aber schwächer als links; ebenso bis zum Schluss der Beobachtung.

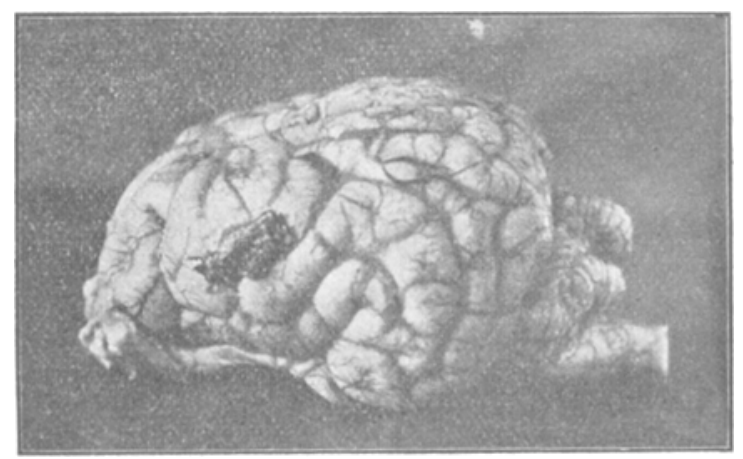

Fig. 80 .

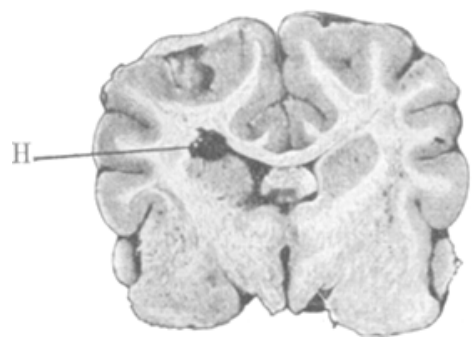

Fig, 81 .

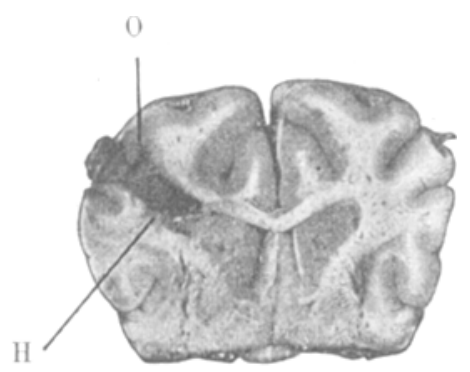

Fig. 82.

Nasenlidreflex: Gleich nach der Operation beiderseits deutlich, am 2. Tage abgeschwächt, weniger beim Beklopfen, als beim Bestreichen; am 5. Tage rechts nur noch wenig schwächer, am 6 . Tage beiderseits gleich.

Plötzlich gestorben am 17. Tage.

Section: Häute normal. Die $14 \mathrm{~mm}$ lange und $6 \mathrm{~mm}$ breite Narbe fängt etwa am vorderen Rande des Centrums für Bewegung und Schntz des Auges an und erstreckt sich in dieser Windung nach vorn, ohne medial auf den lateralen Rand des Gyrus sigmoides ïberzugreifen. Keine Erweichungen oder deutliche narbige Verziehungen im Umkreise. 1. Durchschnitt $(2 \mathrm{~mm}$ hinter dem hinteren Rande der Narbe, ungefähr durch das Orbiculariscentrum): In der lateralsten Ecke des linken Seitenventrikels sitzt ein blntig durchsetzter 
apoplectischer Herd, von dem aus Blut in den Seitenventrikel geflossen ist. (Das Coagulum hängt hier fest.) 2. Durchschnitt (mitten durch die Narbe): Auf der narbig veränderten Rinde sitzt die Narbenkappe auf, $1-1 \frac{1}{1} / 2 \mathrm{~cm}$ tief; gerade an der Grenze von Rinde und Markweiss findet sich der Stichcanal parallel zur Oberfläche; er lässt sich aber nicht scharf umschrieben erkennen, da sich von dort medial in das Markweiss ein $9 \mathrm{~mm}$ langer und an der Basis $4 \mathrm{~mm}$ breiter, dreieckig blutig durchsetzter Erweichungsherd zieht, dessen Spitze an die seitliche und oberste Begrenzung des Seitenventrikels stösst. 3. Durchschnitt (am vorderen Rande der Narbe): Hier sieht man die beiden, etwas verschieden gerichteten Schnitte getrennt. Der basale stösst hier an die Pia, ohne sie zu durchtrennen; der nach vorn gerichtete verläuft hier scharf umschrieben, ohne angrenzende Erweichungen, stumpfwinklig dazu gerade an der Grenze von grauer und weisser Substanz liegend. Diese ist hier abgeblasst. (Vergl. Beob. 5.)

\section{Beobachtung 60 .}

Aufdeckung $17 \mathrm{~mm}$ hinter Spitze des linken Planum semicirculare, schrägsagittal $27 \mathrm{~mm}$, frontal $11 \mathrm{~mm}$. Faradischer Augenschluss nur am und unter dem vorderen Rande der Lücke. Unterschneidung von der Mitte der Lücke an nach vorn, einschliesslich der. reagirenden Theile.

Motilitätsstörungen: An den Extremitäten 5 Stunden nach der Operation und am. 2. Tage nicht zu ermitteln; hängt abor rechts etwas gestreckt. Am 3. Tage geringe Motilitätsstörung vorn, vom 4.-11. Tage ziemlich hochgradig, dann abnehmend. (Sensibilitätsstörung entsprechend.)

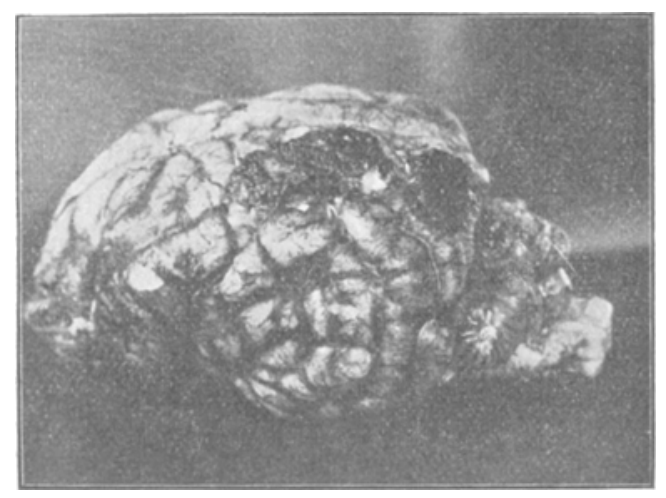

Fig. 83 .

Facialis: 5 Stunden nach der Operation rechtes Auge deutlich weiter; beim passiven Oeftnen des Anges links erheblicher, rechts fehlender Widerstand. In der Folge sind diese Anomalieen nicht mehr nachweisbar. 
Sehstörung: Gegen Fleisch: In den ersten 3 Tagen nicht zu prüfen, am 4. und 5. Tage hochgradig. Reaction aber auch links nur schwach. Am 6. Tage nicht mehr nachweisbar. Gegen Licht: Am 2.-5. Tage nachweisbar, am 6. Tage gleichgültig, am 11. verschwunden.

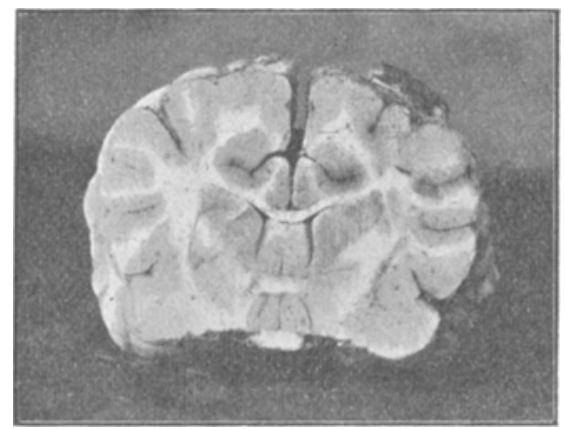

Fig. 84 .

Optische Reflexe: 5 Stunden nach der Operation gegen flache Hand rechts schwächer, gegen schmale Hand fehlend, links deutlich; rom 2.-5. Tage fehlend. Vom 5. T'age an sehr allmählich wiederkehrend, am 27. Tage kein Unterschied mehr.

Cornealreflex: 5 Stunden nach der Operation rechts fehlend, am 3. Tage vorhanden.

Ciliarreflex ohne Anomalieen.

Nasenlidreflex: 5 Stunden nach der Operation bis zum 5. Tage fehlend oder abgeschwächt, dann wieder vorhanden.

Gestorben nach ca. 8 Monaten; inzwischen eine 2. Operation im Hinterlappen.

Section: Hänte normal, nur an der Operationsstelle Verwachsung. Die $2 \mathrm{~cm}$ lange und $1 \mathrm{~cm}$ breite Narbe ist $7 \mathrm{~mm}$ von der Medianspalte des Gehirns entfernt. Medialer Rand der Narbe der Medianspalte parallel, vorderer Rand am Orbiculariscentrum, hinterer Rand bis fast an die Munk'sche Stelle $A_{1}$ heranreichend; lateraler Rand parallel dem medialen. 1. Durchschnitt (durch die Mitte der Narbe) zeigt eine leichte Abblassung des Rindengraues unter dem Narbengewebe. 2. Durchschnitt (etwa $3 \mathrm{~mm}$ vor dem vorderen Rand der Narbe) zeigt $6 \mathrm{~mm}$ unter der Oberfläche in das Markweiss fallend eine feine, fast völlig verklebte Spalte unter der II. Urwindung; das Grau derselben ist abgeblasst, setzt sich kaum gegen das Weiss ab. 3. Durchschnitt ( $1 \mathrm{~cm}$ weiter nach vorn): Hier ist kein Operationsresiduum mehr aufzufinden.

\section{Beobachtung 61 .}

Aufdeckung dicht hinter Spitze des Planum semicirculare links, 4-5mm lateral von Linea semicireularis auf $22 \mathrm{~mm}$ sagittal, $14 \mathrm{~mm}$ frontal. Bei elek- 
trischem Reizversuch Schreien des Thieres, Vordrängung des Hirns, Einreissen mehrerer Gefässe. Unterminirung der vorderen drei Viertel der freigelegten Stelle.

Motilitätsstörungen: Bald nach der Operation anscheinend nicht vorhanden. Vom 2. Tage an hochgradig, nach 7 Wochen noch deutlich.

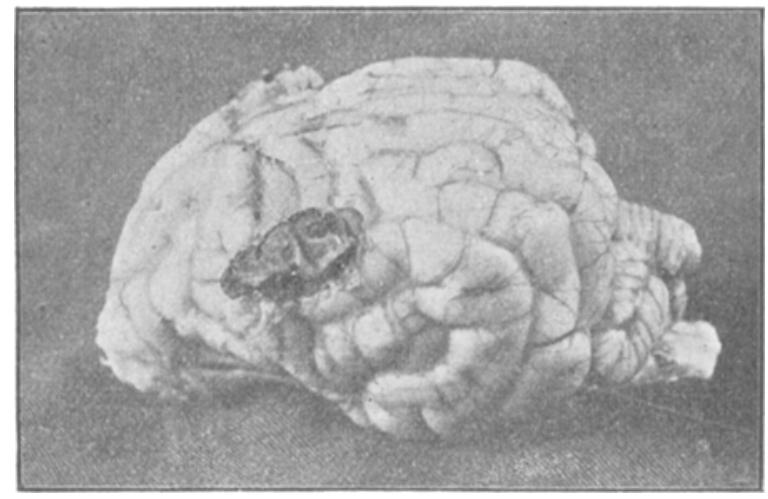

Fig. 85.

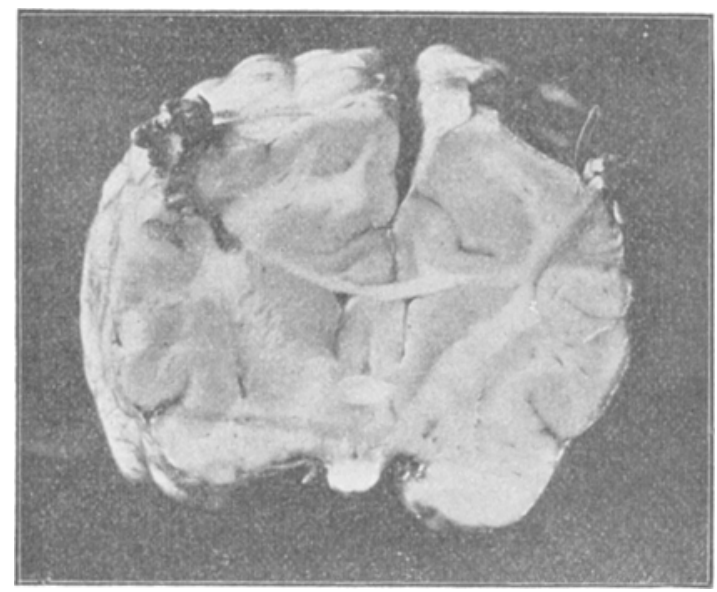

Fig. 86 .

Sehstörung: Gegen Fleisch: Frisst in der Schwebe und auf dem Tisch nicht, daher sonst nicht zu untersuchen, fixirt aber am 2. Tage schon ganz aussen. Gegen Licht: Am 2. Tage beiderseits indifferent; vom 3.-7. Tage rechts ohne Reaction, dann beiderseits gleich. 
Optische Reflexe: Fehlen bis zum 22. Tage, dann langsam wiederkehrend, nach ca. 7 Wochen noch abgeschwächt.

Nasenlidreflex: Am 1. Tage abgeschwächt, dann fehlend, am 17. Tage normal.

Lidspalte in den ersten Tagen weiter.

Nasenloch: Gegen Kitzeln in den ersten beiden Tagen ohne Reaction.

Getödtet nach 51/2 Monaten; inzwischen eine 2. symmetrische Operation.

Section: Häute normal. Die etwa $18 \mathrm{~mm}$ lange, im Mittel $10 \mathrm{~mm}$ breite Narbe liegt lateral vom Gyrus sigmoides, noch ein wenig auf den lateralen Rand desselben übergreifend, erstreckt sich nach hinten etwa bis ans Ende des Centrums für Bewegung und Schutz des Auges, nach vorn bis etwas über die laterale Verlängerung des Sulcus cruciatus hinaus. Durchschnitt (etwa durch die Mitte des hinteren Sohenkels des Gyrus,sigmoides): Von dem oberen Rand der Narbe erstreckt sich ein röthlich verfärbter Erweichungsstreifen durch das etwas abgeblasste Grau bis ins Markweiss; vom unteren Ende der Narbe ebenfalls ein derartiger Streifen. Zwischen beiden ist die Rinde des dort einschneidenden Sulcus weisslich verfärbt und narbig verändert. Die beiden Erweichungsstreifen treffen im Markweiss unter diesem einschneidenden Sulcus zusammen. Von dort aus geht ein feiner Streifen basalwärts nach der inneren Kapsel zu, ohne aber den Fuss des Stabliranzes zu durchtrennen.

\section{Beobachtung $6:$}

Aufdeckung auf Planum semicirculare links ganz vorn auf $26 \mathrm{~mm}$ sagittal, $19 \mathrm{~mm}$ frontal (in der Mitte etwa, an der breitesten frontalen Erweiterung gemessen), dabei Verletzung eines stärkeren Gefässes der Pia. Faradischer Reizeffect im Orbicularis palpebrarum, nur am hinteren medialen Knochenrand bei $60 \mathrm{~mm} \mathrm{R.} \mathrm{A.} \mathrm{Ausgedehnte} \mathrm{Unterschneidung} \mathrm{der} \mathrm{freigelegten} \mathrm{Rindenpartie}$ ziemlich tief vom hinteren Ende der Knochenlücke aus.

Motilitätsstörungen: Am 2. Tage hochgradig, nur sehr allmäblich abnehmend. Am Schluss der Beobachtung, nach mehr als 6 Wochen noch nachweisbar.

In der Schwebe: Hängt noch nach mehr als 2 Monaten gestreckt.

Sehstörung: Gegen Fleisch: Am2. Tage bis auf den Nasenrücken, am 7. Tage stark in der Abnahme, am 9. Tage nicht mehr nachweisbar. Gegen Licht: Anfangs beiderseits indifferent, am 4. Tage nur rechts indifferent, am 7. Tage normal.

Optische Reflexe: Vom 2. Tage bis zum Schluss der Beobachtung (über 6 Wochen) fehlend.

Nasenlidreflex: Am 2. Tage vorhanden (?), am 4.-15. Tage fehlend, abgeschwächt bis zum 26. Tage, am Schluss der Beobachtung normal.

Ciliarreflex: Am 2. Tage deutlich, am4. Tage noch wenig schwächer.

Conjunctival- und Cornealreflex: Am 2. Tage rechts viel schwächer, anı 4. Tage nur noch wenig sohwächer; so noch am 15. Tage. 
Nasenloch: Indifferent gegen Kitzeln am 2. Tage, allmählich abnehmeni, immer noch deutlich am 10 . Tage.

Anästhesie gegen Stiche und Kneifen an Lippe und Haut der Nase und Wange bis zum Lid bis zum 4. Tage, am 7. Tage normal.

Gestorben nach 3 Monaten; inzwischen eine 2. Operation der anderen Seite.

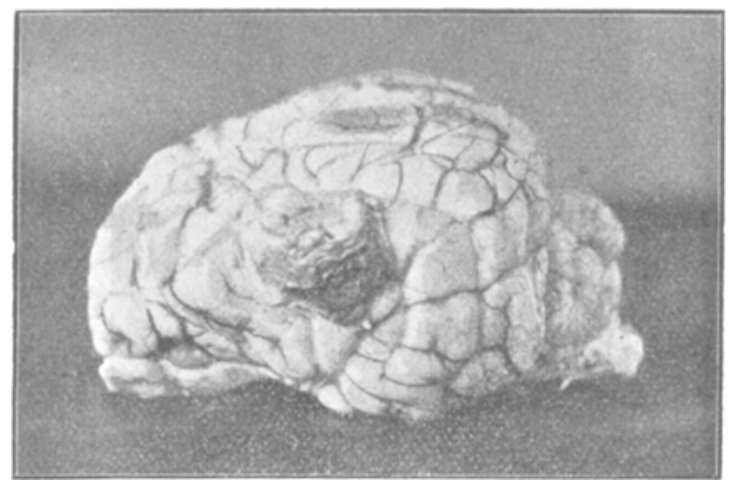

Fig. 87.

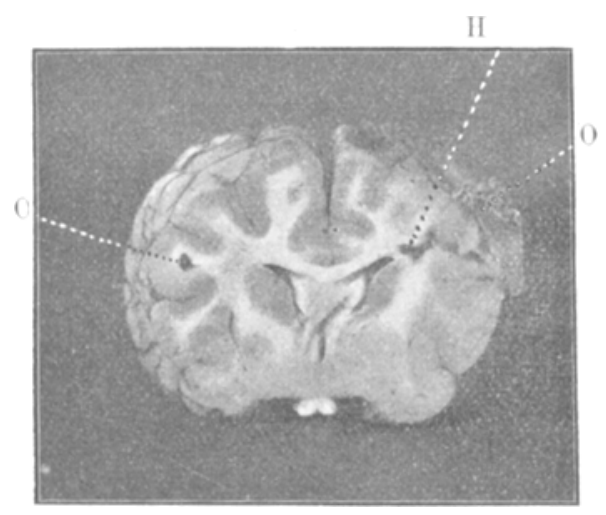

Fig. 88.

0: Operationsstelle; H: Erweichungsherde.

Section: Die etwa dreieckige Narbe (20:20:17) reicht mit ihrer vorderen Spitze ungefähr bis zur hinteren lateralen Ecke des Gyrus sigmoides, ohne auf denselben überzugreifen, und erstreckt sich nach hinten längs des Sulcus coronarius bis fast zur Fossa Sylvii, woselbst sie den lateralen Urwindungen aufsitzt. 1. Durchschnitt ( $8 \mathrm{~mm}$ vor dem hinteren Rande der Narbe): Unter der Narbenkappe ist die Zeichnung von Grau und Markweiss fast ganz 
zerstört, die angrenzenden Theile des Rindengranes sind abgeblasst. Etwa $2 \mathrm{~mm}$ von der äusseren lateralen Spitze des Seitenventrikels befindet sich ein unregelmässig gestalteter Spalt, dessen Ränder erweicht sind. Von dort nach der Narbe zu zieht sich 'eine Kette von Erweichungsherden, durch die das ganze Markweiss von der Unterschneidungsstelle an aus der II. Urwindung

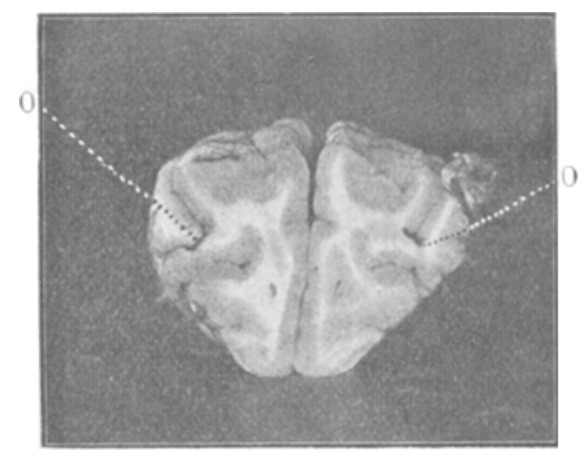

Fig. 89.

0 : Operationsstelle.

durch den Fuss des Stabkranzes in die innere Kapsel hineinreichend bis auf $2 \mathrm{~mm}$ von der Spitze des Seitenventrikels unterbrochen warde. Der Gyrus sigmoides bleibt auch hier unbetheiligt. 2. Durchschnitt (12 mm weiter nach vorn): $8 \mathrm{~mm}$ unter der Oberfläehe liegt gerade am Ende des Sulcus coronalis die Unterschneidungsspalte mit etwas erweichter Umgebung. (Vergl. Beob. 3.)

\section{Beobachtumg 63.}

Aufdeckung auf dem linken Planum semicirculare auf sagittal $23 \mathrm{~mm}$, in der Mitte frontal $14 \mathrm{~mm}$, sich nach vorn und hinten verjüngend. Vorderer Rand der Lücke $18 \mathrm{~mm}$ hinter der Spitze des Planum. Bei Abtragung der Dura Verletzung einer sehr stark blutenden grösseren Arterie der Pia. Exstirpation in der Mitte der Lücke eines Stückes von ca. $5 \mathrm{~mm}$ sagittal, 2,5 mm frontal und etwa ebenso tief mit Präparatenheber. Während und nach der Operation längere Zeit starke Blutung.

3 Stunden post op. Motilitätsstörung an beiden rechten Extremitäten ausgesprochen, namentlich lässt er die Hinterpfote mit dem Dorsum aufgesetzt stehen, vorn reponirt er sie bald. Sehstörung hochgradig, sieht erst über Nasenrücken. Optische Reflexe fehlen gänzlich. Nasenlidreflex anscheinend abgeschwächt. Ciliarreflex intact.

Motilitätsstörungen: In den Beinen hochgradig und lange anhaltend, Spuren noch am 21. Tage, dann nicht mehr.

Sehstörung: Gegen Fleisch: Am 5. Tage bis auf nasalen Streifen, vorher scheinbar nur die temporale Hälfte, vom 7. Tage an in der Abnahme. 
Vom 9. Tage an nur noch ganz aussen bis zum. 21. Tage, am 22. Tage nicht mehr nachweisbar. Gegen Licht: In den ersten 7 Tagen Reaction fehlend oder deutlich schwächer, nachher gleich.

Optische Reflexe: Fehlen bis zum 16. Tage, abgeschwächt bis zum 24. Tage; am 26. Tage normal.

Tasenlidreflex: Schwächer bis zum 10. Tage, dann ohne constante Differenz.

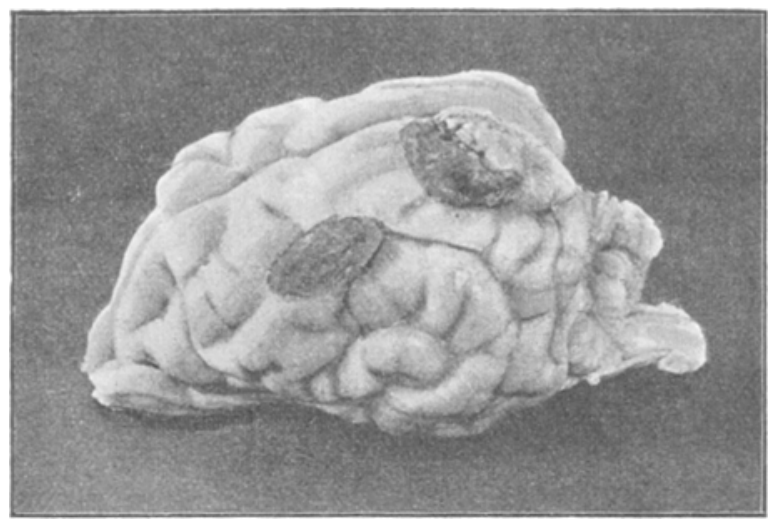

Fig. 90.

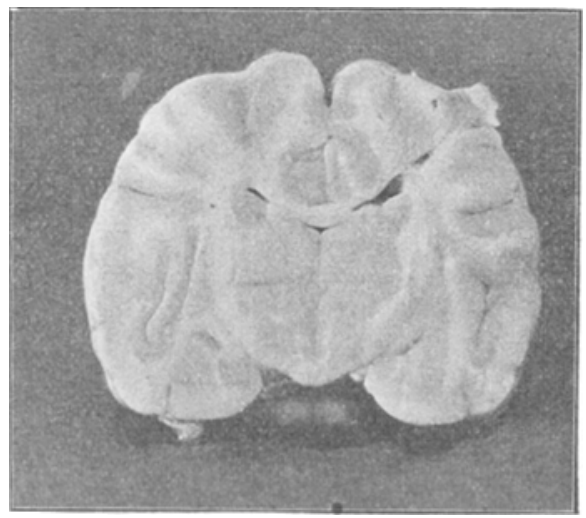

Fig. 91.

Getödtet nach circa 9 Wochen; inzwischen eine 2. Operation im Hinterlappen.

Section: Häute normal. Die Narbe sitzt sehr genau in der II. Urwin- 
dung auf dem Centrum für Bewegung und Schutz des Auges. Auf dem Durchschnitt (durch die Mitte der Narbe) zeigt sich ein keilförmiger bräunlicher Herd aus Narbengewebe, der bis in die weisse Substanz reicht, von der Spilze dieses Keiles aus geht ein spaltförmiger Erweichungsherd bis fast zur Ventrikelwand. Der Seitenventrikel ist stark nach oben aussen nach der Narbe zu ausgezogen und erweitert:

\section{Beobachtung 64 .}

Aufdeckung auf Planum semicirculare links ganz vorn, $2 \mathrm{~mm}$ ron der Linea semicircularis entfernt, auf $19,5 \mathrm{~mm}$ sagittal. Aufschlitzung der Dura ganz hinten, Unterschneidung nach vorn $2,5 \mathrm{~cm}$ lang und dann basal bis an den Knochen; beim Herausziehen der Schneide wird dieselbe nach lateral oben gedreht, so dass die Verbindung des unterschnittenen Rindenstückes nach lateral möglichst durchtrennt wird. Durchschneidung des Facialis.

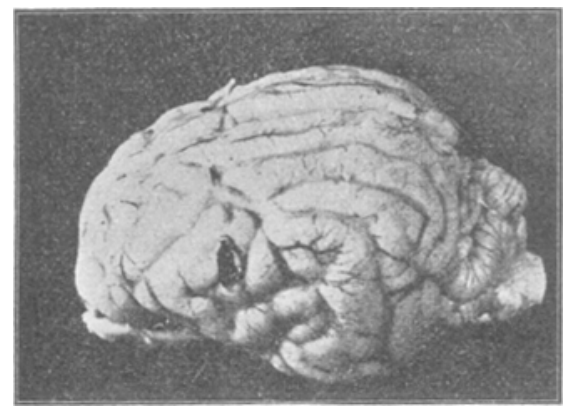

Fig. 92.

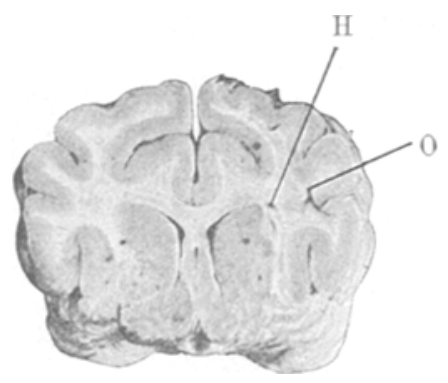

Fig. 93.

Motilitätsstörungen: Am 2. Tage deutlich, hängt auch gestreckt. Keine Reaction beim Begreifen. Vom 4. Tage an Abnahme, am 23. T'age nicht mehr deutlich.

Sensibilitätsstörungen: Nasenloch: Am 2. Tage indifferent gegen 
Kitzeln, dann nicht mehr notirt. Zunge und Wange: Am 2. Tage geräth das Fleisch oft unter die Zunge und fällt rechts heraus, am 3. Tage geräth es nicht mehr unter die Zunge und fällt seltener heraus. Letzteres wird noch am 6. Tage beobachtet. Leckt bis zum 5. Tage auffällig oft nach rechts.

Sehstörung: Gegen Fleisch: Vom 2.-5. Tage absolut, vom 6. -8. Tage sieht er vielleicht spurweise, am 9. Tage sieht er auf schmalem nasalen Streifen, am 10. Tage auf der nasalen Hälfte, im unteren äusseren Quadranten etwas darüber hinaus; 14. Tag: Sehstörung ein Drittel, 19. Tag: im schmalen temporalen Streifen, nachher wieder Zunahme. (Hund beginnt zu kränkeln.) Gegen Licht reagirt er nur auf dem gegen Fleisch reagirenden Theil, dort aber mit Knurren und Beissen.

Optische Reflexe: Gleich nach der Operation vorhanden, fehlen vom 2. Tage bis zum Ende der Beobachtung.

Nasenlidreflex gleich nach der Operation und auch später vorhanden. Gestorben nach ca. 3 Wochen.

Section: Häute normal, nur an der Operationsstelle in einem schmalen Streifen ist die Dura entsprechend dem Einstich in das Gehirn mit der Pia verwachsen. Die Narbe sitzt der II. und dem medialen Rande der III. Urwindung auf, dicht vor und ein wenig lateral vom Orbiculariscentrum. Durchschnitt ( $6 \mathrm{~mm}$ vor dem Einstich): $5^{1 / 2} \mathrm{~mm}$ unter der Gehirnoberfläche parallel dazu findet sicb eine leicht concav nach aussen gebogene Spalte, die die Markstrahlung der II. Urwindung quer durchtrennt und noch in die JII. Urwindung hineinreicht, hier dicht unter dem Rindengrau eines einschneidenden Sulcus endend. Das Grau der unterschnittenen Windung ist ganz leicht abgeblasst. Am Spalte selbst finden sich keine bedeutenderen Erweichungen, eine kleine umschriebene Erweichung liegt lateral und oberhalb vom Nucleus caudatus, bereits in der inneren Kapsel. $7 \mathrm{~mm}$ weiter nach vorn endet der eine Stichcanal unter der Pia sichtbar, ohne dieselbe zu durchschneiden; liurz vorher trennt sich der mehr nach vorn gerichtete Stich daron ab, um etwa $4 \mathrm{~mm}$ weiter nach vorn zu endeñ. (Vergl. Beob. 4).

In der umstehenden Tabelle III habe ich die Resultate der vorstehenden Beobachtungen nach der Dauer der bei ihnen festzustellenden Sehstörung geordnet.

1. Sehstörungen: Eine Sehstörung fehlte gänzlich bei der Beob. 55 - Anätzung der caudalen Hälfte der II. Urwindung - und Beob. 56 - Unterschneidung der vorderen Hälfte der II. Ǔrwindung mit Abtremnung dor III. und IV. Urwindung von dem Marklager und Zertrümmerung des Letzteren. Eine verhältnissmässig kurze Dauer, bis zu 5 Tagen, hatte die Sehstörung in den Beobb. 57 bis 60. Bei der Beob. 57 war unter ganz geringer Eröffnung der Dura eine Untersclineidung der II. und III. Urwindung vorgenommen worden; eine Sehstörung war nur am 2. Tage und selbst da nicht einmal deutlich nachzuweisen. Bei der Beob. 58 war die ganze Il. Urwindung von hinten nach vorn unter- 
T a be Ile III. $\left.{ }^{1}\right)$

\begin{tabular}{|c|c|c|c|c|c|c|}
\hline \multirow{2}{*}{$\begin{array}{l}\text { No. } \\
\text { der } \\
\text { Beob. }\end{array}$} & \multirow{2}{*}{$\begin{array}{c}\text { Art } \\
\text { der Operation }\end{array}$} & \multirow{2}{*}{ Motilitätsstörungen } & \multicolumn{2}{|c|}{$\begin{array}{l}\text { Sebstörung } \\
\text { gegen }\end{array}$} & \multirow{2}{*}{$\begin{array}{l}\text { Optische } \\
\text { Reflexe }\end{array}$} & \multirow{2}{*}{$\begin{array}{l}\text { Nasen- } \\
\text { lid- } \\
\text { reflex }\end{array}$} \\
\hline & & & Fleisch & Licht & & \\
\hline 55 & Anätzung & gering, nur bis zum & 0 & 0 & 0 & $19)$ \\
\hline 56 & Unterschneidung & ziemlich hochgradig & 0 & 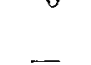 & Frcialisläl & hmutnor \\
\hline 57 & $\begin{array}{l}\text { Unterschneidung } \\
\text { der 2. Seite }\end{array}$ & 7 Tage, spurweise & $2 ?$ & 0 & $\begin{array}{c}14(25) \\
\text { mindestens }\end{array}$ & \\
\hline 58 & $\begin{array}{l}\text { Unterschneidung } \\
\text { der 2. Seite }\end{array}$ & $\begin{array}{l}\text { nur anfangs hoch } \\
\text { gradig }\end{array}$ & 2? & 3 & ten & $?$ \\
\hline 59 & $\begin{array}{l}\text { Unterminirung u. } \\
\text { theilweise Ex- } \\
\text { stirpation }\end{array}$ & hochgradig & 5 & - & $2(14)$ & (5) \\
\hline 60 & Unterschneidung & $\begin{array}{l}\text { bis zum 11. Tage } \\
\text { (zunehmend) }\end{array}$ & 5 & 5 & $4(22)$ & 5 \\
\hline 61 & Unterschneidung & r. Lidspalte weiter; & 0 & 7 & $29(30)$ & 16 \\
\hline 62 & Unterschneidung & hochgradig, noch nach & & & 42 & \\
\hline 63 & Exstirpation & $\begin{array}{r}6 \text { Woch } \\
\text { hochgrad }\end{array}$ & $\begin{array}{r}8 \\
21\end{array}$ & $\begin{array}{l}6 \\
7\end{array}$ & $\begin{array}{l}\text { dauernd } \\
16(9)\end{array}$ & $\begin{array}{c}15(11) \\
(10)\end{array}$ \\
\hline 64 & Unterschneidung & sehr deutlich & $\begin{array}{c}22 \\
\text { minde- } \\
\text { stens }\end{array}$ & 22 & 22 & 0 \\
\hline
\end{tabular}

schnitten worden; es fand sich bei der Section ein grosser Erweichungsberd am Fusse des Stabkranzes, der einen nicht geringen Theil der Strahlung aus dem Gyrus sigmoides neben der Markstrahlung aus der II. Urwindung unterbrochen haben musste; die Sehstörung erwies sich gleichwohl nur gegen Licht bis zum 3. Tage deutlich, gegen Fleisch war sie nur am 2. Tage undeutlich vorhanden. Bei der Beob. $59-$ ausgiebige Unterminirung und theilweise Exstirpation der vorderen Hälfte des vorderen Schenkels der II. Urwindung unter Betheiligung der Nachbarwindungen mit Späthämorrhagie - dauerte die Sehstörung gegen Fleisch 5 Tage. Bei der Beob. 60 war der sylvische Theil der II. Urwindung und der anschliessende Theil der sogenannten „Augenregion" aufgedeckt, aber nur die Markstrahlung der II. Urwindung annähernd senkrecht auf ihre Verlaufsrichtung unterschnitten worden. Die Sehstörung war sowohl gegen Fleisch als gegen Licht einschliesslich des 5. Tages nachweisbar. In den übrigen 4 Fällen hielt eine Sehstörung von versehiedener Intensität $7-22$ Tage an. Bei der Beob. 61

1) Die in Klammern gesetzten Zahlen bedenten eine Abschwächung oder eine fernere Abschwächung um die Dauer der betreffenden Zahlen in Tagen. Wegen der Bedeutung der Fragezeichen wird auf den Text verwiesen. 
war das mittlere Drittel der II. Urwindung unter Schonung des Gyrus sigmoides unterminirt worden; bei der Section zeigte sich, dass dieser Gyrus gleichwohl etwas in den Bereich der Läsion hineingezogen war, ausserdem zog ein feiner Erweichungsstreifen bis in den Fuss des Stabkranzes hinein. In diesem Falle war die Sehstörung nur gegen Licht auf die Dauer von 7 Tagen deutlich nachweisbar. Bei der Untersuchung mit Fleisch fixirte der Hund zwar, da er aber nicht frass, blieb es fraglich, ob er den Gegenstand erkannte oder nicht. Bei der Beob. 62 war der grössere Theil des vorderen Schenkels der II. Urwindung fast von seinem caudalen Ende an unterschnitten worden. Der Gyrus sigmoides war zwar geschont, aber eine Kette von Erweichungsherden zag sich von der II. Urwindung aus derart durch seine Verbindungen mit der inneren Kapsel hindurch, dass sie an dieser Stelle gänzlich oder fast gänzlich unterbrochen sein mussten. Die Sehstörung dauerte in diesem Falle gegen Fleisch 8 , gegen Licht 6 Tage. Bei der Beob. 63 war eine verhältnissmässig kleine Exstirpation im Orbiculariscentrum ziemlich abseits vom Gyrus sigmoides ausgeführt worden. Bei der Section ergab sich aber, dass sich ein Erweichungsstreifen von der Narbe aus durch das ganze Marklager hindurch bis fast an die Spitze des Seitenventrikels zog. Die Sehstörung dauerte gegen Fleisch 21 und gegen Licht 7 Tage. Bei der Beob. 64 endlich waren die 3 lateralen Windungen von einem Schlitz der Dura aus, der sich ungefähr über der vorderen basalen Hälfte des Orbiculariscentrums befand, won ihren Verbindungen abgetrennt worden. Auf dem Querschnitt zeigte sich nur eine Unterschneidungsspalte und ausserdem ein kleiner Erweichungsherd in der inneren Kapsel. Indessen liessen sich auch die Endigungen der basalen und frontalen Stichcanäle verfolgen. Die Sehstörung dauerte hier 22 Tage, bis zum Tode des Thieres, welches allerdings in den letzten Tagen kränkelte.

2. Die optischen Reflexe waren in 1 Falle (Beob. 56), bei dem übrigens auch die Sehstörung fehlte, wegen Facialislähmung nicht zu untersuchen. In dem 2. Falle von feblender Sehstörung (Beob. 5̃5) waren sie 'gleichfalls nicht beeinträchtigt. In allen anderen Fällen waren sie mehr oder minder stark beeinträchtigt. Wirft man einen Blick auf die Tabelle, so fällt sofort auf, dass die Dauer dieser Beeinträchtigung durchgehends unverhältnissmässig viel länger war als die Dauer der Sehstörung. Allerdings fehlten sie dann vielfach nicht ganz, sondern waren nur mehr minder stark abgesehwächt. Wir sehen darunter aber doch 1 Fall (Beob. 61), in dem sie 22 Tage lang gänzlich fehlten und dann noch lange abgeschwächt waren, während der Hund schon von Anfang an auf Fleisch normal reagirte und nur gegen Licht 
eine Sehstörung erkennen liess. Aehnlich fehlten die optischen Reflexe bei der 57. Beob. 14 Tage gänzlich, um noch lange abgeschwächt zu sein, während die Reaction auf Fleisch nur an 2. Tage undeutlich und auf Licht garnicht gestört war. Ohne auf anderweitige Einzelbeiten näher einzugehen, hebe ich hier nur wieder die Selbständigkeit der beiden Symptome und die sich hier geltend machenden Beziehungen zu. denjenigen Arealen hervor, die nach den Ergebnissen der electrischen Untersuchung der Innervation des Orbicularis vorstehen oder ibnen benachbart liegen.

3. Der Nasenlidreflex war ungestört nur in 2 Fällen (Beobb. 57 und 64). In beiden Fällen fand sich eine erbebliche Störung der optischen Reflexe. In dem ersteren Falle dauerte diese mindestens 39, in dem anderen 22 Tage, bis zum Tode. In den übrigen Fällen war der Nasenlidreflex zwischen 5 und 26 Tagen theils aufgehoben, theils gestört. Unter ihnen befindet sich 1 Fall (Beob. 55), in dem er 12 Tage abgeschwächt war, während die optischen Reflexe keine Störung zeigten. In den übrigen Fällen waren die optischen Reflexe länger gestört als der Nasenlidreffex. Das Verhältniss betrug 16:5, 26:5, $52: 16$, $42: 26$ und $25: 10$.

4. Das gegenseitige Verhältniss der Sehstörung, der optischen Reflexe und des Nasenlidreflexes. Ich habe bereits in dem vorigen Kapitel und in den vorstehenden Abschnitten dieses Kapitels dieser Abhandlung die Unabhängigkeit der Störung der optischen Reflexe von der Sehstörumg betont. Thatsache ist, dass ein Hund nicht nur sehr gut sehen, sondern überhaupt keine Sehstörung gehabt haben kann, während seine optischen Reflexe dennoch in mehr minder hohem Grade und auf mehr minder lange Zeit geschädigt waren. Ebensowohl kann aber auch eine Sehstörung vorhanden sein, ohne dass die optischen Reflexe darunter zu leiden brauchten. Die Anschauung Luciani's, nach der das Ausfallen des optischen Reflexes (Gesticulationsversuch) eine Sehstörung bedeutet, ist demnach, wie ich bereits gesagt habe, irrig. Diese Anschaung hat aber mit derjenigen Ilunk's ungeachtet aller Verschiedenheit im Einzelnen etwas Gemeinsames mit Rücksicht auf die Construction des Reflexbogens und den Mechanismus seiner functionellen Schädigung. Gemeinsam ist Beiden die Auffassung; dass der optische Reiz gleichviel zu einem wie beschaffenen corticalen optischen Centrum gelangt und von diesem aus zunächst das corticale und dann das subcorticale Orbiculariscentrum in Erregung versetzt. Eine Verschiedenheit, mindestens im Vortrage, besteht darin, dass die Schädigung der Function, also des Lidschlusses, nach Luciani nur in 
der optischen, nach llunk aber sowohl in der optischen als auch in der motorischen Region der Rinde stattfinden kann.

Jedenfalls aber giebt bei beiden Forschern die Rinde die einzigen, für den Vorgang direct in Betracht kommenden Factoren ab; die subcorticalen Centren werden von Beiden bei den durch corticale Eingriffe verursachten Störungen als unbetheiligt angesehen, während Goltz mit seiner Schule umgekehrt alle nach corticalen Eingriffen auftretenden Erscheinungen - mit den hier besprochenen Reflexen hat er sich meines Wissens nicht beschäftigt - auf die subcorticalen Centren bezogen wissen will.

$Z u$ den corticalen Störungen rechnet $\left.\| \mathrm{Hnk}^{2}\right)$, auch die nach Eingriffen in die „Kopfregion" eintretende Aufhebung der Druckgefühle der Wange, also ein Trigeminusreflex, ohne freilich anzugeben, wadurch sich diese Aufhebung äussert. Dagegen gehörten nach ihm die Ciliar-, Conjunctival- und Connealreflexe, also eine andere Reihe von Trigeminusreflexen, ebenso wie der Pupillarreflex zu den niederen, der Mitwirkung des Grosshirns nicht bedürfenden Reflexen.

Das gesammte Schema der Reflexthätigkeit und ibrer Störungen würde sich nach dieser Theorie aiso sehr einfach gestaiten und es ist vielleicht aus diesem Grunde geschehen, dass sie so bestechend gewirkt hat. Die Sehthätigkeit kann nur gestört werden durch Eingriffe in die "Sehsphäre". Der reflectorische Lidschluss aber sowohl durch Eingriffe in die "Sehsphäre", weil dam das Thier nichts sieht oder durch Eingriffe in die "selbstständige Fühlsphäre des Auges", weil dann der dazu erforderliche Rindenreflex auf den Orbicularis in Fortfall kommt.

Legen wir mun an diese Theorien den Maassstab der in dieser $\mathrm{Ab}$ handlung vorgetragenen Thatsachen, so ergiebt sich zunächst als übereinstimmend mit derselben, dass der optische Reflex sowobl bei solchen Eingriffen, welche auf die "Sehsphäre", als anch bei solchen, welche auf das Orbiculariscentrum streng localisirt sind, fehlen kann, und dass die Ciliar- und Cornealreflexe, wie dies neuerdings auch von Eckhard angegeben worden ist, unter diesen Umständen erhalten bleiben.

Neben diesen mit der Theorie übereinstimmenden Thatsachen werden wir aber auf andere zuräckkommen, welche mit ihr nicht übereinstimmen. Sehen wir zunächst von unseren Erfahrungen über die Sehstörung ab und beschäftigen uns nur mit den motorischen und Reflexorganen, so ist es, um Klarheit in die Sache zu bringen, durchaus erforderlich, die einzelnen Reflexapparate wait Bezug auf ihre Störung ge-

1) H. Munk, Gesammelte Mittheilungen. 1890. S. 53. 
sondert zu betrachten. Dies ist der Apparat der willkürlichen Innervation, zugleich des cerebralen Tonus, der Apparat des optischen Reflexes und die Apparate der Trigeminusreflexe.

Alsbald stossen wir hier auf eine Schwierigkeit. Nach Munk sollen Exstirpationen seiner "Augenregion" Ptosis bewirken. Ich habe dagegen nach Eingriffen in mein Orbiculariscentrum nur, und zwar nicht regelmässig Erweiterung der Lidspalte, niemals Ptosis beobachtet und ebenso lauten die Angaben Luciani's. Nach Eckhard sind keine constanten Veränderungen $z u$ beobachten; man empfinge zwar in einigen Fällen den Eindruck als ob die Lidspalte auf der entgegengesetzten Seite etwas weiter sei als auf der operirten. Wegen der Inconstanz der Erscheinung will Eckhard aber kein Gewicht darauf legen. Man könnte nun die widersprechenden Angaben von Munk vielleicht in der Weise erklären, dass er bei denjenigen Exstjrpationen, bei denen er - auch inconstant - Ptosis beobachtete, andere und zwar solche Theile angegriffen hat, die den Levator palpebrae superioris innerviren, und dass bei denjenigen Operationen von ihm, von Luciani und mir, bei denen der Effect mit Bezug auf die Lidspalte latent blieb, beide Felder angegriffen waren, sodass die Wirkung der Verletzung des einen durch die Wirkung der Verletzung des anderen aufgehoben wurde. $\mathrm{Da}$ Munk aber meines Wissens niemals eine genauere Localisation seiner Lähmungsversuche innerbalb seiner langen und breiten "Augenregion" kundgegeben hat, so muss ich es bei dieser Vermuthung bewenden lassen.

Die willkürliche Beweglichkeit der Lidmuskeln scheint bei diesen Versuchen, auch wenn sie ein positives Resultat ergeben, nicht aufgehoben zu sein; wenigstens habe ich nicht beobachtet, dass die Hunde mit erweiterter lidspalte sie nicht schliessen konnten, auch bei Luciani finde ich keine derartige Angabe und dass man bei vorbandener Ptosis vom Hunde darüber, ob er seine Lidspalte weiter zu öffnen vermag, keine Auskunft erhalten kann, ist selbstverständlich. Hiernach tritt die nach diesen Operationen zu beobachtende Erweiterung der Lidspalte, vielleicht auch ihre Verengerung, in eine Reihe mit dem Herabhängen der geschädigten Pfoten schwebender Hunde, das ich in den vorhergehenden Abhandlungen ausführlich erörtert habe. Sie ist also, wie jenes Symptom, auf das Fehlen des normalen cerebralen Tonus zurückzuführen, ohne dass jedoch bier, wie dort das Phänomen in allen seinen Theilen gänzlich aufgeklärt worden wäre. Für diese Auffassung spricht auch die gelegentlich gemachte (Beob. 60), aber in den anderen Fällen nicht weiter verfolgte Beobachting, dass der normale Widerstand, den man bei der 
passiven Eröffnung des nicht geschädigten Auges antraf, auf dem geschädigten, eine Erweiterung der Lidspalte zeigenden, fehlte.

Betrachten wir von diesem Gesichtspunkte aus das Fehlen des optischen Reflexes, so lüsst es sich gleichfalls in eine Reihe mit dem Fehlen des normalen Reflexes beim "Begreifen" der Pfoten schwebender" Hunde stellen. In jedem der beiden Fälle können die Hunde Willensimpulse zu der Musculatur der geschädigten Seite gelangen lassen, aber die normale Antwortsbewegung auf den adäquaten centripetalen Reiz bleibt aus.

Das Fehlen des Nasenlidreflexes lässt sich zwar in ähnlicher Weise erklären; inclessen ist dies nur unter Zuhülfenahme einer Annahme möglich, welche mit den geläufigen Anschauungen über das Wesen der Functionen innerhalb der motorischen Rindencentren sich nicht ganz deckt. Bei den hier mitgetheilten Versuchen hat sich gezeigt, dass ein Theil der vom Trigeminus auf den Orbicularis palpebrarum wirkenden Reflexe - die Ciliar-, Conjunctival- und Cornealreflexe - so gut wie immer ungestört bleibt, dass ein anderer Theil der vom Trigeminus auf den gleichen Muskel wirkenden Reflexe - der Nasenlidreflex - gestört sein kann, während der vom Opticus auf den gleichen Muskel wirkende Reiz die normale Contraction hervorruft und dass umgekebrt, die letztere Function, der optische Reflex fehlen kann, während der Nasenlidreflex vollkommen intact ist. Wenn wir nun auch den Ciliar-, Conjunctival- und Comealreflex dadurch eliminiren, dass wir diesen Aggregaten des Trigeminus eine eigene Repräsentirung in der Rinde überhaupt nicht zuschreiben, was sehr unwahrscheinlich ist, oder wenn wir annehmen, dass der Einfluss einer solchen corticalen Repräsentirung: ganz und gar gegen die subcorticale Innervation zurücktritt, so bleibt doch immer die Schwierigkeit bestehen, dass der gleiche Muskel, der Orbicularis in zahlreichen Fällen auf den einen Reflexreiz antwortet, auf den anderen aber nicht. Diese Schwierigkeit ist unlösbar, wenn man den Sitz der Störung in allen Fällen in das Orbiculariscentrum verlegt, sie lässt sich aber lösen, wenn man den nasalen Theilen des Trigeminus ein besonderes Innervationsgebiet in der Rinde zuschreibt, welches dann aber nicht nur allein mit der Musculatur der Nase und Wange und nicht mit derjenigen des Orbicularis, wie es nach der erwähnten Theorie sein sollte, sondern auch mit der letzteren in corticaler reflectorischer Verbindung stehen müsste.

Insoweit sind also die sich aufdrängenden Fragen einer leidlich befriedigenden Lösung zugänglich; die gesetzten Krankheitserscheinungen lassen sich sämmtlich direct von dem Eingriff in die Rinde ableiten. 
Die Schwierigkeiten beginnen erst, sobald man zu ihrer Localisation schreitet.

Betrachten wir die vorgetragenen in Frage kommenden 40 Versuche zunächst um festzustellen, bei welchen von ihnen eine Schädigung der beiden uns jetzt beschäftigenden Reflexe notirt ist, so ergiebt sich, dass eine Schädigung des Nasenlidreflexes bei den 22 Versuchen am Gyrus sigmoides nur 12 mal notirt ist und von diesen 12 Malen hat er nur 2 mal, das eine Mal 8 Tage lang, das 2. Mal 5 Tage lang gänzlich gefehlt, in den iubrigen 10 Fällen war er nur abgeschwächt. Bei den 18 in Frage kommenden Versuchen an den lateralen Urwindungen ist eine Schädigung dieses Reflexes dagegen 11 mal, und zwar davon $4 \mathrm{mal}$ eine gänzliche Aufhebung desselben notirt, je einmal auf 2, 5, 16 und 15 Tage. In der 1 . Serie dieser Fälle dauerte die einfache $A b$ schwächung 1 mal 2, 3 mal 3, je 1 mal 4, 5, 11, 13, 28 und 35 Tage; ausserdem schloss sich noch eine 3 tägige Abschwächung an das 8 tägige Fehlen und eine 4 tägige Abschwächung an das 5 tägige Fehlen an. In der 2. Serie dieser Versuche dauerte die einfache Abschwächung: je einmal $3,5,10,12,13,16$ und 35 Tage; ausserdem schloss sich noch eine 14 tägige Abschwächung an das 2 tägige und eine 11 tägige Abschwächung an das 15 tägige gänzliche Fehlen dieses Reflexes an. Es zeigt sich also ganz allgemein gesprochen, dass die Folgen für den Nasenlidreflex schwerer waren, wenn in den lateralen Urwindungen, als wenn in der medialen, dem Gyrus sigmoides, operirt wurde. Dies ist auch insofern ganz verständlich, als in dem ersteren Falle die Operation die beiden Windungen, in denen sich das von Fritsch und mir nachgewiesene Orbiculariscentrum und das von mir nachgewiesene Centrum für die unteren Aggregate des Facialis befindet, betraf. Die Schädigung des uns beschäftigenden Refiexes kann nach meinen bisherigen Auseinandersetzungen durch Verletzung des einen, wie des anderen Centrums bedingt sein. Immerhin wäre es auffallend genug, wenn Eingriffe, die auf den Gyrus sigmoides selbst begrenzt waren, eine Schädigung der Function des letztgedachten, ziemlich weit abliegenden Centrums zur Folge hätten.

Fassen wir weiter diejenigen Beobachtungen ins Auge, bei denen ein Trauma des Centrums für den Orbieularis durch Lagophthaimus wabrscheinlich gemacht wird, so ergiebt sich, dass bei der Beob. 26 das Centrum für den Orbicularis mitaufgedeckt und in den Bereich der Störung hineingezogen war. Die bis zum Ende der Beobachung (35 Tage) dauernde Auf hebung sowohl des optischen als des Nasenlidreflexes wird hierdurch vollkommen erklärt. Ganz anders liegen die Verhältnisse in dem Falle 48, bei dem die allerdings nur 4 Tage anhaltende 
Erweiterung der Lidspalte durch den Ort der Verletzung in der Mitte des vorderen Schenkels der II. Urwindung nicht recht motivirt war und noch dazu die optischen Reflexe garnicht, der Nasenlidreflex kaum gestört war. Bei der Beob. 50 war das mittlere, und ein Theil des unteren Drittels der II. Urwindung und damit der vordere Theil des Orbiculariscentrums so gut wie ausgeschaltet. In diesem Falle entsprach wieder die 4 Tage dauernde Erweiterung der Lidspalte, sowie die bis zum Ende der Beobachtung (35 Tage) dauernde Störung des optischen und des Nasenlidreflexes der Localisation der Verletzung. Das Gleiche gilt von der Beob. 53, bei der auf eine Unterschneidung: des Orbiculariscentrums eine 23 Tage lang dauernde Erweiterung der Lidspalte und eine 18 bezw. 13 Tage dauernde Störung des optischen und des Nasenlidreflexes folgte. Bei der Beob. 61 war gleichfalls das Orbiculariscentrum in eine Narbe verwandelt, die optischen Reflexe 52 und der Nasenlidreflex 16 Tage gestört. Ueber das unter diesen Umständen auffallende Fehlen des Lagophthalmus bei Angriffen auf die hintere Hälfte des vorderen Schenkels der II. Urwindung habe ich mich bereits (S. 90) ausgesprochen.

Mindestens ebenso auffällig ist eine Reihe von Fällen, bei denen nach Eiugriffen in die lateralen Windungen die optischen Reflexe zu einer Zeit gestört waren, zu der keine Sehstörung bestand, während der Nasenlidreflex nicht oder nicht mehr gestört war. Hier war also der Weg durch das Orbiculariscentrum frei und dennoch versagte auf der geschädigten Seite der optische Reiz.

Wir hatten bereits bei der 1. Reihe dieser Beobachtungen (Beobb. 9-16) gesehen, dass die einfache Freilegung des Gyrus sigmoides auch bei denjenigen Fällen, bei denen das Orbiculariscentrum nicht betheiligt sein konnte, genügte, um die optischen Reflexe zu schädigen.: Das gleiche Resultat haben nun auch die jetzt mitgetheilten 22 Versuche am Gyrus sigmoides ergeben. Die optischen Reflexe blieben in keinem einzigen Falle intact und waren in vielen Fällen sehr hochgradig und lang andauernd geschädigt. Es würde zu weit führen auf alle diese Fälle einzeln einzugehen. Dagegen muss ich mit aller Entschiedenheit hervorheben, dass diese Erfahrungen keineswegs durchgehends durch Nachbarwirkungen auf das Orbiculariscentrum zu erklären sind. Ich selbst habe wiederbolt auf die Gefahr der Täuschung durch Nachbarschaftssymptome hingewiesen, ja, einer der vornehmlichsten. Zwecke dieser Untersuchungen besteht darin, den Werth solcher Symptome festzustellen und damit die wirklichen Folgen localisirter Verletzungen aus der Fülle der Symptome berauszuschälen. So habe ich denn auch bei der Analyse dieser Beobachtungen von allen denjenigen Fällen abge- 
sehen, bei denen die II. Urwindung sich in die Hirnlücke hineingelegt hatte, sodass die Narbe darauf übergriff, oder bei denen selbst die weit nach vorn vor dem Orbiculariscentrum gelegenen Theile in Mitleidenschaft gezogen waren. Es giebt aber denn doch Fälle genug, bei denen von solchen Nachbarschafts- und ebenso von anderen Fernewirkungen gar keine Rede sein kann. leh führe von solchen als vollkommen beweisend die Beobb. 43 links und 43 rechts an, bei denen eine einfache frontale Durchtrennung am vordersten Rande des Gyrus sigmoides ansgeführt wurde und die optischen Reflexe auf die Dauer von 11 bezw. 27 Tagen gestört waren. Ich übersehe nicht, dass sich bei diesem Hunde auf der rechten Seite ein Erweichungsherd im Marklager und ein Blutherd im medialen Rindengrau fand. Aber einmal waren diese Herde nur einseitig vorhanden, während die Störung doppelseitig war und dann lagen sie so weit nach vorn, dass sie die Strahlung aus dem sylvischen Theil der II. Urwindung unmöglich schädigen konnten. Ausserdem erwähne ich beispielsweise die Beobb. 29, 30, 32 und 33 mit 13-35 Tage dauernden Störungen der optischen Refiexe. Beiläufig sei bemerkt, dass sich auch die Sehstörungen in diesen Fällen analog verhielten, obschon bei ihnen von einem Trauma der "Sehsphäre" noch viel weniger die Rede sein konnte, als von einem solchen des Orbiculariscentrums. Ja, sogar in den Beobb. 43 links und 43 rechts, bei denen die Operation fast am entgegengesetzten Pol der Hemisphäre ausgeführt wurde, war die Sehstörung noch am 15. Tage nach der Operation nachweisbar.

Aus dem Vorgetragenen scheint mir mit Sicherheit hervorzugeben, dass nach frontalen Eingriffen Sehstörungen und Störungen der optischen Reflexe als unmittelbare Folgen von Verletzungen des Gyrus sigmoides so gut wie regelmässig, Störungen der optischen Reflexe nach Verletzungen des Orbiculariscentrums gleichfalls als directe Folgen der Verletzung so gut wie regelmässig eintreten, dass ferner die Verletzung dieses Centrums häufig zu einer Erweiterung der Lidspalte und die Verletzung seiner mehr nach vorn und lateral gelegenen Nachbarschaft (meines Centrums für den Rest des Facialis) noch häufiger zu einer Störung des Nasenlidreflexes führt, während die vorderen Schenkel der II. - IV. Urwindung, einschliesslich des vorderen Theiles des grossen Marklagers und der inneren Kapsel in jeder Weise verletzt sein können, ohne dass hieraus jemals direct eine Sehstörung resultirte.

5. Nach und durch die Erledigung dieser umständlichen Vorfragen 
gestaltet sich die Beantwortung unserer Hauptfrage, ob Sehstörungen auch durch Verletzungen der Markstrahlungen des Gyrus sigmoides bedingt sein können, soweit sie überhaupt auf Grund des vorliegenden Materials unteruommen werden kann, sehr einfach.

In Betracht kommen nur diejenigen Verletzungen der hinteren Hälfte der lateralen Urwindungen, bei denen die Rinde des Gyrus sigmoides selbst nicht verletzt war. Wir gehen am besten von denjenigen Fällen aus, bei denen die Sehstörung am hochgradigsten war und am längsten anhielt. Bei der Beob. 63 dauerte die Sehstörung gegen Fleisch 21 und gegen Licht 7 Tage. Der Gyrus sigmoides selbst war unbetheiligt, aber ein unmittelbar hinter demselben angelegter Frontalschnitt ergab, dass sich ein Erweichungsstreifen von der Narbe aus durch das ganze Marklager hindurch bis fast an die Spitze des Seitenventrikels zog. Die Schädigung der Markstrahlung aus dem Gyrus sigmoides manifestirte sich denn auch durch eine hochgradige, erst nach dem 21. Tage verlöschende Motilitätsstörung. Bei der Beob. 64 dauerte die Sehstörung gegen Fleisch und Licht noch 1 Tag länger (22 Tage), die letzten Tage können aber wegen Erkrankung des Thieres nicht mit in Betracht gezogen werden. Hier lag der Eingriff noch weiter ab vom Gyrus sigmoides, aber es fand sich ein, auf dem angelegten Durchschnitt makroskopisch kleiner Erweichungsherd in der inneren Kapsel. Es ist möglich, dass dieser auf anderen Schnittebenen oder mikroskopisch grössere Dimensionen annahm. Jedenfalls hat er aber die Strahlung aus dem hinteren Schenkel des Gyrus sigmoides schwer geschädigt, da die Operation erhebliche Motilitätsstörungen zur Folge hatte, ohne dass die Rinde des Gyrus sigmoides irgendwie geschädigt sein konnte. Es folgt die Beob. 62, bei der die Verletzung die Rinde des Gyrus sigmoides jedenfalls nicht betroffen hatte, während die durch eine Kette von Erweichungsherden, die sich bis an die Spitze des Seitenventrikels hinzog, in der II. Urwindung angerichtete Zerstörung so hochgradig war, dass die Markstrahlung aus dem Gyrus sigmoides jedenfalls auf der Schnittebene so gut wie gänzlich unterbrochen war; aber diese lag weiter nach vorn als in 'dem vorigen Falle. Die Sehstörung dauerte nur 8 Tage; die anfangs sehr hochgradige Motilitätsstörung dagegen war noch nach mehr als 6 Wochen nachweisbar. Von grösserem Interesse ist noch die Beob. 60, bei der eine 5 tägige Sehstörung gegen Fleisch und Licht aller Wahrscheinlichkeit nach durch eine in der II. Urwindung sehr tief geführte Unterschneidung, welche an deren Fuss schon innerhalb des Centrum semiovale lag bedingt war; der Hund hatte daneben eine vom 4.--11. Tage ziemlich hochgradige, dann abnehmende Motilitätsstörung. 
Von der Heranziehung der übrigen Beobachtungen, bei denen nur eine Sehstörung von kürzerer Dauer in die Erscheinung trat, nehme ich Abstand.

Durch diese Beobachtungen wird es sehr wahrscheinlich, dass vorübergehende Sehstörungen nicht nur auf Grund von Verletzungen der Rinde des Gyrus sigmoides, sondern auch auf Grund von Verletzungen. eines Theils seiner Markstrahlung oder vielmehr von deren Einstrahlungen in das grosse Marklager oder die innere Kapsel entsteben können. Ich hätte gewünscht, diese Bahnen mit einiger Sicherheit näher bezeichnen zu kömen; indessen ist dies nur in ganz unvollkommener Weise gelungen. Selbstverständlich können es nicht die gleichen Projectionsbahnen sein, deren Zerstörung die hier beobachteten Motilitätsstörungen hervorrufen, denn diese begeben sich sicherlich zu den motorischen und sensiblen Centren des Rückenmarks. Indessen gewinnt man vielfach, wenn auch nicht überall den Eindruck, als wenn die motorischen Bahnen für die Extremitäten gemeinsam mit denjenigen verliefen, deren Verletzung die Sehstörung hervorbringt. Ganz ähnlich gestaltet sich auch allem Anscheine nach das Verhalten dieser Theile in der grauen Rinde des Gyrus sigmoides. Es scheint auch hier ganz bestimmte Regionen, ich meine besonders den lateralen Bogen, zu geben, deren Verletzung die Motilität und den Sehact besonders schädigt. Allerdings wird man sich den Hergang nicht in der Art vorzustellen haben, dass die Grösse der Letzteren in geradem Verhältniss zu der Grösse der Ausschaltung stehe - ich habe das schon oben erläutert - sondern man wird amnehmen müssen, dass es innere, mit dem Heilungsprocess in Verbindung stehende Reizvorgänge sind, durch deren Vermittelung das Phänomen in die Erscheinung tritt. -

Diese Fragen sind also, wie man sieht, keineswegs ganz aufgeklärt, womit sie das Schicksal der meisten anderen die Physiologie des Grosshirns betreffenden Fragen theilen. Die vorstehende Darstellung unterscheidet sich aber vielleicht insofern von manchen anderen Arbeiten auf unserem Gebiete, als ich gefiissentlich alle Lücken unseres, auch meines eigenen Wissens, hervorgehoben habe. Es giebt noch Mittel, diese Lücken auszufüllen, wenn man sie nur kennt. lch selbst war aber genöthigt, diesen Theil meiner Arbeit zum Abschluss zu bringen. 